\title{
Innovative Fresh Water Production Process for Fossil Fuel Plants
}

\author{
Annual Report \\ Reporting Period: 9/30/04-9/30/05 \\ Principal Investigators: James F. Klausner and Renwei Mei \\ Graduate Students: Yi Li, Jessica Knight and Venugopal Jogi
}

September 2005

DOE Award Number DE-FG26-O2NT41537

University of Florida

Department of Mechanical and Aerospace Engineering

Gainesville, Florida 32611 


\title{
Disclaimer*
}

"This report was prepared as an account of work sponsored by an agency of the United States Government. Neither the United States Government nor any agency thereof, nor any of their employees, makes any warranty, express or implied, or assumes any legal liability or responsibility for the accuracy, completeness, or usefulness of any information, apparatus, product, or process disclosed, or represents that its use would not infringe privately owned rights. Reference herein to any specific commercial product, process, or service by trade name, trademark, manufacturer, or otherwise does not necessarily constitute or imply its endorsement, recommendation, or favoring by the United States Government or any agency thereof. The views and opinions of authors expressed herein do not necessarily state or reflect those of the United States Government or any agency thereof."

\begin{abstract}
This project concerns a diffusion driven desalination (DDD) process where warm water is evaporated into a low humidity air stream, and the vapor is condensed out to produce distilled water. Although the process has a low fresh water to feed water conversion efficiency, it has been demonstrated that this process can potentially produce low cost distilled water when driven by low grade waste heat. This report describes the annual progress made in the development and analysis of a Diffusion Driven Desalination (DDD) system. A dynamic analysis of heat and mass transfer demonstrates that the DDD process can yield a fresh water production of 1.03 million gallon/day by utilizing waste heat from a $100 \mathrm{MW}$ steam power plant based on a condensing steam pressure of only 3" $\mathrm{Hg}$. The optimum operating condition for the DDD process with a high temperature of $50^{\circ} \mathrm{C}$ and sink temperature of $25^{\circ} \mathrm{C}$ has an air mass flux of $1.5 \mathrm{~kg} / \mathrm{m}^{2}$-s, air to feed water mass flow ratio of 1 in the diffusion tower, and a fresh water to air mass flow ratio of 2 in the condenser. Operating at these conditions yields a fresh water production efficiency $\left(\mathrm{m}_{f w} / \mathrm{m}_{L}\right)$ of 0.031 and electric energy consumption rate of $0.0023 \mathrm{~kW}-\mathrm{hr} / \mathrm{kg}_{f w}$. Throughout the past year, the main focus of the desalination process has been on the direct contact condenser. Detailed heat and mass transfer analyses required to size and analyze these heat and mass transfer devices are described. The analyses agree quite well with the current data. Recently, it has been recognized that the fresh water production efficiency can be significantly enhanced with air heating. This type of configuration is well suited for power plants utilizing air-cooled condensers. The experimental DDD facility has been modified with an air heating section, and temperature and humidity data have been collected over a range of flow and thermal conditions. It has been experimentally observed that the fresh water production rate is enhanced when air is heated prior to entering the diffusion tower. Further analytical analysis is required to predict the thermal and mass transport with the air heating configuration.
\end{abstract}




\section{Table of Contents}

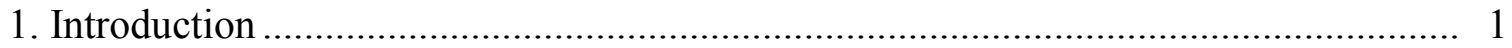

$1.1 \quad$ Description of DDD Process …………………............................................. 1

1.2 Advantages of the DDD Process Compared with HDH and MEH ...................... 3

1.3 Disadvantages of the DDD Process ………….............................................. 4

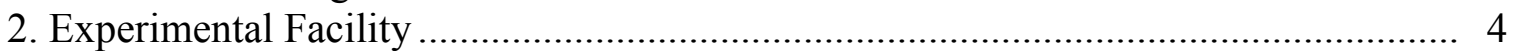

2.1 Description of Individual Components ........................................................ 7

3. Heat and Mass Transfer for the Direct Contact Condenser with Packing .................. 14

3.1 Physical Model ............................................................................... 14

$3.2 \quad$ Mathematic Model ………….................................................................. 15

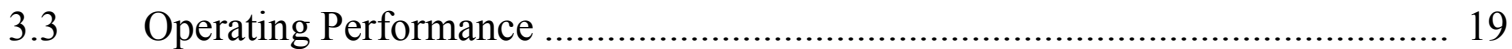

4. DDD Process Design, Analysis, and Optimization ................................................. 23

5. Economic Analysis...................................................................................... 33

6. Numerical Modeling of Falling Droplet Direct Contact Condenser .......................... 38

7. Experiment Exploration of the DDD Process with Air Heating ................................. 48

8. Summary of Completed Tasks .......................................................................... 51

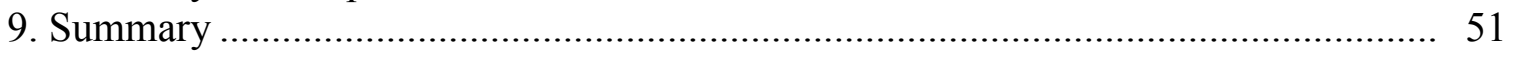

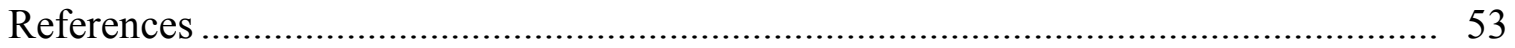

Appendix A Onda's Correlation ........................................................................ 54

Appendix B Co-current Flow Condenser Experimental Data with Packing................... 55

Appendix C Counter-current Flow Condenser Experimental Data with Packing .......... 56

Appendix D Diffusion Tower Experimental Data with Air Heating ................................ 57

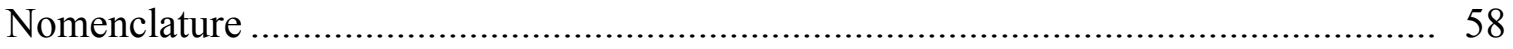




\section{Introduction}

It is well understood that fresh water is indispensable to life, industrial development, economic growth, preservation of natural resources and social wellbeing. Due to economic and social development, the demand for fresh water resources continues to grow. It is estimated that fresh water shortages affect the lives of hundreds of millions of people on a daily basis worldwide [1]. The utilization of mineralized water desalination is one of the viable approaches to mitigating fresh water shortages. Desalination technologies are currently used throughout the world and have been under development for the past century.

Humidification Dehumidification $(\mathrm{HDH})$ is a relatively new desalination technology which has been under development over the last 20 years. It is a process in which water vapor diffuses into dry air from saline water, thus humidifing the air. The water vapor is condensed out from the saturated air to produce fresh water (dehumidification of the air). Muller-Holst [2] described an experimental Multi Effect Humidification (MEH) facility driven by solar energy. Its performance was considered over a wide range of operating conditions. Al-Hallaj and Selman [3] provide an excellent comprehensive review of the HDH process. Although there is a significant advantage for this type of technology because it provides a means for low pressure, low temperature desalination driven off of waste heat, it was concluded that it is not currently cost competitive with reverse osmosis (RO) and multistage flash evaporation (MSF).

Therefore, an economically feasible diffusion driven distillation process must improve on the progress made in HDH desalination. Klausner et al. [4] have reported on a diffusion driven desalination (DDD) process that is potentially economically viable for large scale fresh water production ( $>1$ million gallons per day).

\subsection{Description of DDD Process}

A simplified schematic diagram of the DDD process and system, designed to be operated off of waste heat discharged from thermoelectric power plants, is shown in Fig. 1. The process includes three main fluid circulation systems denoted as mineralized water, air/vapor, and freshwater. In the mineralized water system, low pressure condensing steam from an adjacent power plant heats the mineralized feed water in the main feed water heater (a). The main feed water heater is typically a main condenser when used in conjunction with thermoelectric power plants. Because the required feed water exit temperature from the heater can be relatively low for the DDD process, the required heat input can be provided by a variety of sources such as low pressure condensing steam in a power plant, exhaust from a combustion engine, waste heat from an oil refinery, low grade geothermal energy, or other waste heat sources. The heated feed water then is sprayed into the top of the diffusion tower (b). A portion of feed water will evaporate and diffuse rapidly into the air. Evaporation in the tower is driven by a concentration gradient at the liquid/vapor interface and bulk air, as dictated by Fick's law. Via gravity, the water falls downward through a packed bed in the tower which is composed of very high surface area packing material. A thin film of feed water will form over the packing material and contact the upward flowing air through the diffusion tower. The diffusion tower should be designed such that the air/vapor 
mixture leaving it should be fully saturated. The purpose of heating the water prior to entering the diffusion tower is that the rate of diffusion and the exit humidity ratio increase with increasing temperature, thus yielding greater production. The water not evaporated in the diffusion tower, will be collected at the bottom and discharged.

In the air/vapor system, low humidity cold air is pumped into the bottom of the diffusion tower, and flows upward to be heated and humidified by the feed water. As mentioned before, the air/vapor mixture leaving the diffusion tower is saturated and drawn into the direct contact condenser (c), where it is cooled and dehumidified by the fresh water in the condenser. The air could be directed back to the diffusion tower and used repeatedly. The condenser is another important component of the DDD process, because film condensation heat transfer is tremendously degraded in the presence of non-condensable gas. In order to overcome this problem Bharathan et al. [5] describe the use of direct-contact heat exchangers. The direct contact condenser approach is best suited for the DDD process.

In the freshwater system, the cold fresh water will gain heat and mass in the condenser. After discharging from the direct contact condenser, it will be cooled in a conventional shell-and-tube heat exchanger (d) by the incoming feed water. Here, the intake feed water flow is preheated by the heat removed from the fresh water, which helps to reduce the amount of energy needed in the main feed water heater. Finally, a portion of the cooled fresh water will be directed back to the direct contact condenser to condense the water vapor from the air/vapor mixture discharging from the diffusion tower. The remaining fresh water is production.

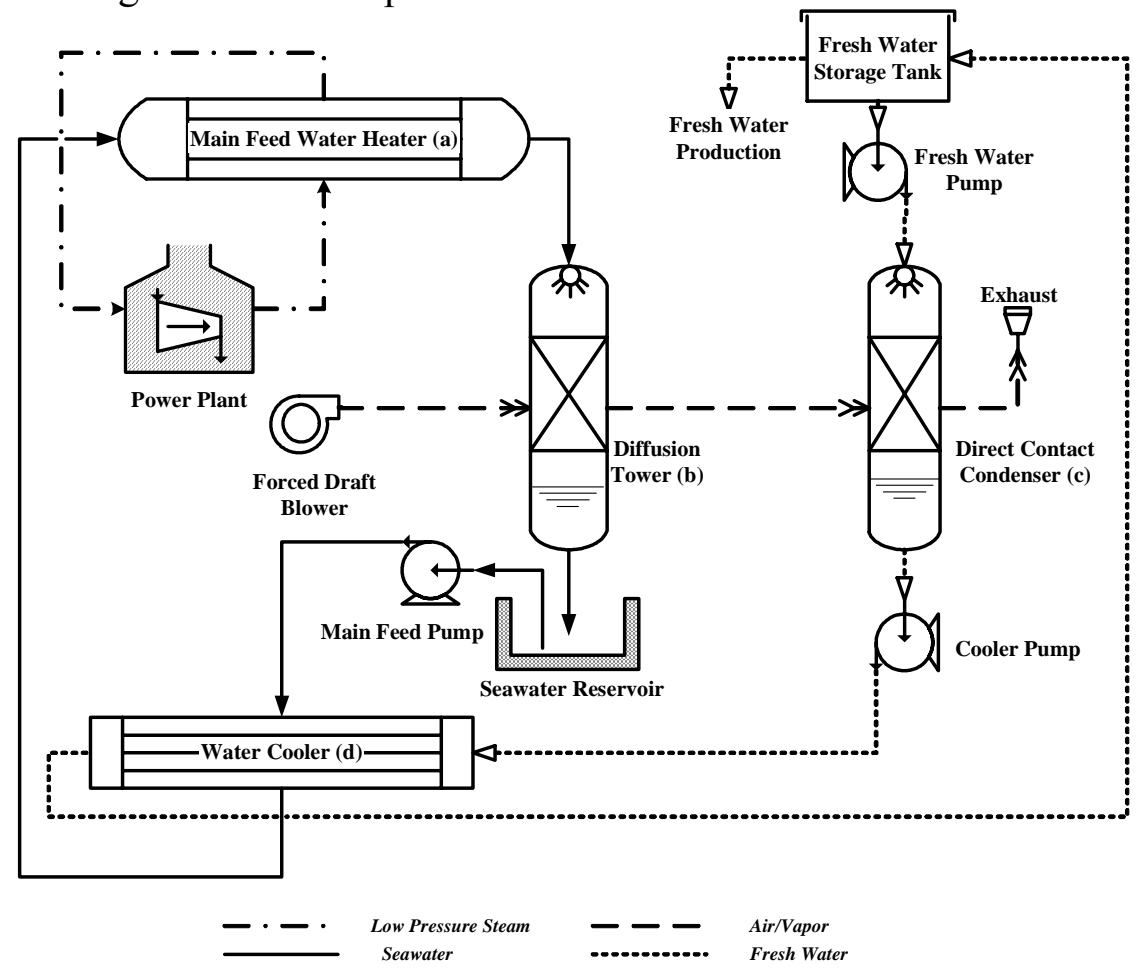

Figure 1 Flow Diagram for Diffusion Driven Desalination Process

Furthermore, a new DDD process has been considered by Klausner et. al. during the past year. A simplified schematic diagram of the new DDD process and 
system, designed to be operated off of waste heat discharged from thermoelectric power plants, is shown in Fig. 2. The new development involves heating the intake air to the diffusion tower using a portion of the waste heat and heating the feed water with the remaining waste heat. This process is well suited for power plants employing air cooled condensers. Several advantages are gained with this configuration. First, the air/vapor mixture will discharge the diffusion tower at a higher temperature and higher absolute humidity. Second, the feed water flow rate can be reduced to achieve a significantly higher fresh water conversion efficiency (about 60\%) without reducing the fresh water production rate.

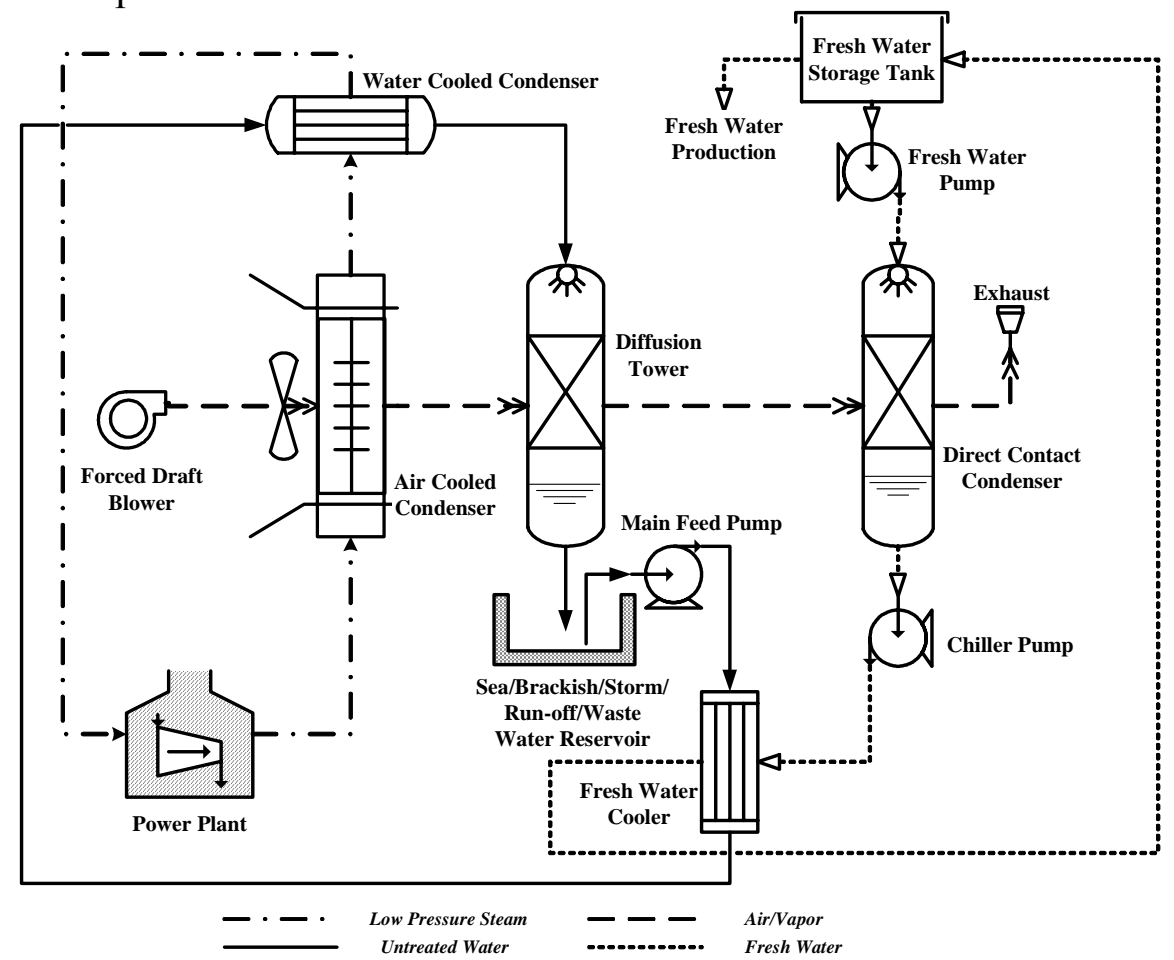

Figure 2 Flow Diagram for Diffusion Driven Desalination Process with Air Heating

\subsection{Advantages of the DDD Process Compared with HDH and MEH}

1) The DDD process utilizes thermal stratification in the seawater to provide improved performance. In fact, the DDD process can produce fresh water without any additional heating by utilizing the seawater thermal stratification.

2) The thermal energy required for the DDD process may be entirely driven by waste heat therefore eliminating the need for additional heating sources. This helps keep the DDD plant compact, which translates to reduced cost. The DDD process recommends using the heat source that is best suited for the region requiring fresh water production. The DDD process is very well suited to be integrated with steam power plants, specifically in using the waste heat generated from these plants. The current proposed project will focus on using solar heating, wind energy, and geothermal energy resources to drive the desalination process.

3) In the DDD process the evaporation occurs in a forced draft packed bed diffusion tower as opposed to a natural draft humidifier. The diffusion tower is packed with low pressure-drop, high surface area packing material, that provides significantly greater surface area. This is very important because the rate of water evaporation is 
directly proportional to the liquid/vapor surface area available. In addition, the forced draft provides for high heat and mass transfer coefficients. Thus, a diffusion tower is capable of high production rates in a very compact and low capital cost unit. The price paid in using forced draft is the pumping power required to pump the fluids through the system, but the projected cost is low, thus providing the potential for an economically competitive desalination technology.

4) The DDD process uses a direct contact condenser to extract fresh water from the air/water vapor mixture. This type of condenser is significantly more efficient than the conventional tube condenser, as is used with the HDH process. Thus, the condenser will be considerably more compact for a given design production rate, resulting in reduction of cost.

5) The diffusion tower and direct contact condenser can accommodate very large flow rates, and thus economies of scale can be taken advantage of to produce large production rates.

6) No specialized components are required to manufacture a DDD plant. All of the components required to fabricate a DDD plant are manufactured in bulk and are readily available from different suppliers. This facet of production also translates to reduced cost.

\subsection{Disadvantage of the DDD Process}

The fraction of feed water converted to fresh water using the conventional DDD process is largely dependent on the difference in high and low temperatures in the system. When driving the process using low grade waste heat, this temperature difference will be moderate. Thus the fraction of feed water converted to fresh water will be low. With the air heating configuration, the fresh water conversion efficiency is significantly improved. For either configuration, a large amount of water and air must be pumped through the facility to accomplish a sizable fresh water production rate. This disadvantage is an inherent characteristic of the DDD process. However, as long as the production cost of fresh water using the DDD process is cost competitive, it is a tolerable characteristic.

\section{Experimental Facility}

In the 2004 annual report by Klausner et al [6], the direct contact condenser of a diffusion driven desalination facility was described and its performance based on thermodynamic and dynamic transport considerations was discussed. In addition, an experiment was developed to validate an analytical model for the DDD process. The overall fresh water production efficiency of the entire experiment was explored. Through continuing research, there are several research objectives for the DDD project that have been explored this year. One major research objective is to analyze the effect of co-current and counter-current flows on the performance of the direct contact condenser and efficiency of the DDD process. Another major objective is to modify the facility to adequately heat the input dry air. Theoretical considerations suggest that heating the input air can significantly enhance the fresh water conversion efficiency. Thus, the performance of the DDD process with heated input air will be explored. Currently, the first objective has been successfully achieved and is described in detail 
within the report. The co-current and counter-current flow experiments in the direct contact condenser are used to validate and guide the modeling effort. The original analytical model was calibrated using the experimental data. Further improvements to the model are required and will be discussed in the report. Also, the facility has been modified to accommodate heated air, and preliminary experimental data have been collected. These results will be explored in the report.

The objectives of the current experimental investigation are as follows:

a) Modify the laboratory scale diffusion driven desalination facility to adequately heat the input dry air.

b) Provide sufficient instrumentation such that detailed heat and mass transfer measurements may be made as well as measurements of fresh water production and energy consumption.

c) Conduct an array of experiments over the range of parameter space considered in the analysis, and make extensive measurements of heat and mass transfer coefficients, pressure drop, and evaporation rate, with a heated air input.

d) Compare the experimental results with the analytical results.

e) Examine the dimensionless correlations for the heat transfer coefficient for air and water flow through packed beds. Make adjustments to the analytical model as required.

f) Investigate the performance of the direct contact condenser, and investigate the actual fresh water production efficiency with heated air input.

Fig. 3 shows a pictorial view of the modified laboratory-scale DDD facility. Fig. 4 shows a schematic diagram of the modified experimental facility. The main feed water, which simulates the seawater, is drawn from one municipal water line. The feed water initially passes through a vane type flow meter and then enters a preheater which is capable of raising the feed water temperature to $50^{\circ} \mathrm{C}$. The feed water then flows through the main heater, which can raise the temperature to saturated conditions. The feed water temperature is controlled with a PID feedback temperature controller where the water temperature is measured at the outlet of the main heater. The feed water is then sent to the top of the diffusion tower, where it is sprayed over the top of the packing material. The water sprayed on top of the packing material gravitates downward and that which is not evaporated is collected at the bottom of the diffusion tower in a sump and discharged through a drain. The temperature of the discharge water is measured with a thermocouple. Strain gauge type pressure transducers are mounted at the bottom and top of the diffusion tower to measure the static pressure. A magnetic reluctance differential pressure transducer is used to measure the pressure drop across the length of the packing material.

Dry air is drawn into a centrifugal blower equipped with a $1.11 \mathrm{~kW}(1.5$ horsepower) motor. The discharge air from the blower flows through a $10.2 \mathrm{~cm}$ vertical duct in which a thermal mass flow meter is inserted. The air flow rate is controlled by varying the speed of the blower. A three-phase autotransformer is used to control the voltage to the motor and therefore regulate the speed. The air then flows through a vertical section of duct where the thermal mass flow meter measures the air flow rate. The flow meter must be placed before the heater so the heated air does not 
interfere with the data measurement. Next, the air flows down through a $9.53 \mathrm{~cm}$ inner diameter duct where a $4 \mathrm{~kW}$ tubular heater is installed. The amount of power supplied to the heater is regulated by a single-phase autotransformer. The temperature and inlet relative humidity of the air are measured with a thermocouple and a resistance type humidity gauge downstream of the mass flow meter and heater, in the horizontal section of pipe. The air is forced through the packing material in the diffusion tower and discharges through a duct at the top of the diffusion tower. At the top of the tower, the temperature and humidity of the discharge air are measured in the same manner as at the inlet.

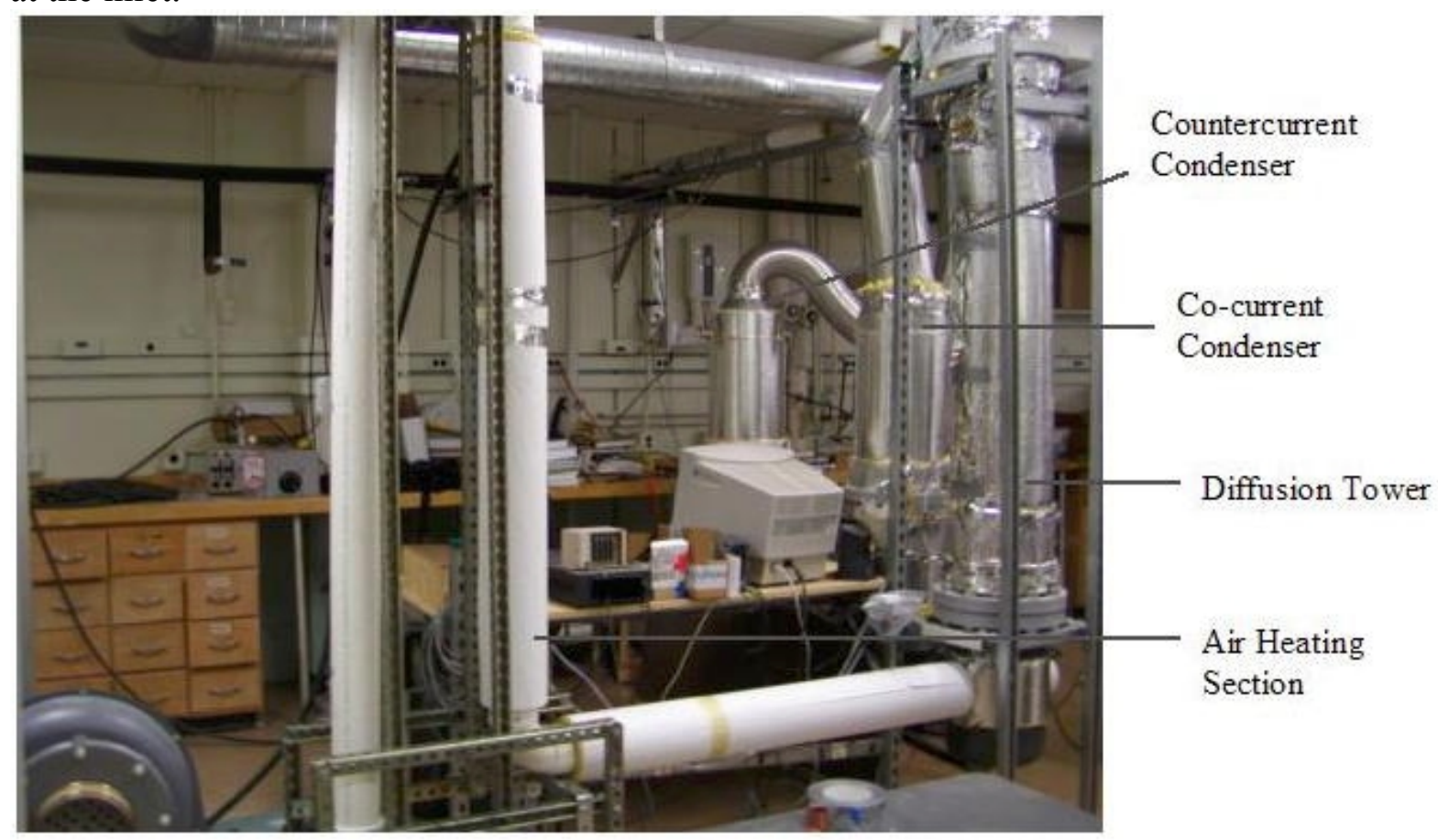

Figure 3 Pictorial view of the laboratory-scale DDD experiment

The condenser is comprised of two stages in a twin tower structure. The main feed water, which simulates the cold fresh water, is drawn from another municipal water line. The feed fresh water is separated into two waterlines and passes through two different turbine flow meters. After the fresh water temperature is measured at the inlet of the condenser tower, it is sprayed from the top of each tower.

The air drawn by the centrifugal blower flows out of the top of the diffusion tower with an elevated temperature and absolute humidity. It then flows into the first stage of the direct contact condenser, which is also called the co-current flow stage. Here, the cold fresh water and wet air will have heat and mass exchange as they both flow to the bottom of this tower. The twin towers are connected by two PVC elbows where the temperature and relative humidity of air are measured by a thermocouple and a resistance type humidity gauge. The air is then drawn into the bottom of the second stage of the condenser. Because the fresh water is sprayed from the top and the wet air comes from the bottom, this stage of the condenser is denoted as the counter-current flow stage. The air will continue being cooled down and dehumidified by the cold fresh 
water until it is discharged at the top of the second stage. At this outlet, the temperature and humidity of the discharge air are measured in the same manner as at the inlet.

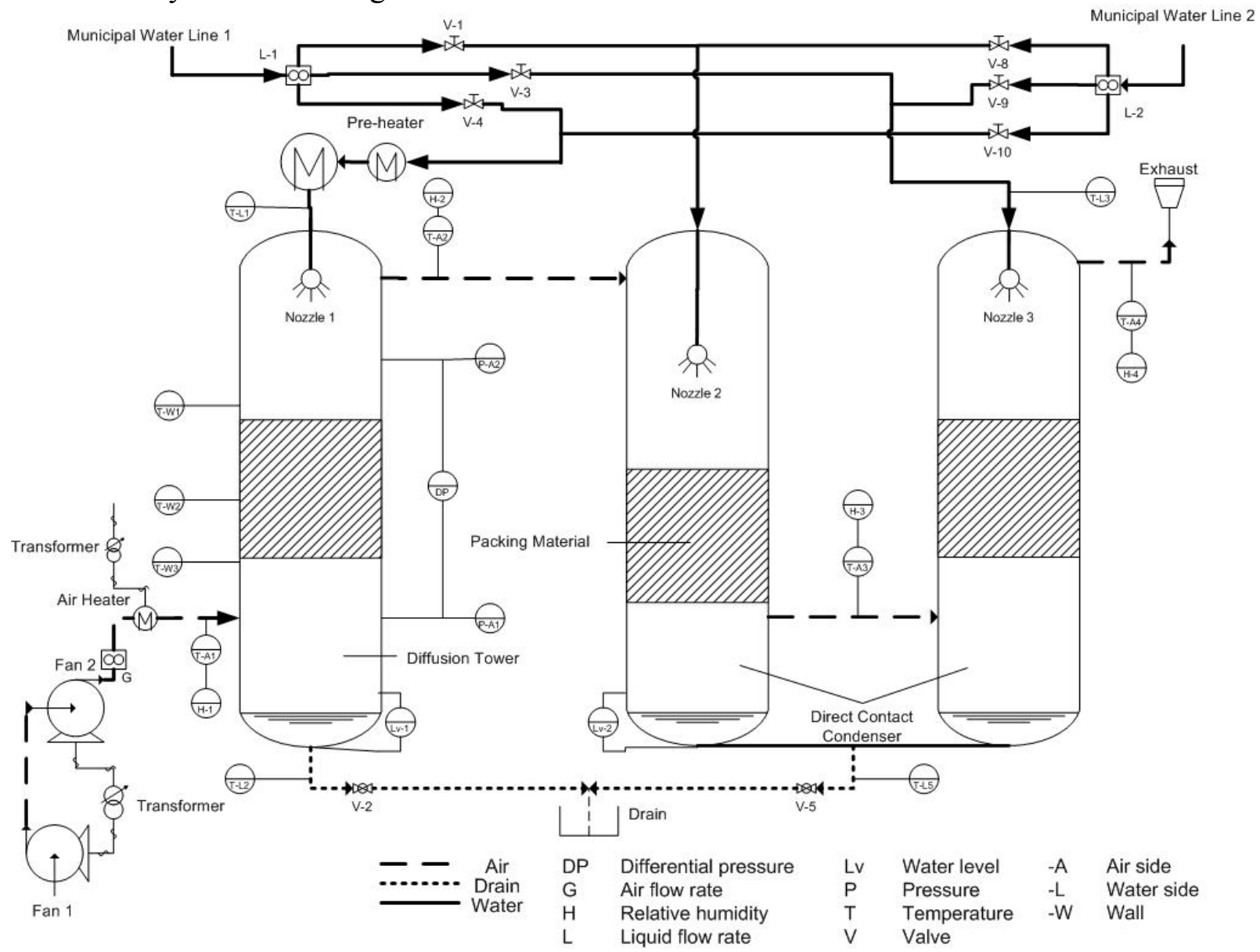

Figure 4 Schematic diagram of DDD facility

The water sprayed on top of the condenser gravitates toward the bottom. The portion of the water condensate from the vapor is collected together with the initial inlet cold fresh water at the bottom of the twin towers and discharged through a drain. The temperature of the discharge water is measured with a thermocouple.

There are two optional components with the condenser. One is a traditional fin tube surface condenser and the other is the packing material. Whether or not they are required depends on the fresh water production efficiency yielded by the direct contact condenser. The best condenser performance is achieved with packing. The tube surface condenser has not been used with the current experiments.

\subsection{Description of Individual Components}

\section{Diffusion Tower}

A schematic representation of the diffusion tower is shown in Fig. 5. The diffusion tower consists of three main components: a top chamber containing the air plenum and spray distributor, the main body containing the packing material, and the bottom chamber containing the air distributor and water drain. The top and bottom 
chambers are constructed from $25.4 \mathrm{~cm}$ (10" nominal) ID PVC pipe and the main body is constructed from $24.1 \mathrm{~cm}$ ID acrylic tubing with wall thickness of $0.64 \mathrm{~cm}$. The three sections are connected via PVC bolted flanges. The transparent main body accommodates up to $1 \mathrm{~m}$ of packing material along the length.

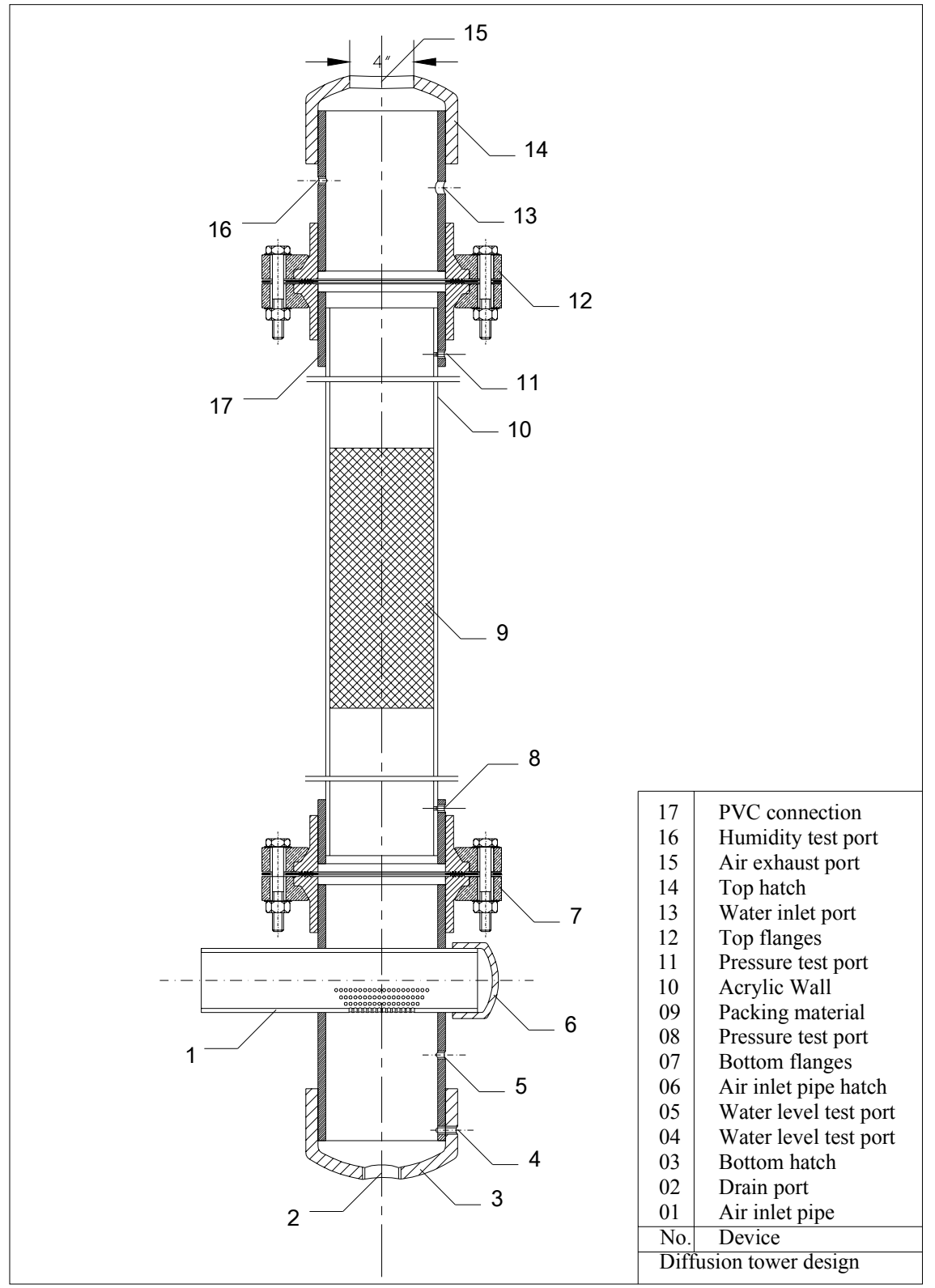

Figure 5 Schematic diagram of experimental diffusion tower

\section{Direct contact condenser}

A schematic representation of the direct contact condenser is shown in Fig. 6. The condenser includes two towers. Each tower consists of two main components: a top chamber containing the air plenum and spray distributor, and a bottom chamber containing the packing material and water drain. The top chamber is constructed from $25.4 \mathrm{~cm}$ (10" nominal) ID acrylic tubing and the bottom chamber is constructed from $25.1 \mathrm{~cm}$ ID PVC pipe. The two sections are connected via PVC bolted flanges. The 


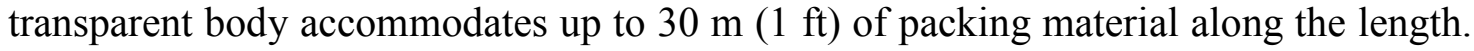
The two towers are connected by two $25.4 \mathrm{~cm}$ (10" nominal) ID PVC elbows which provide sufficient space for both holding drain water and providing an air flow channel.

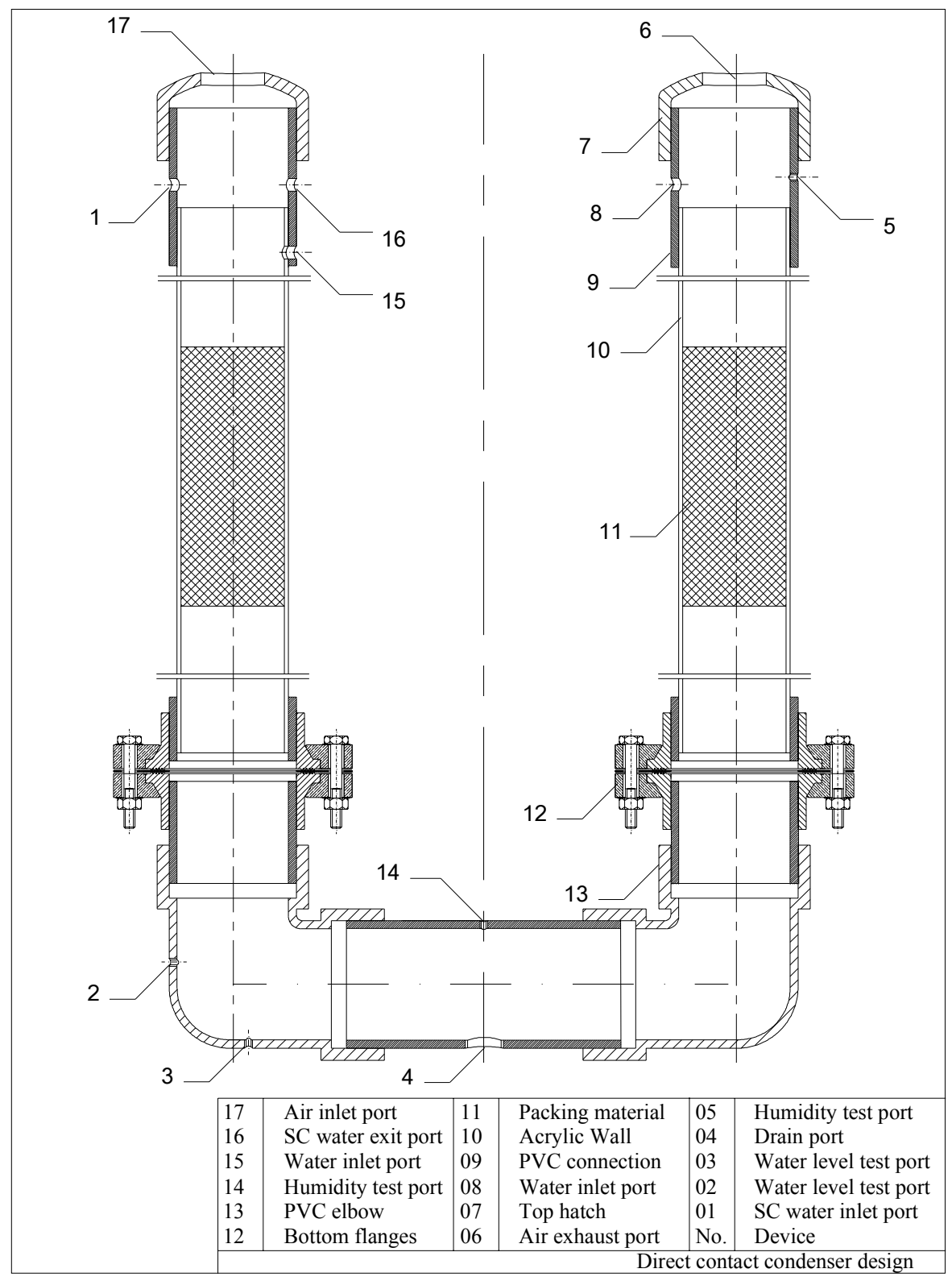

Figure 6 Schematic diagram of experimental direct contact condenser

\section{Water Distributor}

The water distributors for the entire experimental system consist of 3 full cone standard spray nozzles manufactured by Allspray. The three nozzles each maintain a uniform cone angle of $60^{\circ}$. The nozzle is designed to allow a water capacity of about $14.7 \mathrm{lpm}$, and it is placed more than $50 \mathrm{~cm}$ away from the packing material in the diffusion tower to ensure that the spray covers the entire desired area. The spray nozzle pictured in Fig. 7 is a one-piece construction machined from brass bar stock. 


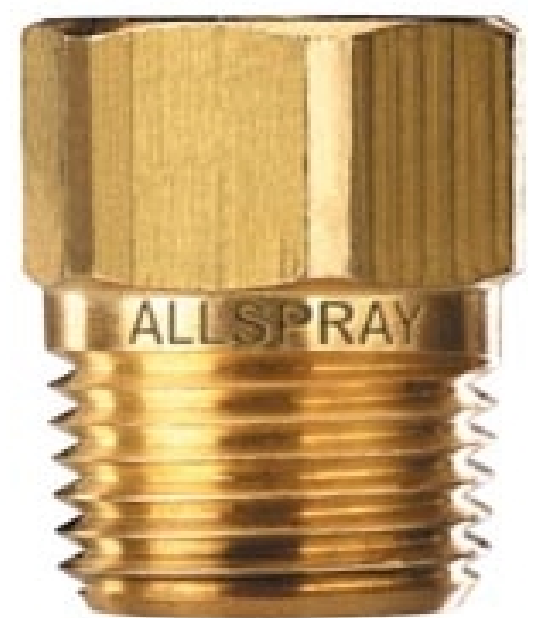

Figure 7 Pictorial view of spray nozzle

Pre-heater

The pre-heater used for the present experiment is a $240 \mathrm{~V}$ point source water heater. It possesses a self-contained temperature controller and can deliver water outlet temperatures ranging from $30^{\circ}$ to $50^{\circ} \mathrm{C}$.

\section{Main Heater}

The main heater consists of two $3 \mathrm{~kW}$ electric coil heaters wrapped around a copper pipe through which the feed water flows. The power to the heaters is controlled with two PID feedback temperature controllers with a $240 \mathrm{~V}$ output. The feedback temperature to the controllers is supplied with a type $\mathbf{J}$ thermocouple inserted in the feed water flow at the discharge of the heater.

\section{Air Heater}

The air heater is a $4 \mathrm{~kW} 1.21 \mathrm{~cm}$ diameter round cross section tubular heater. It has a $240 \mathrm{~V}$ rating and has a watt density of $194 \mathrm{~W} / \mathrm{cm}^{2}$. The sheath is Incoloy, which has a maximum temperature of $815^{\circ} \mathrm{C}$. It has a sheath length of $254 \mathrm{~cm}$ and a heated length of $236 \mathrm{~cm}$. The heater has been bent to fit inside the $9.5 \mathrm{~cm}$ inner diameter pipe. Figure 8 shows the bent heater shape. The power to the heater is controlled with a single-phase autotransformer.

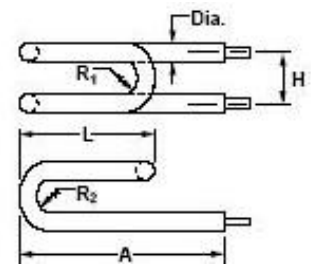

Figure 8 Pictorial view of bent heater

\section{Packing Material}

The packing material used in the initial experiments is HD Q-PAC manufactured by Lantec and is shown pictorially in Fig. 9. The HD Q-PAC, constructed from polyethylene, was specially cut using a hotwire so that it fits tightly 
into the main body of the diffusion tower. The specific area of the packing is 267 $\mathrm{m}^{2} / \mathrm{m}^{3}$ and its effective diameter for modeling purposes is $1 \mathrm{~cm}$.

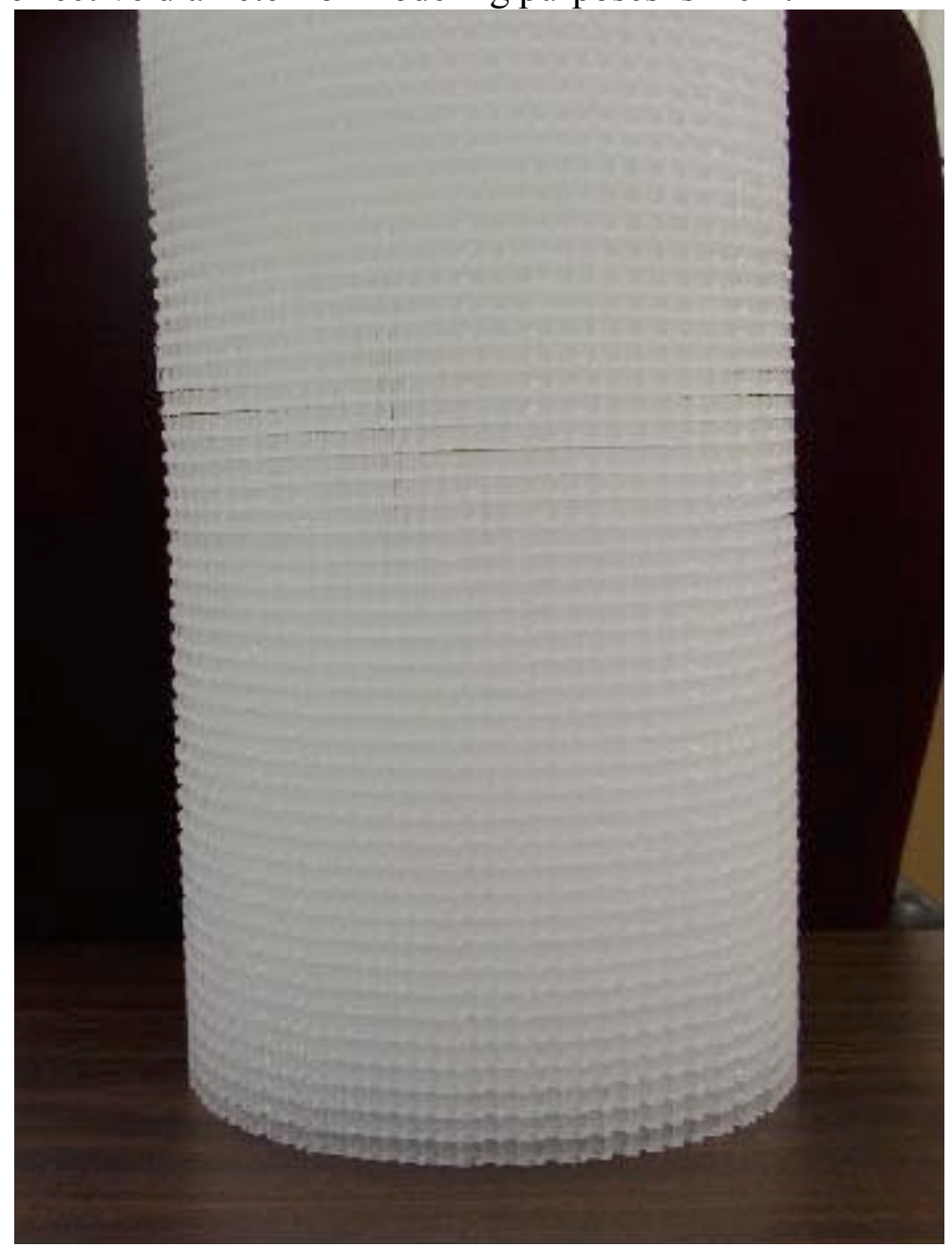

Figure 9 Pictorial view of packing matrix

\section{Water Mass Flow Meter}

The vane-type water mass flow meter, constructed by Erdco Corporation, has a range of 1.5-15.14 lpm. It has been calibrated using the catch and weigh method. The flow meter has a 4 to $20 \mathrm{~mA}$ output that is proportional to flow rate and has an uncertainty of $\pm 1 \%$ of the full scale.

The turbine water flow meters, constructed by Proteus Industries Inc., have a range of 5.7-45.4 $\mathrm{lpm}$. They are also calibrated using the catch and weigh method. These flow meters have a 0 to $20 \mathrm{~mA}$ or $0-5 \mathrm{~V}$ output that is proportional to flow rate, and an uncertainty of $\pm 1.5 \%$ of the full scale.

\section{Air Mass Flow Meter}

The air mass flow rate is measured with a model $620 \mathrm{~S}$ smart insertion thermal mass flow meter. The flow meter has a response time of $200 \mathrm{~ms}$ with changes in mass flow rate. The mass flow meter has a microprocessor-based transmitter that provides a 0-10 V output signal. The mass flow meter electronics are mounted in a NEMA 4X 
housing. The meter range is $0-1125 \mathrm{SCFM}$ of air at $25^{\circ} \mathrm{C}$ and 1 atm (14 PSIG). The uncertainty of the flow meter is $\pm 1 \%$ Full scale $+0.5 \%$ Reading.

\section{Relative Humidity}

The relative humidity is measured with two duct-mounted HMD70Y resistancetype humidity and temperature transmitters manufactured by Vaisala Corp. The humidity and temperature transmitters have a $0-10 \mathrm{~V}$ output signal and have been factory calibrated.

\section{Temperature and Pressure}

All temperature measurements used in the thermal analysis are measured with type E thermocouples. The pressures at the inlet and exit of the diffusion tower are measured with two Validyne P2 static pressure transducers. All of the wetted parts are constructed with stainless steel. The transducers have an operating range of $0-.34 \mathrm{~atm}$ (0-5 psi) and have a 0-5 VDC proportional output. The transducers have an uncertainty of $\pm 0.25 \%$ of full scale. They are shock resistant and operate in environments ranging in temperature from $-20^{\circ}$ to $80^{\circ} \mathrm{C}$.

The pressure drop across the test section is measured with a DP15 magnetic reluctance differential pressure transducer. The pressure transducer signal is conditioned with a Validyne carrier demodulator. The carrier demodulator produces a 0-10 VDC output signal that is proportional to the differential pressure. The measurement uncertainty is $\pm 0.25 \%$ of full scale.

\section{Data Collection Facility}

A digital data acquisition facility has been developed for measuring the output of the instrumentation on the experimental facility. The data acquisition system consists of a 16-bit analog to digital converter and a multiplexer card with programmable gain manufactured by Computer Boards calibrated for type $J$ thermocouples and 0-10V input ranges. A software package, SoftWIRE, which operates in conjunction with MS Visual Basic, allows a user defined graphical interface to be specified specifically for the experiment. SoftWIRE also allows the data to be immediately sent to an Excel spreadsheet. An example program layout using SoftWIRE is shown in Fig. 10.

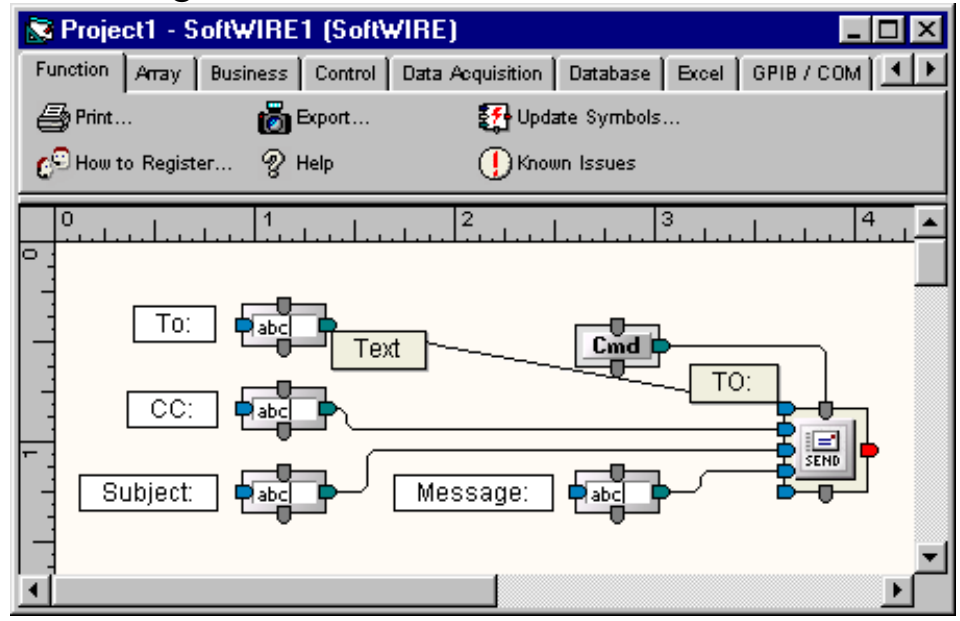

Figure 10 Example program of SoftWIRE 
The experimental data acquisition system is designed by using the Virtual Instrumentation module. The control and observation panels are shown in Figs. 11-13. On the "Main" panel, shown in Fig. 11, there is a switch button to begin or stop the data acquisition program. Once the program begins, the experimental data will be recorded in a database file. The file's name, destination and recording frequency can be defined on this panel. Also, all of the experimental measurements are displayed here in real time.

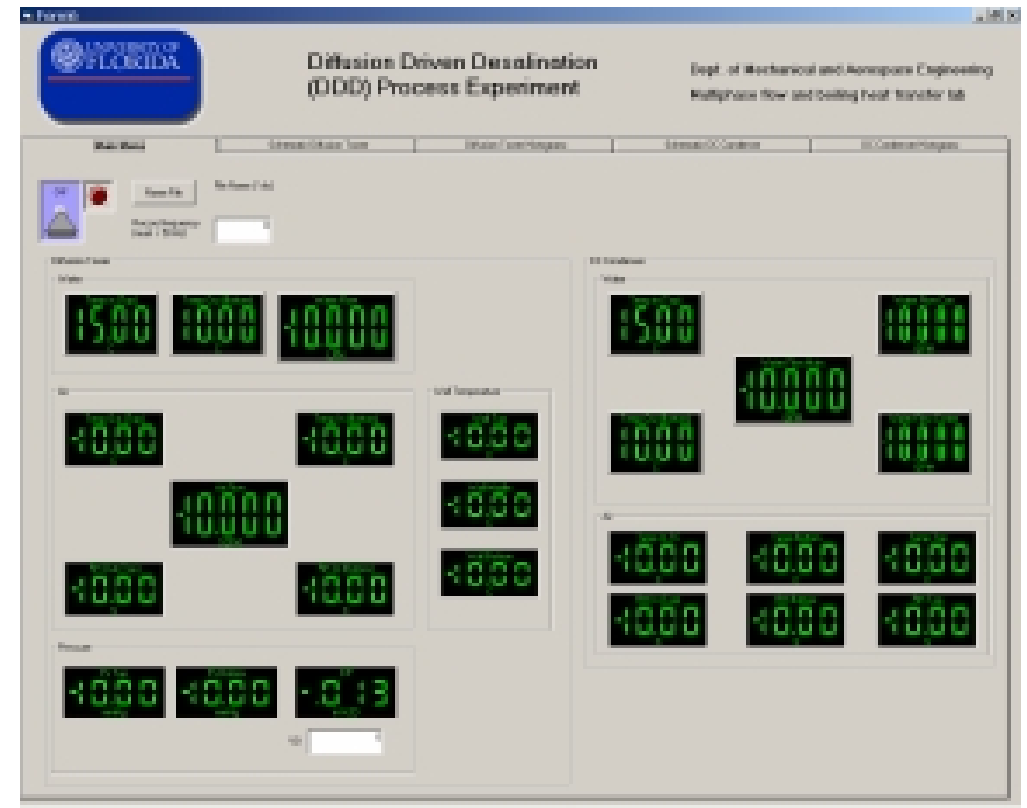

Figure 11 "Main" panel of the DDD data acquisition program

This program also supplies the schematic view panels for the diffusion tower and direct contact condenser, shown in Fig. 12. It shows the position and values of all the measurements from the experimental facility so that the operator can easily control the fresh water production.
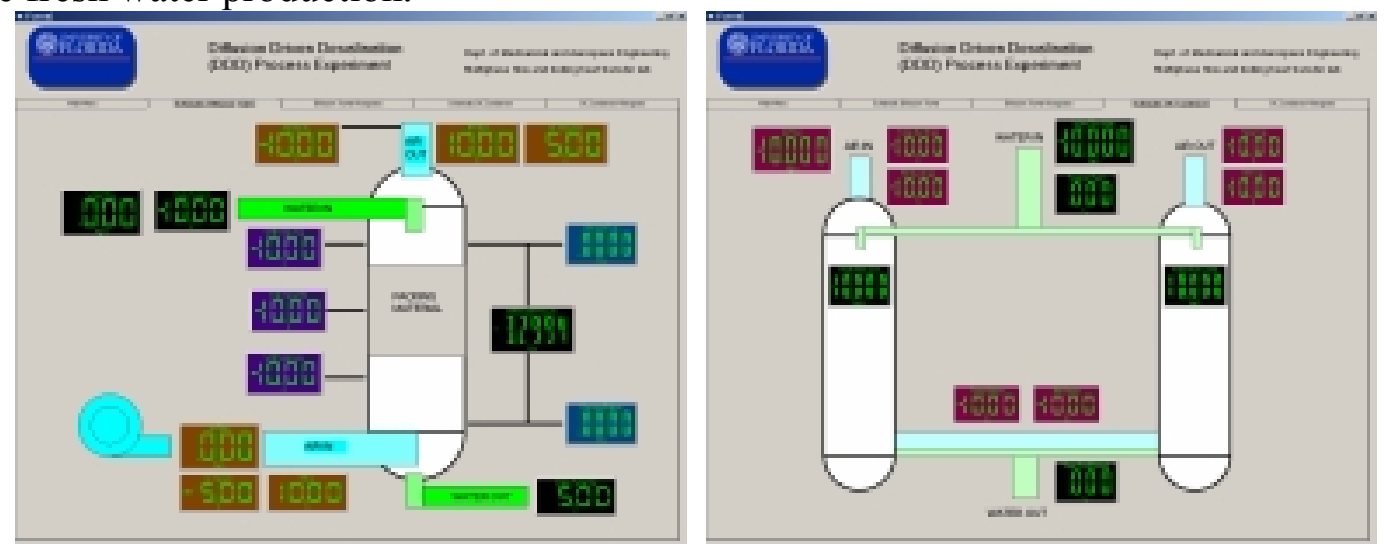

Figure 12 "Schematic view" panels of the DDD data acquisition program

Because the latest research investigation focuses on steady-state operation it is important to know when the physical processes have reached steady-state. The "Histogram View" panels, shown in Fig. 13, are used to display the measurement variations with time. The $\mathrm{x}$-axis is the time coordinate and $\mathrm{y}$-axis displays the 
measurement value. The measurement range shown on the y-axis can be changed manually at any time during the experiment to accurately observe the parametric trend.
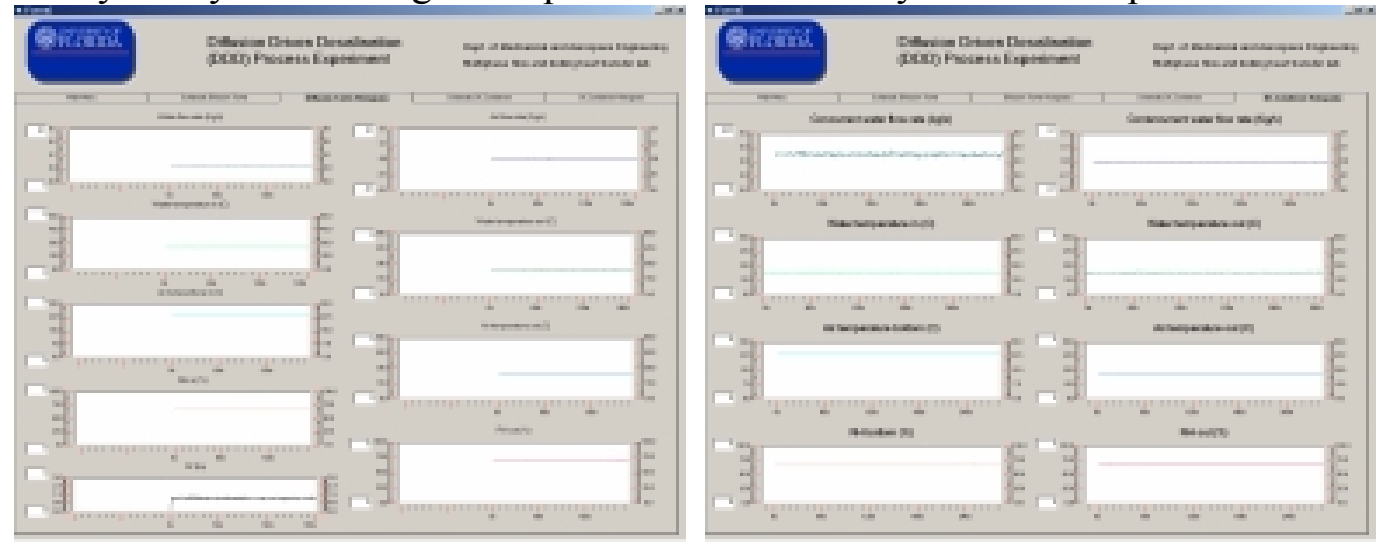

Figure 13 "Histogram view" panels of the DDD data acquisition program

\section{Ion Chromatograph}

One objective of the experimental facility is to quantify the purity of fresh water produced with the DDD facility. For this purpose a Dionex ICS-90 isochromatic ion chromatograph has been installed in the Multiphase Heat Transfer and Fluid Dynamics laboratory. The ICS-90 is capable of measuring mineral concentrations down to several parts per billion.

\section{Heat and Mass Transfer for the Direct Contact Condenser with Packing}

Heat and mass transfer models for the diffusion tower have been reported in the 2004 annual report [6], and are not included here.

\subsection{Physical Model}

A one dimensional two fluid condensation model is used to quantify the change in mean humidity ratio through the condenser. Conservation equations for mass and energy are applied to a differential control volume for co-current flow which is shown in Figure 14.

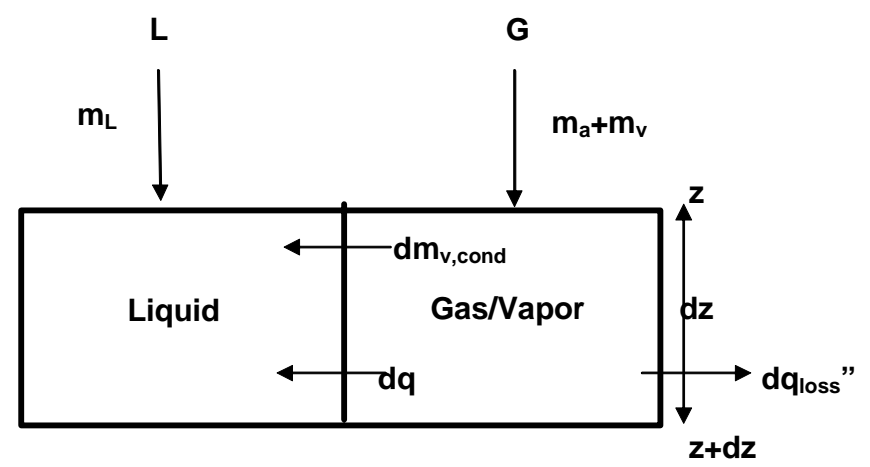

Figure 14 Differential control volume for liquid/gas heat and mass transfer within cocurrent condenser 
Similarly, a one dimensional two fluid counter-current differential control volume is shown in Fig.15. Conservation equations for mass and energy are applied to the control volume.

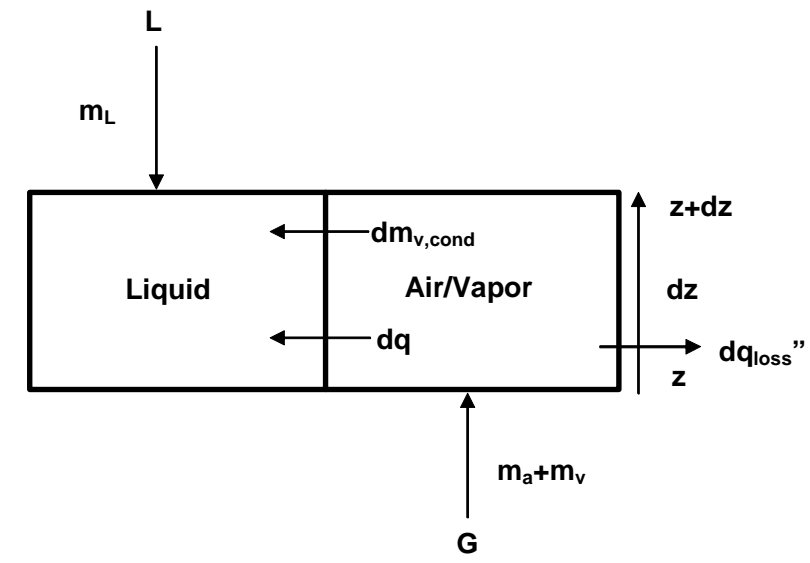

Figure 15 Differential control volume for liquid/gas heat and mass transfer within counter-current condenser

Within the direct contact condenser, the transverse air temperature distribution could play an important role in the condensation process. Therefore, a non-uniform distribution of the air temperature in the transverse direction is considered in the analysis. The flow structure within the packing material is shown in Figure 16. The local humidity based on local transverse air temperature is averaged, and the mean humidity is used on the one dimensional conservation equations.

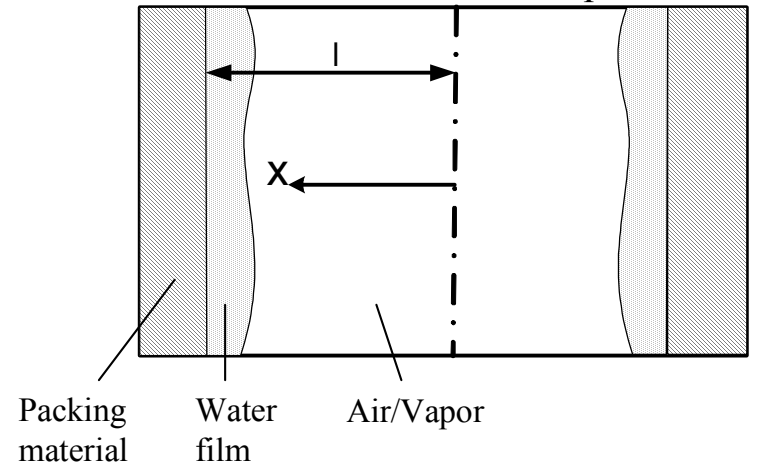

Figure 16 Flow structure within the packing material

\subsection{Mathematic Model}

As mentioned previously, the air temperature non-uniformity within the cocurrent flow condenser may influence the condensation process. Therefore, a nonuniform distribution of the air temperature in the transverse direction is considered in the condensation analysis. Because the air in the channel is highly turbulent, following Kays and Crawford [7], a 1/7 $7^{\text {th }}$ law variation of temperature is assumed as,

$$
\frac{T_{L}-T_{a, x}}{T_{L}-T_{a, c}}=\left(1-\frac{x}{l}\right)^{1 / 7} .
$$


where $T_{a, c}$ is the centerline air temperature, $l$ is the half width of the flow channel, and $\mathrm{x}$ is the transverse axis. The centerline air temperature can be solved as,

$$
T_{a, c}=T_{L}+1.2\left(T_{a}-T_{L}\right) \text {. }
$$

The transverse distribution of air temperature is calculated from Eqn (1). The local humidity ratio $\omega$, based on local transverse air temperature $T_{a, x}$, is related to the relative humidity $\Phi$ through as

$$
\omega_{x}=\frac{m_{V}}{m_{a}}=\frac{0.622 \Phi P_{s a t}\left(T_{a, x}\right)}{P-\Phi P_{s a t}\left(T_{a, x}\right)}
$$

where $\mathrm{P}(\mathrm{kPa})$ is the total system pressure, and $\mathrm{P}_{\text {sat }}(\mathrm{kPa})$ is the water saturation pressure corresponding to the local air temperature $\mathrm{T}_{\mathrm{a}, \mathrm{x}}$ and can be calculated using an empirical representation of the saturation line,

$$
P_{\text {sat }}(T)=a \exp \left(b T-c T^{2}+d T^{3}\right),
$$

where empirical constants are $a=0.611379, b=0.0723669, c=2.78793 \mathrm{e}-4, \mathrm{~d}=6.76138 \mathrm{e}-7$, and $\mathrm{T}\left({ }^{\circ} \mathrm{C}\right)$ is the saturation temperature. The local humidity ratio is area averaged, and the mean humidity $\omega_{\mathrm{m}}$ is used in the one dimensional condensation model (Eqs (5), (6) and (7) ).

Noting that the relative humidity of air remains $100 \%$ during the condensation process, the absolute humidity $\omega$ is only a function of air temperature $\mathrm{T}_{\mathrm{a}}$. Differentiating Eqn. (3) and combining with Eqn. (4), the gradient of humidity can be expressed as,

$$
\frac{d \omega}{d z}=\frac{d T_{a}}{d z} \frac{P}{P-P_{s a t}\left(T_{a}\right)} \omega_{m}\left(b-2 c T_{a}+3 d T_{a}^{2}\right) .
$$

The gradient of water temperature in the condenser is found by considering the energy conservation in liquid phase as,

$$
\frac{d T_{L}}{d z}=-\frac{G}{L} \frac{d \omega}{d z} \frac{\left(h_{F g}\left(T_{a}\right)-h_{L}\left(T_{L}\right)\right)}{C_{p_{L}}}-\frac{U a\left(T_{L}-T_{a}\right)}{C_{p_{L}} L},
$$

The gradient of air temperature in the condenser is found by considering energy conservation in the gas phase. Equations presented in Appendix A are used to evaluate the overall heat transfer coefficient in Eqs (6) and (7). Because heat loss is observed in the experiments, it is considered as an additional term in the energy conservation of the air side,

$$
\frac{d T_{a}}{d z}=-\frac{h_{L}\left(T_{a}\right)}{C_{p_{G}}\left(1+\omega_{m}\right)} \frac{d \omega}{d z}+\frac{+U a\left(T_{L}-T_{a}\right)}{G C_{p_{G}}\left(T_{a}\right)\left(1+\omega_{m}\right)}-\frac{q_{\text {loss }}^{\prime \prime} \pi D_{o} / A}{G C_{p_{G}}\left(T_{a}\right)\left(1+\omega_{m}\right)},
$$

The specific heat of the air/vapor mixture is evaluated as,

$$
C_{p_{G}}=\frac{m_{a}}{m_{a}+m_{V}} C_{P a}+\frac{m_{V}}{m_{a}+m_{V}} C_{p_{V}} .
$$

Here $D_{o}(m)$ is the cross section diameter of the packed bed, $q_{\text {loss }} "\left(\mathrm{~kW} / \mathrm{m}^{2}\right)$ is the heat loss flux, and A $\left(\mathrm{m}^{2}\right)$ is the total exposed area to the ambient temperature. Finally, Eqs. $(5-7)$ are used to evaluate the heat and mass transfer performance in the co-current condenser.

A similar mass and energy balance analysis has been done for the countercurrent flow condenser. The equations for evaluating the humidity gradient and air temperature gradient are same as that for co-current flow. The gradient of water 
temperature in the condenser is found by considering the energy conservation in the liquid phase as,

$$
\frac{d T_{L}}{d z}=\frac{G}{L} \frac{d \omega}{d z} \frac{\left(h_{F g}-h_{L}\right)}{C p_{L}}+\frac{U a\left(T_{L}-T_{a}\right)}{C p_{L} L}
$$

Thus, Eqs. (5), (9) and (7) are used to evaluate the heat and mass transfer process in the counter-current flow condenser, and Onda's correlation and heat and mass transfer analogy shown in Appendix A are used to close them.

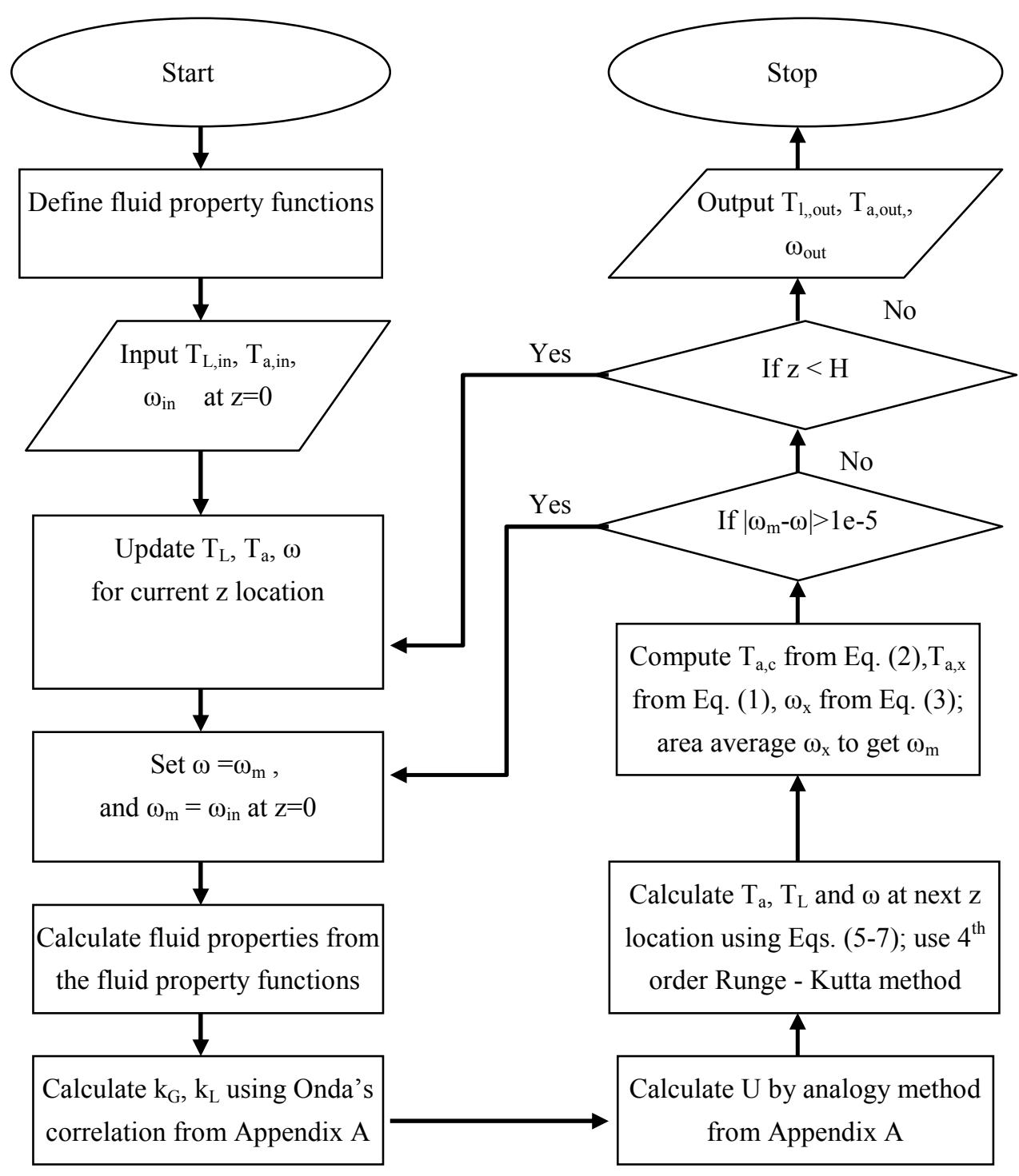

Figure 17 Flow diagram of the co-current flow condenser computation

For the co-current flow condensation analysis presented above, the exit water temperature, exit air temperature, and exit humidity ratio are computed using the following procedure: 1) specify the inlet water temperature, air temperature and bulk humidity; 2) compute the temperatures and bulk humidity at the next step change in height using Eqs $(5-7)$; 3) compute the local humidity in the x-direction at this $\mathrm{z}$ location using Eqs $(1-3)$ and area average the humidity; 4) check whether the area 
average humidity is the same as the bulk humidity; repeat steps $2-4$ until agreement is achieved; 5) proceed to a new height, and restart computation from step 2;6) compute the temperatures and humidity through the condenser using steps $2-5$ until the computed height matches the experimental height. Detailed flow diagram of the cocurrent flow condenser compuation is shown in Fig. 17.

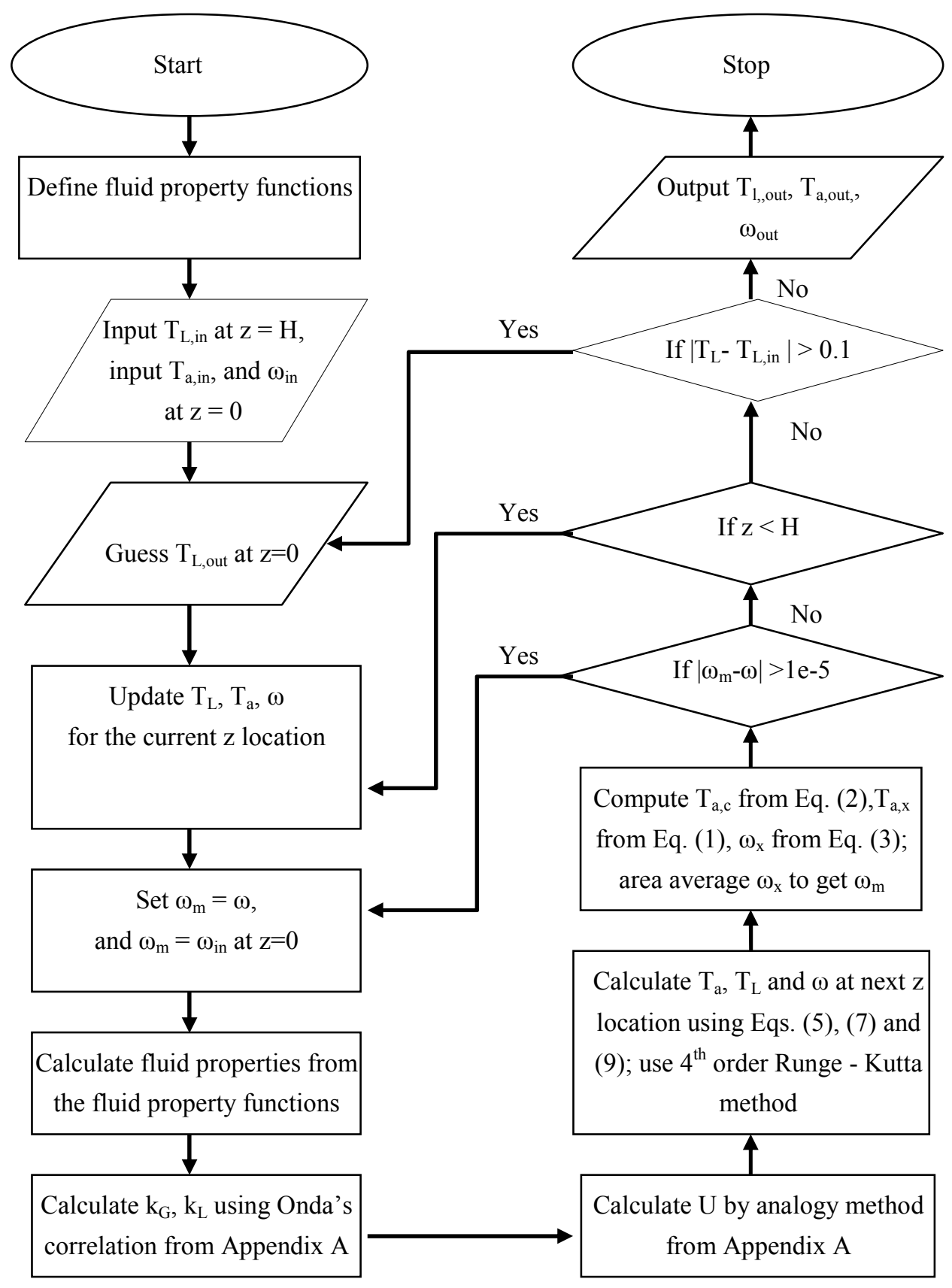

Figure 18 Flow diagram of the counter-current flow condenser computation

For the counter-current condensation analysis, the exit water temperature, exit air temperature, and exit humidity ratio are computed using the following procedure: 1) specify the inlet water temperature, air temperature and bulk humidity; 2) guess the exit 
water temperature; 3) compute the temperatures and bulk humidity at the next step change in height using Eqs. (5), (7) and (9); 4) compute the local humidity at that height using Eqs. $(1-3)$, and area average the humidity; 5) check whether the computed bulk humidity agrees with the area average humidity, repeat steps $3-5$ until agreement is achieved; 6) proceed to a new height, and restart the computation from step $3 ; 7)$ compute the temperatures and humidity through the condenser using steps 3 - 6 until the computed height matches the experimental height; 8) check whether the computed inlet water temperature agrees with the specified inlet water temperature, and stop the computation if agreement is found, otherwise repeat the procedure from step 2 . A detailed flow diagram of the computation procedure is shown in Fig.18.

\subsection{Operating Performance}

At the outset, experiments were run to calibrate the heat loss from the cocurrent condenser. Fig.19 shows the variation of heat loss in the co-current condenser with the temperature difference between the air/vapor mixture and ambient, $\mathrm{T}_{\text {inf }}$.

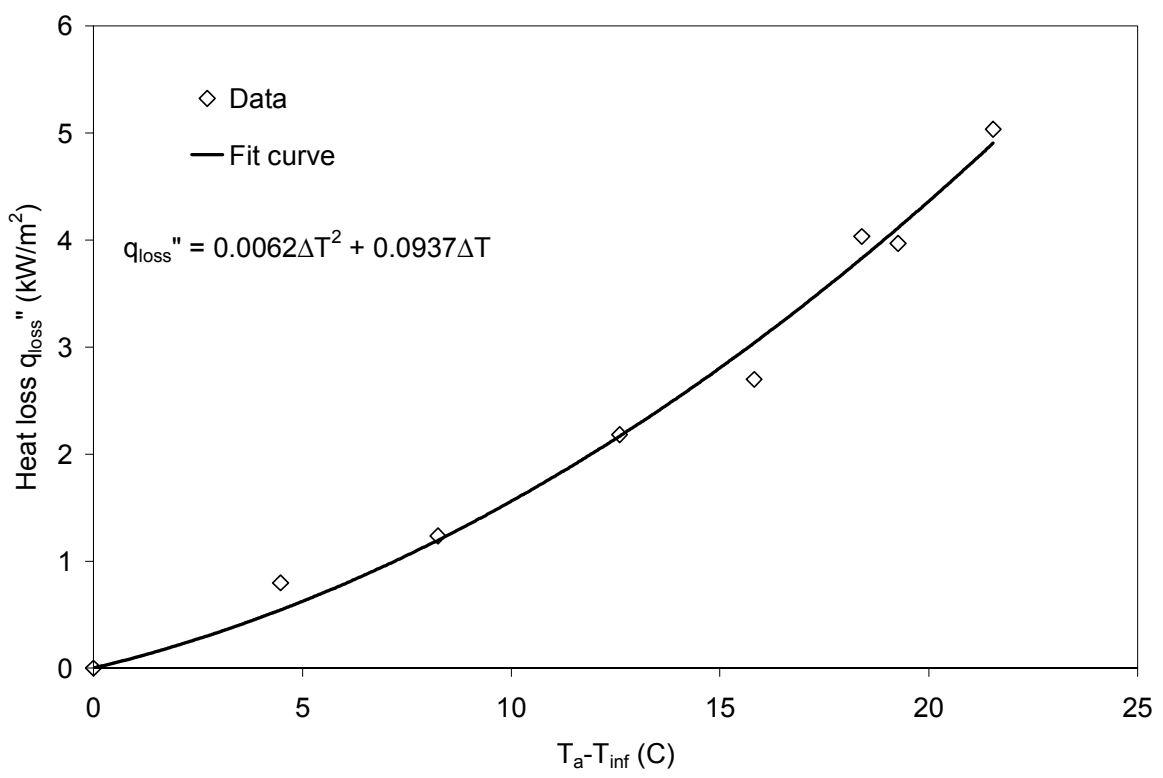

Figure 19 Variation of heat loss in the co-current condenser with the temperature difference between air and ambient.

A least squares fit results in the system heat loss expression

$$
q_{\text {loss }}^{\prime \prime}=0.0937\left(T_{a}-T_{\infty}\right)+0.0062\left(T_{a}-T_{\infty}\right)^{2} .
$$

Combining Eqs. (10) and (7), the gradient of air temperature can be expressed as,

$$
\frac{d T_{a}}{d z}=\frac{\frac{U a\left(T_{L}-T_{a}\right)-q_{\text {loss }}^{\prime \prime} \pi D_{o} / A}{G C_{p_{m i x}}\left(T_{a}\right)\left(1+\omega_{m}\right)}}{1+\frac{h_{L}\left(T_{a}\right)}{C_{P \operatorname{mix}}\left(T_{a}\right)} \cdot \frac{\omega_{m}}{1+\omega_{m}} \cdot \frac{P}{P-P_{\text {sat }}\left(T_{a}\right)}\left(b-2 c T_{a}+3 d T_{a}^{2}\right)} .
$$

Eq. (11) is finally used in the co-current condensation model to calculate the air side temperature gradient.

Heat and mass transfer experiments were carried out in the co-current condenser with a packing bed height of $20 \mathrm{~cm}$. The saturated air inlet temperature was 
fixed at 33,40 , and $44{ }^{\circ} \mathrm{C}$, air mass flux was fixed at $0.68 \mathrm{~kg} / \mathrm{m}^{2}$-s and the water to air mass flow ratio was varied from $0-2.5$. The inlet water temperature was maintained at approximately $25^{\circ} \mathrm{C}$. The experiments were repeated to verify the repeatability of the results. The measured exit humidity, exit air temperature, and exit water temperature are compared with those predicted with the model for all three different saturated air inlet temperatures in Figs. $20-22$. It is observed that the repeatability of the experiments is excellent, and so is the comparison between the predicted and measured outlet conditions.

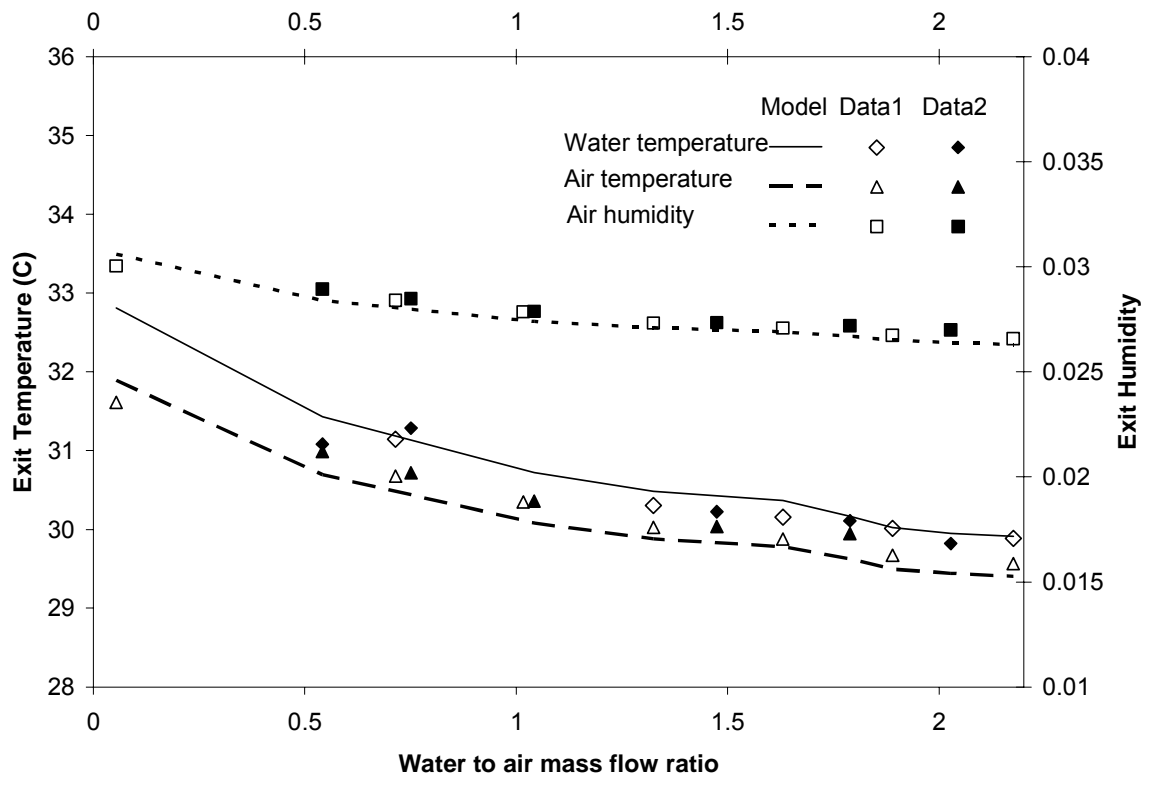

Figure 20 Comparison of predicted exit temperatures and humidity with the experimental data for different water to air mass flow ratio $\left(\mathrm{T}_{a, i n}=33^{\circ} \mathrm{C}\right)$

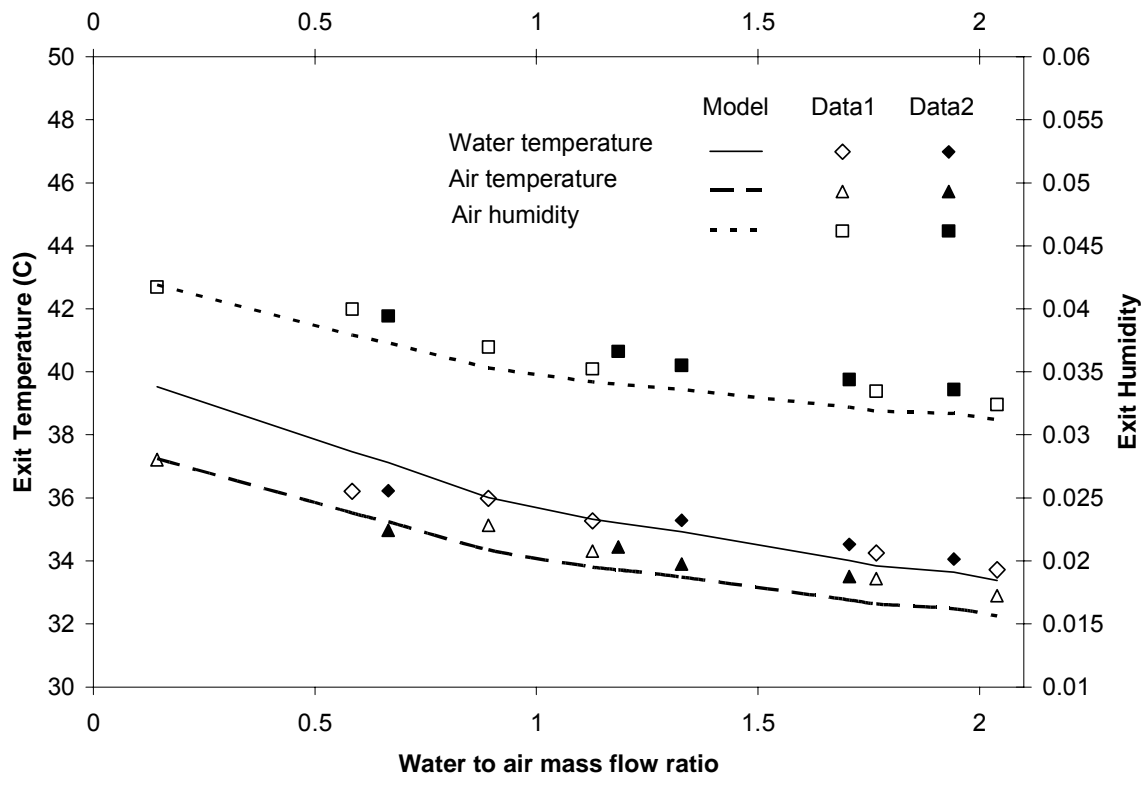

Figure 21 Comparison of predicted exit temperatures and humidity with the experimental data for different water to air mass flow ratio $\left(\mathrm{T}_{a, i n}=40^{\circ} \mathrm{C}\right)$ 


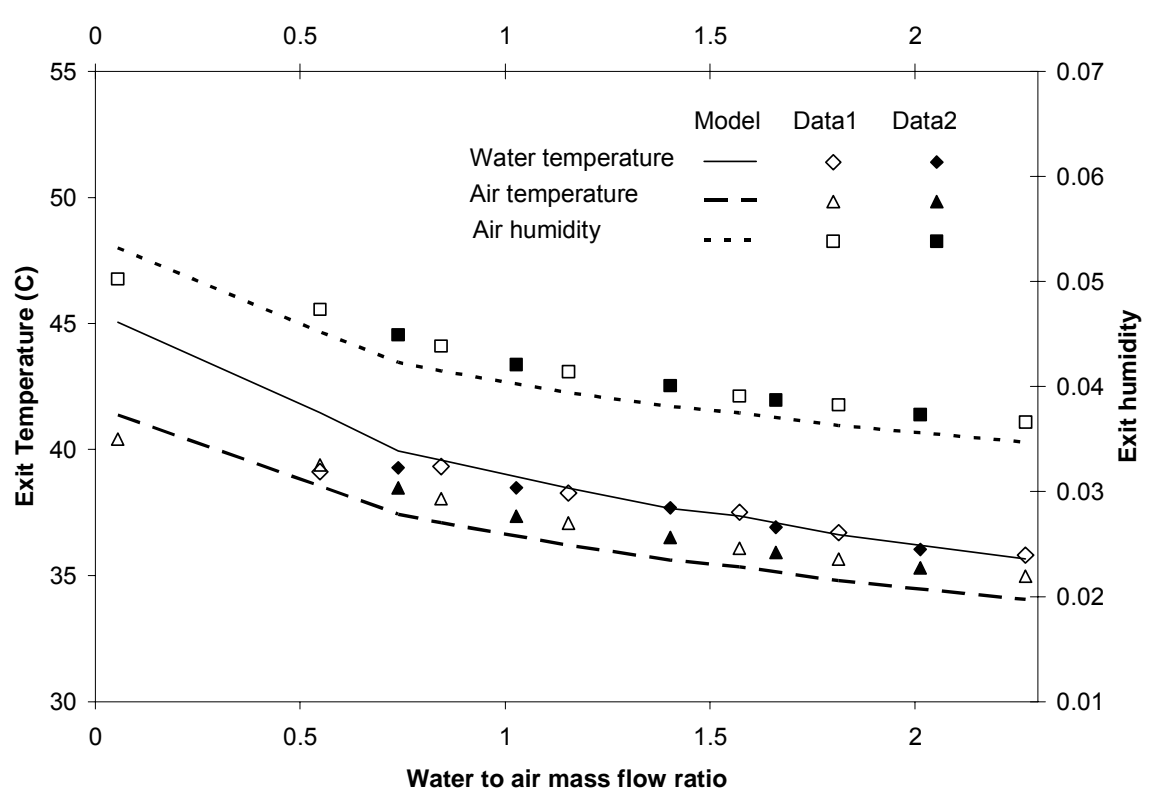

Figure 22 Comparison of predicted exit temperatures and humidity with the experimental data for different water to air mass flow ratio $\left(\mathrm{T}_{a, i n}=44{ }^{\circ} \mathrm{C}\right)$

In general, the analytical model proves to be quite satisfactory in predicting the thermal performance of the co-current flow condenser. The excellent agreement suggests model will be useful for parametric simulation for the DDD process.

Heat and mass transfer experiments were also carried out in the counter-current condenser with a packing bed height of $20 \mathrm{~cm}$. Essentially, no heat loss was observed for the counter-current condenser and thus the last term in Eqn (7) is neglected. Agreement between the heat and mass transfer predictions and computation could only be achieved by modifying the gas side mass transfer coefficient as,

$$
k_{G}=3.2 \operatorname{Re}_{G A}{ }^{0.7} S c_{G}{ }^{1 / 3}\left(a d_{p}\right)^{-2} a D_{G},
$$

In the experiments, the saturated air inlet temperature was fixed at 37,41 , and $43{ }^{\circ} \mathrm{C}$, air mass flux was fixed at $0.68 \mathrm{~kg} / \mathrm{m}^{2}$-s and the water to air mass flow ratio was varied from $0-2.5$. The inlet water temperature was about $25^{\circ} \mathrm{C}$. The experiments were repeated to verify the repeatability of the results. The measured exit humidity, exit air temperature, and exit water temperature are compared with those predicted with the model for all three different saturated air inlet temperatures in Figs. $23-25$. It is observed that the repeatability of the experiments is excellent, and so is the comparison between the predicted and measured exit conditions. 


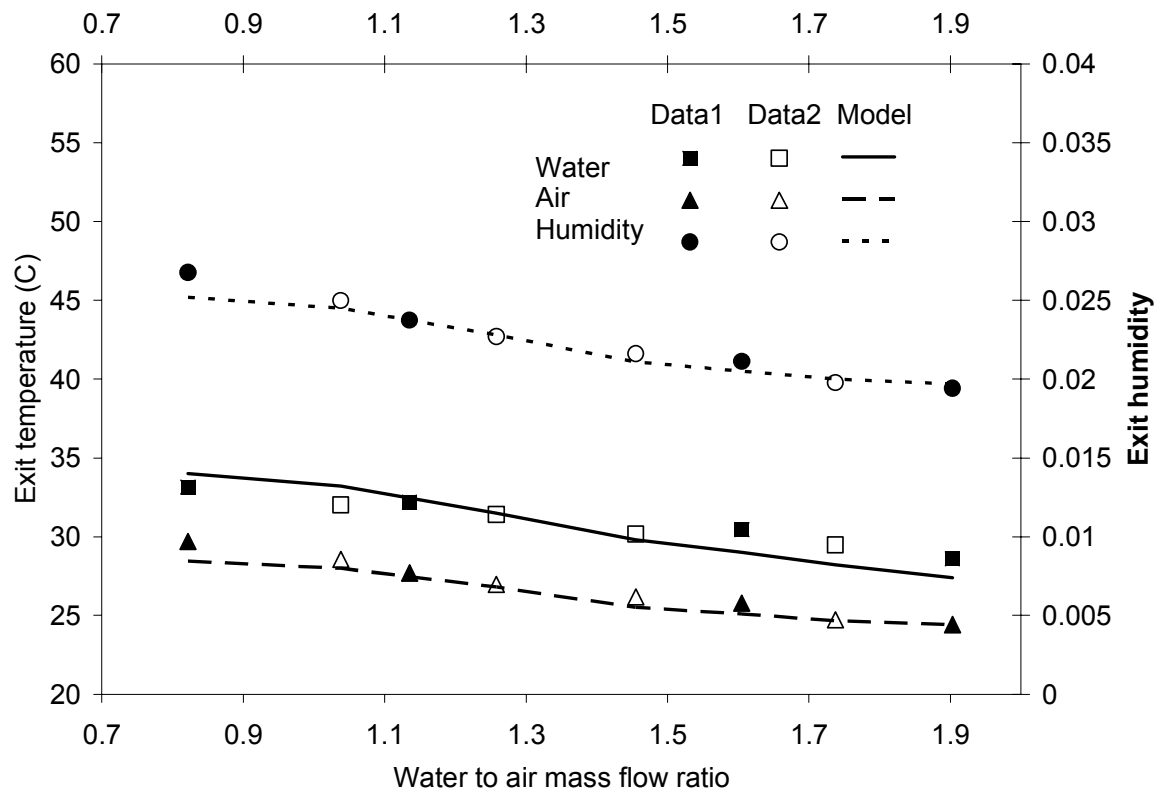

Figure 23 Comparison of predicted exit temperatures and humidity with the experimental data for different water to air mass flow ratio $\left(\mathrm{T}_{a, i n}=37^{\circ} \mathrm{C}\right)$

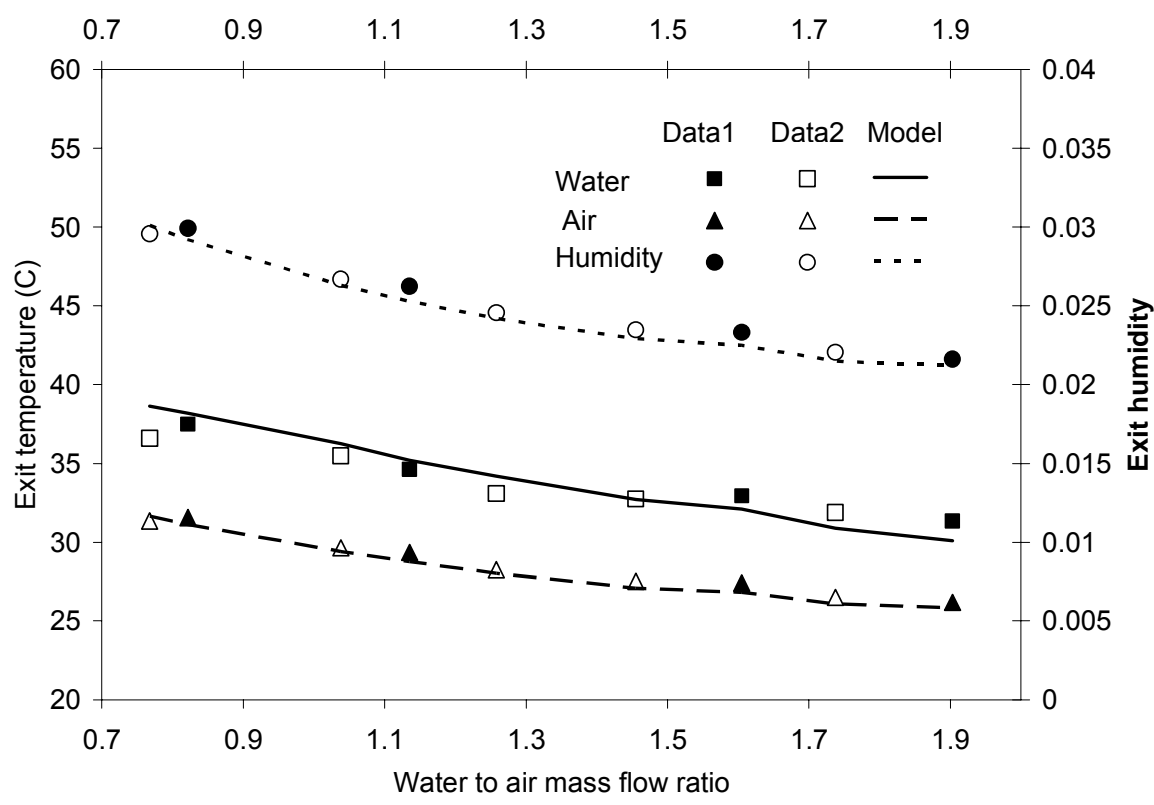

Figure 24 Comparison of predicted exit temperatures and humidity with the experimental data for different water to air mass flow ratio $\left(\mathrm{T}_{a, i n}=41^{\circ} \mathrm{C}\right)$ 


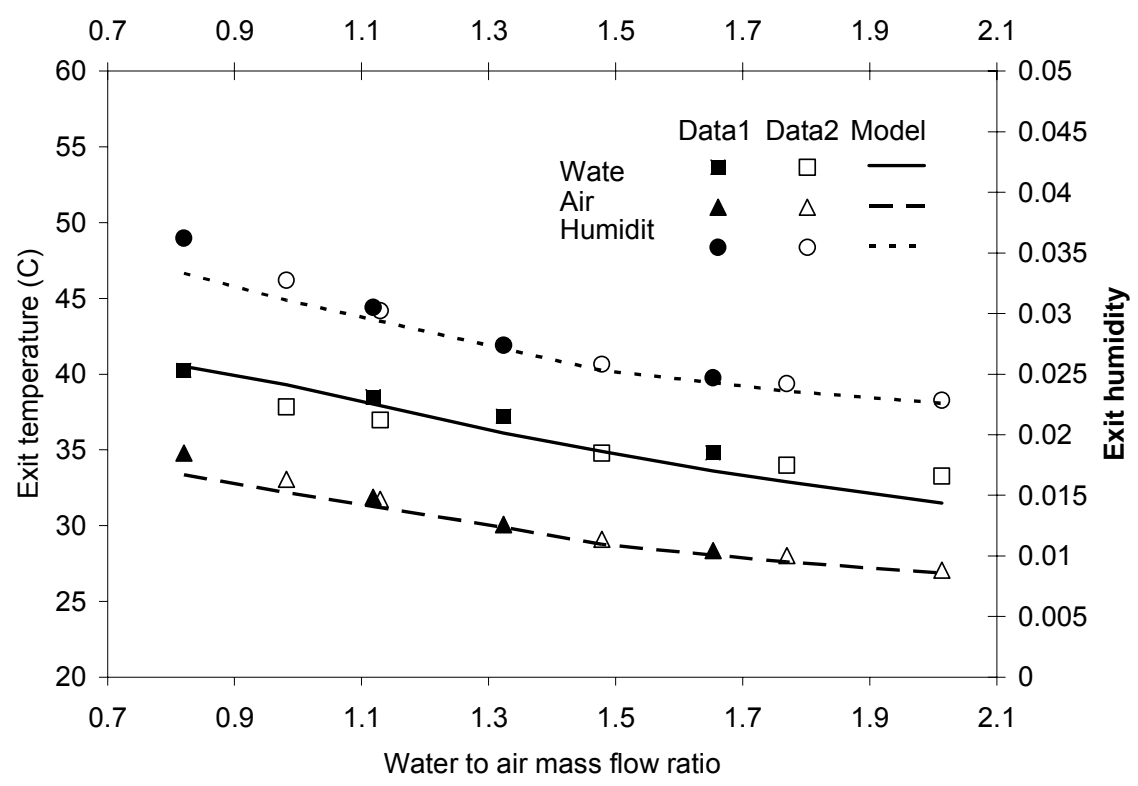

Figure 25 Comparison of predicted exit temperatures and humidity with the experimental data for different water to air mass flow ratio $\left(\mathrm{T}_{a, i n}=43{ }^{\circ} \mathrm{C}\right)$

Onda's original work [14] was scrutinized, and he reported the effective packing diameter influences the mass transfer coefficient on the gas side. He reported two individual curves to present the wide spread experimental data variation with different effective packing diameters. He suggested using 5.23 for the coefficient in Eq. (A2) for the cases that the effective packing diameters are larger than $15 \mathrm{~mm}$, and 2 for those less than $15 \mathrm{~mm}$. The experimental data from his paper show that the constant in Eq. (A2) should range from $2-5.23$. Currently, the packing material using in the condenser has an effective packing diameter of $17 \mathrm{~mm}$, which is close to the threshold condition suggested by Onda. It is believed that the thicker liquid film flowing through the packing with counter-current condensation reduces the flow area and hence the effective packing diameter, thus requiring a modification of the coefficient shown in Eq. (12).

\section{DDD Process Design, Analysis, and Optimization}

The evaporation of mineralized feed water in the diffusion tower is achieved by spraying heated feed water on top of a packed bed and blowing the dry air concurrently through the bed. The falling liquid will form a thin film over the packing material while in contact with the low humidity ratio turbulent air stream. Heat and mass transfer principles govern the evaporation of the water and the humidification of the air stream. When operating at design conditions, the exit air stream humidity ratio should be as high as possible. The ideal state of the exit air/vapor stream from the diffusion tower is saturated, which is typically not achieved in actual practice. The humidified air stream is discharged to a counter-current direct contact condenser with packed bed for fresh water production. 
In order to design a DDD facility, it is necessary to size the diffusion tower and condenser. Once the size is determined, its performance requires determination of the temperature/humidity ratio distribution, energy consumption and fresh water production rate. Therefore mathematical models that simulate the diffusion tower [8] and the counter-current condenser are combined in order to evaluate the DDD performance over a range of operating conditions.

In performing the analyses, the following assumptions have been made:

1) The process operates at steady-state conditions.

2) There are no energy losses to the environment from the heat and mass transfer apparatus.

3) Both the air and water vapor may be treated as perfect gases,

4) Changes in kinetic and potential energy are relatively small.

5) The pumping power for water is that which is necessary to overcome gravity (estimating the exact required pumping power would require significant details regarding the construction of the diffusion tower, heat transfer equipment, and the plumbing; these are beyond the scope of the current analysis).

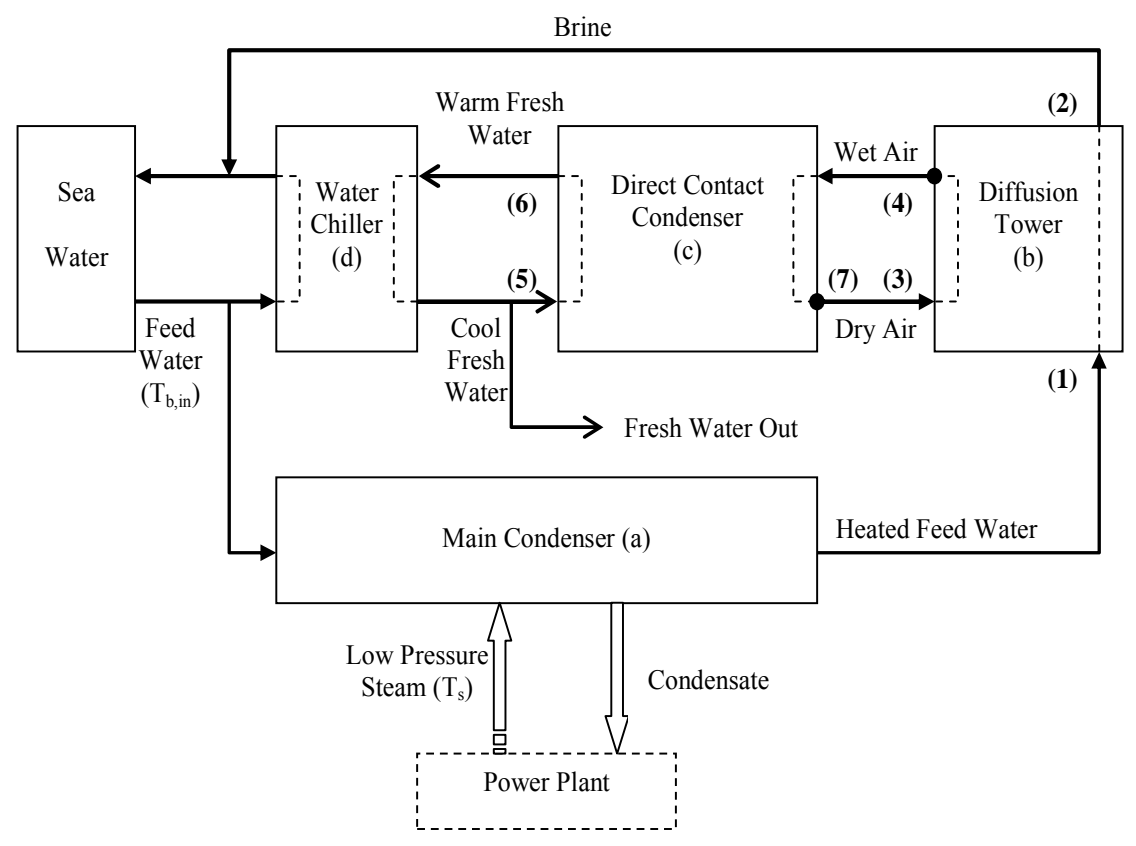

Figure 26 Flow diagram for the DDD process.

A simple flow diagram of the DDD process is shown in Fig. 26. The fresh water production rate is calculated as,

$$
m_{f w}=G A\left(\omega_{\text {in }}-\omega_{\text {out }}\right),
$$

where subscripts $f w$, in, and out respectively refer to the fresh water, and condenser inlet and outlet. Here it is assumed that $\omega_{i n}$ is the inlet humidity to the condenser and is identical to the exit humidity of the diffusion tower.

An empirical relation for pressure drop provided by the manufacturer of the packing material, which has been validated with experiments, is used to compute the pressure drop for the gas/vapor passing through the diffusion tower and condenser, 


$$
\frac{\Delta P_{G}}{z}=\frac{G^{2}}{\rho_{G}}\left[0.0354+5.05 \times 10^{-5}\left(\frac{L}{\rho_{L}}\right)^{2}+7.0 \times 10^{-8}\left(\frac{L}{\rho_{L}}\right)^{4} \frac{G^{4}}{\rho_{G}^{2}}\right] .
$$

Here $\Delta P_{G}(\mathrm{kPa})$ is the air/vapor pressure drop, $\mathrm{z}(\mathrm{m})$ is the height of packed bed, $\mathrm{G}$ $\left(\mathrm{kg} / \mathrm{m}^{2}-\mathrm{s}\right)$ is the air/vapor mixture mass flux, $\mathrm{L}\left(\mathrm{kg} / \mathrm{m}^{2}-\mathrm{s}\right)$ is the liquid mass flux, $\rho_{G}$ $\left(\mathrm{kg} / \mathrm{m}^{3}\right)$ is the air/vapor mixture density and $\rho_{L}\left(\mathrm{~kg} / \mathrm{m}^{3}\right)$ is the liquid density.

It is noted that estimating the exact required pumping power would require significant details regarding the construction of the diffusion tower condenser, heat transfer equipment, and the plumbing. However, the majority of pumping power is consumed pumping the fluids through the diffusion tower and the direct contact condenser. Therefore, the pumping power for air/vapor through the diffusion tower and direct contact condenser is calculated as,

$$
E_{G}=V_{G} \Delta P_{G}=\frac{m_{G}}{\rho_{G}} \Delta P_{G}=\frac{G A}{\rho_{G}} \Delta P_{G} .
$$

The pumping power for water is that which is necessary to overcome gravity in raising water to the top of the diffusion tower and condenser is,

$$
E_{L}=\frac{m_{L}}{\rho_{L}} \Delta P_{L}=m_{L} g H .
$$

The total pumping energy consumption rate for the DDD process includes the pumping power consumed by the diffusion tower and condenser for both the water side and air/vapor side as,

$$
E_{\text {total }}=E_{L}+E_{G} \text {. }
$$

So the energy consumption rate per unit of fresh water production is defined as,

$$
E_{f w}=\frac{E_{\text {total }}}{m_{f w}} .
$$

where $\mathrm{E}_{\text {total }}$ is the total pumping energy consumption rate.

The objective of the computational analysis is to explore the influence of the operating parameters on the DDD process performance. These parameters include the water/air/vapor temperatures, humidity ratio, water mass flux, air to feed water mass flow ratio, and tower size. The water mass flux and the air to feed water mass flow ratio through the tower are two primary controlling variables in the analysis.

For all computations considered in the diffusion tower, the water inlet temperature, gas inlet temperature, inlet humidity ratio, specific area and diameter of the packing material are fixed as $50^{\circ} \mathrm{C}, 26^{\circ} \mathrm{C}, 0.023,267 \mathrm{~m}^{2} / \mathrm{m}^{3}$ and $0.018 \mathrm{~m}$. The inlet feed water mass flux is varied from $0.5 \mathrm{~kg} / \mathrm{m}^{2}-\mathrm{s}$ to $3 \mathrm{~kg} / \mathrm{m}^{2}-\mathrm{s}$, meanwhile the air to feed water mass flow ratio $\left(\mathrm{m}_{\mathrm{a}} / \mathrm{m}_{L 1}\right)$ is varied from 0.5 to 1.5 for every fixed inlet feed water mass flux. All the cases analyzed in this report are below the flooding curve of the packing material. The reason that the inlet feed water temperature is fixed at $50^{\circ} \mathrm{C}$ is that this is typically the highest water temperature that can be expected to exit the main condenser of a thermoelectric power plant.

\section{Diffusion Tower Size}

Figure 27 shows the required diffusion tower height for different inlet water mass flux and varying air to feed water mass flow ratio. The tower height is computed such that the maximum possible humidity ratio leaves the diffusion tower. For every 
fixed air to feed water mass flow ratio, the required diffusion tower height decreases with increasing inlet water mass flux and decreases with increasing air to feed water mass flow ratio.

Figure 27 shows that for a fixed inlet water temperature and the maximum possible exit humidity ratio, the required diffusion tower height is strongly influenced by both the inlet water mass flux and the air to feed water mass flow ratio. It is particularly noteworthy that the typically required diffusion tower height does not exceed 2 meters for an air to feed water mass flow ratio above unity. This is an important consideration in evaluating the cost of fabricating a desalination system. Due to the small size of the diffusion tower, it is feasible to manufacture the tower off site and deliver it to the plant site following fabrication and thus lower the overall cost.

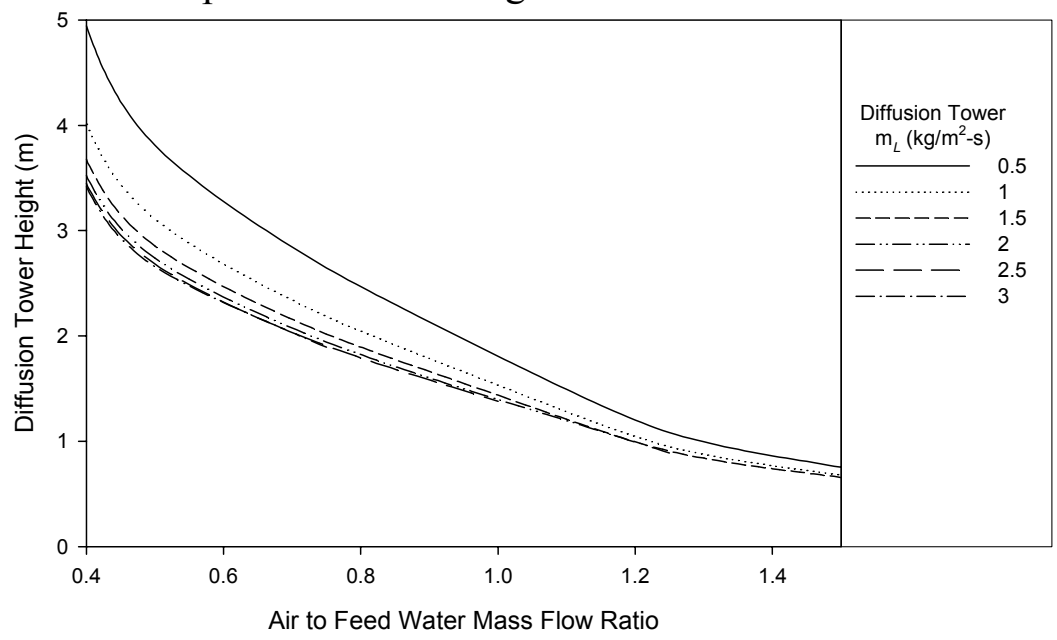

Figure 27 Required diffusion tower height with variations in air to feed water mass flow ratio

\section{Maximum Exit Humidity Ratio from Diffusion Tower}

Figure 28 shows the maximum possible exit humidity ratio for different inlet water mass flux and varying air to feed water mass flow ratios. For fixed inlet water and air temperatures, the maximum possible exit humidity ratio is strongly dependent on the air to feed water mass flow ratio and is largely independent of the inlet water mass flux. These results indicate that increasing the air to water mass flow ratio will not necessarily assist in increasing the fresh water production since the exit humidity ratio decreases with increasing air to water mass flow ratio. 


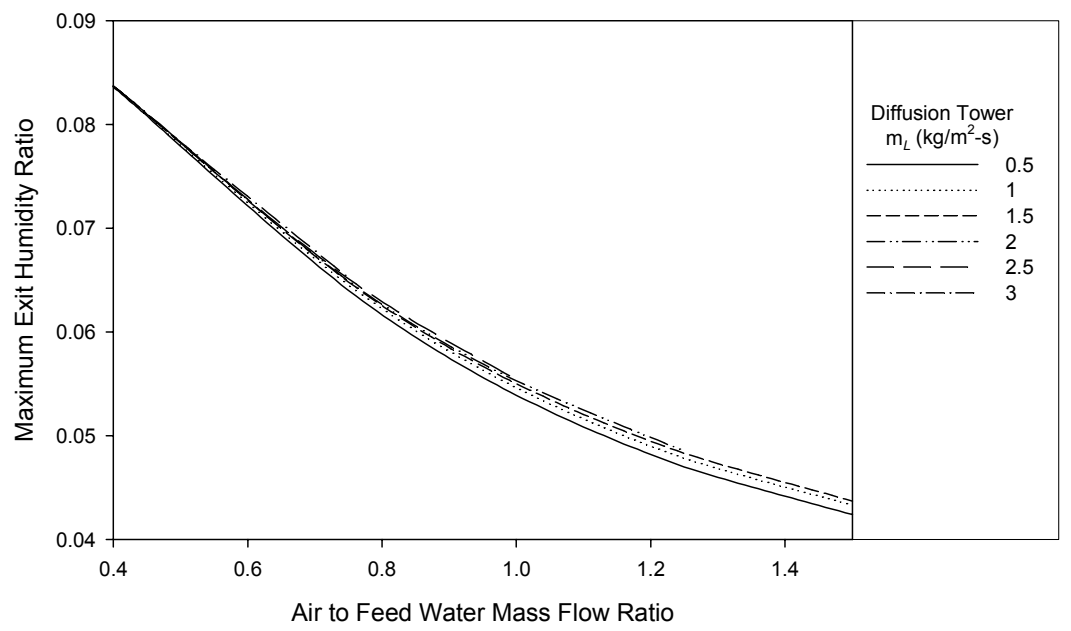

Figure 28 Maximum exit humidity ratio dependence on air to feed water mass flow ratio

\section{Exit Air Temperature from Diffusion Tower}

Figure 29 shows the exit air temperature for different inlet water mass flux and varying air to feed water mass flow ratios. The exit air temperature is sensitive to variations in both the inlet water mass flux and the air to feed water mass flow ratio.

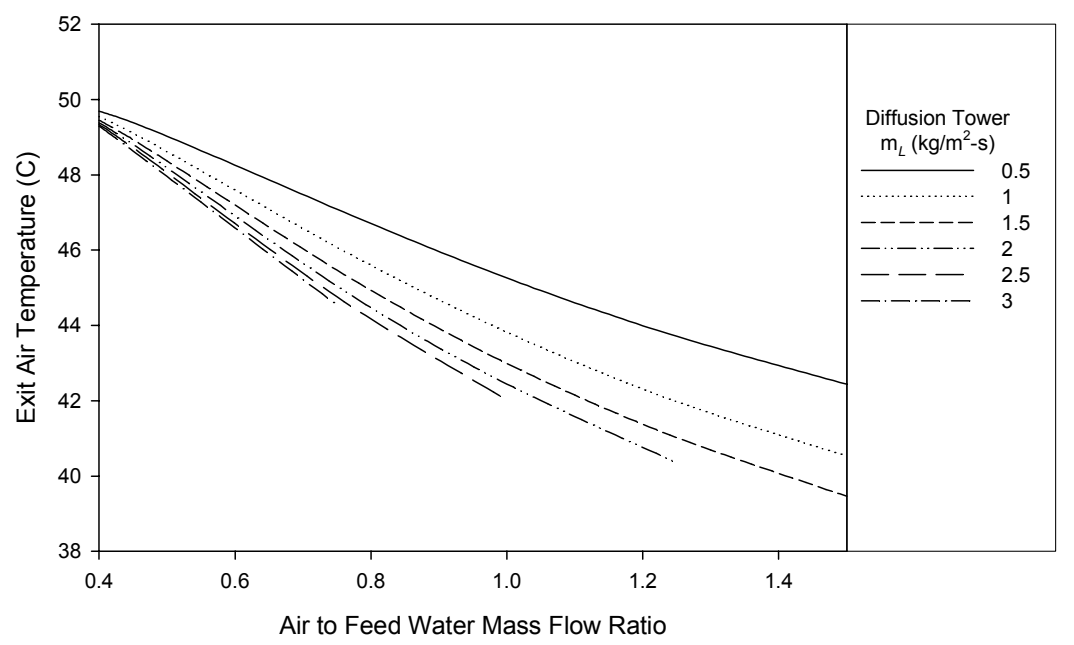

Figure 29 Exit air temperature variation with air to feed water mass flow ratio

\section{Diffusion Tower Pressure Drop}

Figure 30 shows the variation of the water side pressure drop across the diffusion tower with varying air to feed water mass flow ratio. The water pressure drop decreases with increasing inlet water mass flux and decreases rapidly with increasing air to feed water mass flow ratio. Figures 30 illustrates that the water side pressure drop follows the same trend as the diffusion tower height, which is to be expected since the water side pressure drop is due to the gravitational head which must be overcome to pump the water to the top of the diffusion tower. 


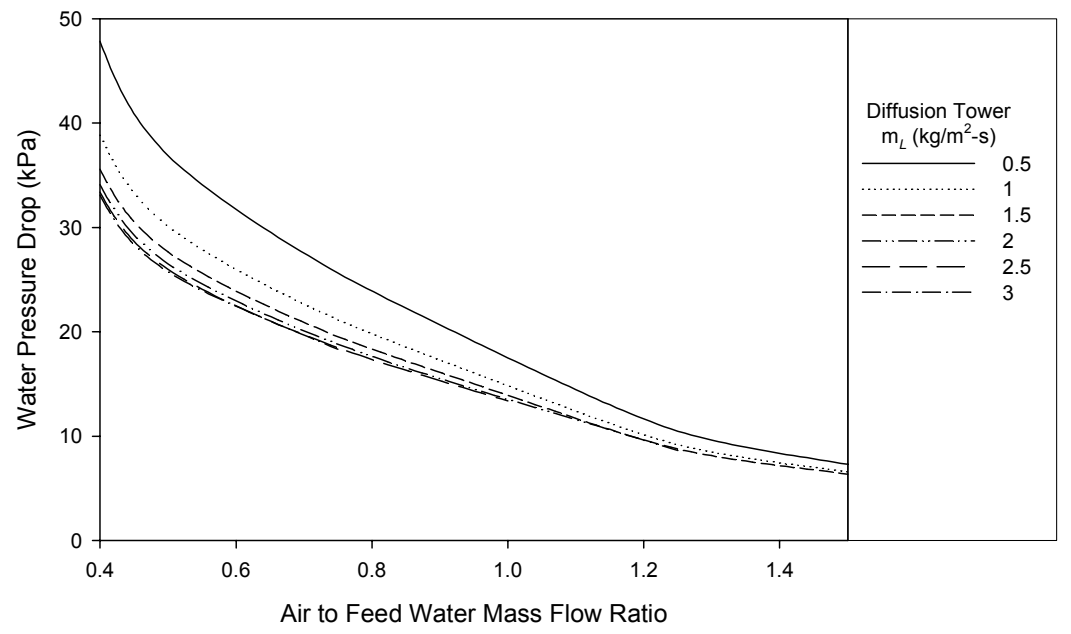

Figure 30 Water side pressure drop variation with air to feed water mass flow ratio

Figure 31 shows the variation of the air side pressure drop with the air to feed water mass flow ratio. For high water mass flux, the air side pressure drop increases rapidly when the air to feed water mass flow ratio exceeds 0.5 .

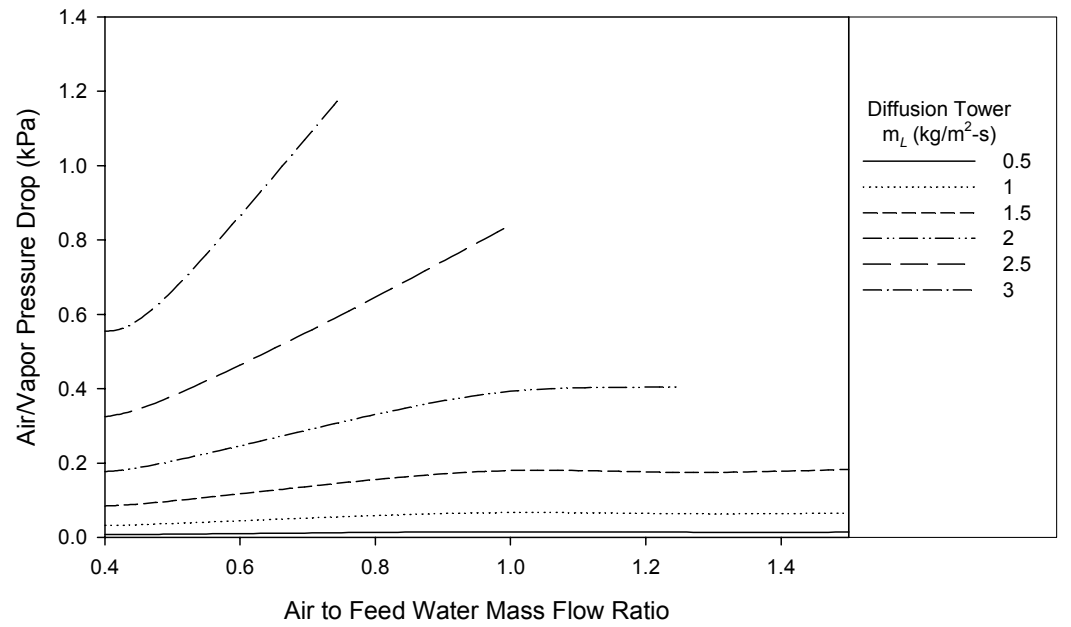

Figure 31 Air/vapor side pressure drop variation with air to feed water mass flow ratio

The main energy consumption for the DDD process is due to the pressure loss through the diffusion tower and condenser. Although the air side pressure drop is much lower than that for water, the volumetric flow rate of air is much larger than that of water. Thus, both the air and water pumping power contribute significantly to the total energy consumption.

\section{Temperature and Humidity Variation in the Direct Contact Condenser}

The flow conditions used to investigate temperature and humidity variations in the direct contact condenser are the exit flow conditions from the diffusion tower. A typical set of flow conditions are as follows, inlet air temperature of $42.5^{\circ} \mathrm{C}$, air mass flux of $2.0 \mathrm{~kg} / \mathrm{m}^{2}-\mathrm{s}$, and fresh water inlet temperature of $25^{\circ} \mathrm{C}$. When the fresh water to air mass flow ratio is 2 , the required condenser tower height is $0.784 \mathrm{~m}$, and Figure 32 
shows the water temperature, air temperature and humidity ratio distributions through the condenser. With a fresh water mass flux of $4.0 \mathrm{~kg} / \mathrm{m}^{2}-\mathrm{s}$, the exit humidity ratio is approximately 0.0235 , which corresponds to a fresh water production rate of about $0.064 \mathrm{~kg} / \mathrm{m}^{2}-\mathrm{s}$.

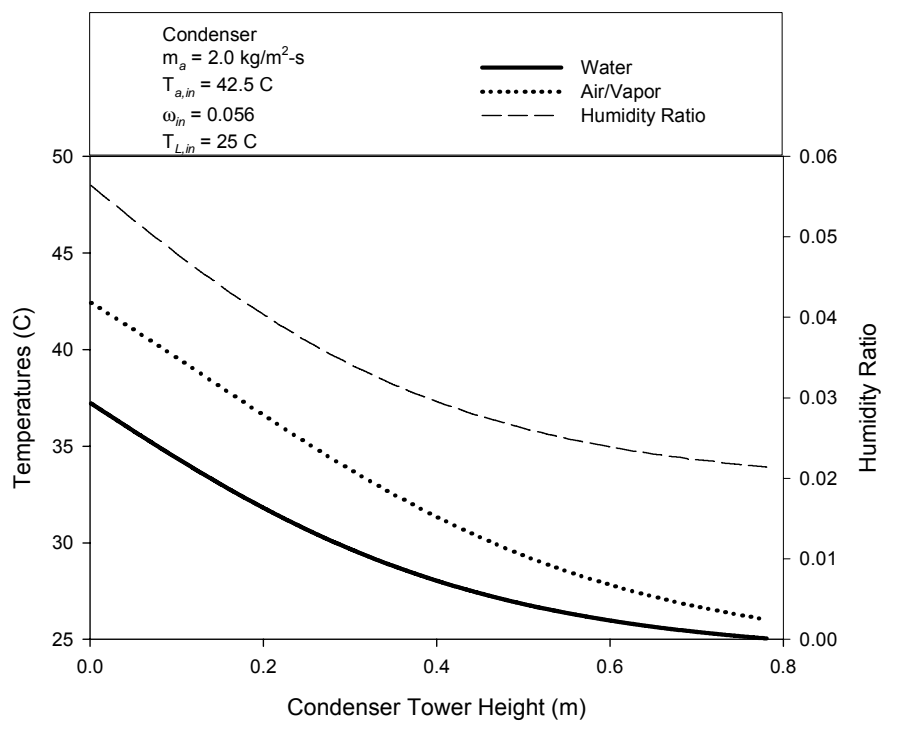

Figure 32 Temperature and humidity ratio profiles through the condenser

Figure 33 shows the condenser exit water temperature, minimum air temperature and exit humidity ratio variation with varying fresh water to air mass flow ratio with the same inlet air temperature and mass flux. Although not shown, all the values decrease with increasing inlet water mass flux. However, the results in Figure 33 show that there is no further decreases in exit humidity ratio when the fresh water to air mass flow ratio exceeds 2 . Thus the optimum fresh water to air mass flow ratio that yields the maximum fresh water production is 2 .

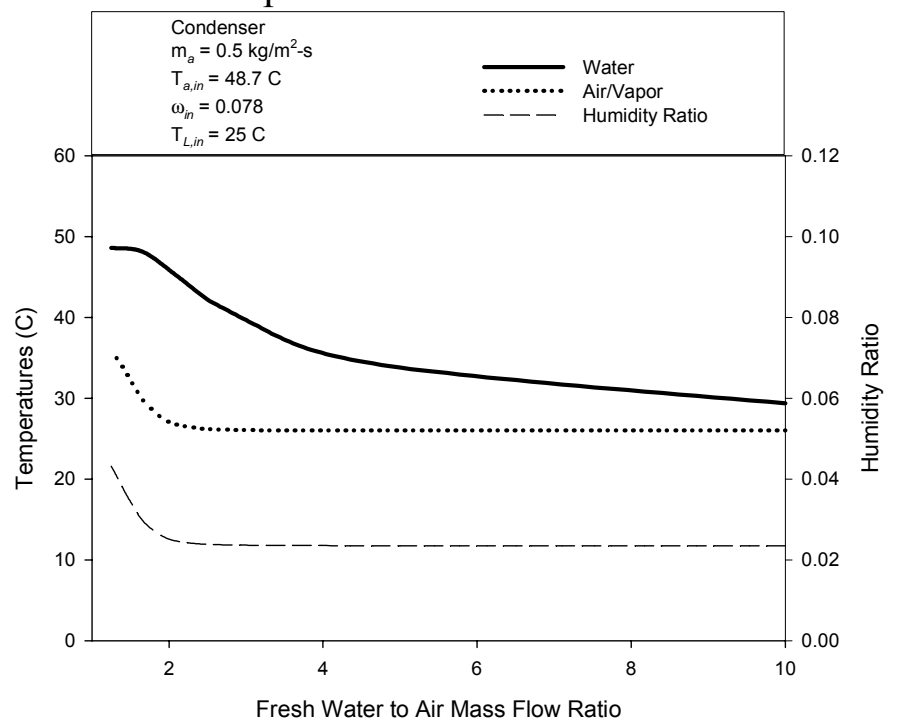

Figure 33 Condenser temperature and humidity ratio variation with fresh water to air mass flow ratio 


\section{Direct Contact Condenser Height}

Figure 34 shows the required condenser height for different air mass flux with a constant fresh water to air mass flow ratio of 2 in the condenser. The tower height is computed such that the minimum humidity ratio leaves the condenser. For a fixed feed water mass flux at the inlet of the diffusion tower, the required condenser height decreases with increasing air mass flux, and it also decreases with decreasing the feed water mass flux with the same air mass flux. Figures 34 indicates that the condenser height follows the same trend as the diffusion tower exit air temperature, which is to be expected since the required condenser height strongly depends on the air inlet humidity ratio.

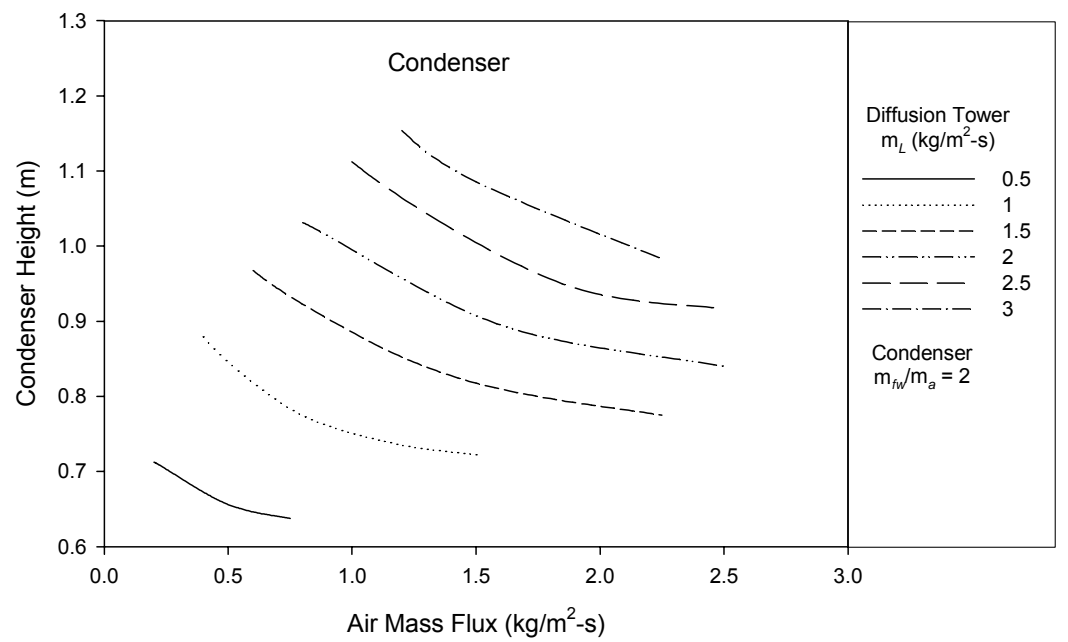

Figure 34 Required direct contact condenser height with variations in air mass flux

\section{Fresh Water Exit Temperature from Direct Contact Condenser}

Because the sink temperature is $25^{\circ} \mathrm{C}$, the minimum condenser exit air temperature is taken as $26^{\circ} \mathrm{C}$. Figure 35 shows the condenser fresh water exit temperature for different inlet feed water mass flux in the diffusion tower and varying air mass flux. The fresh water exit temperature is sensitive to variations in both the feed water inlet mass flux and air mass flux.

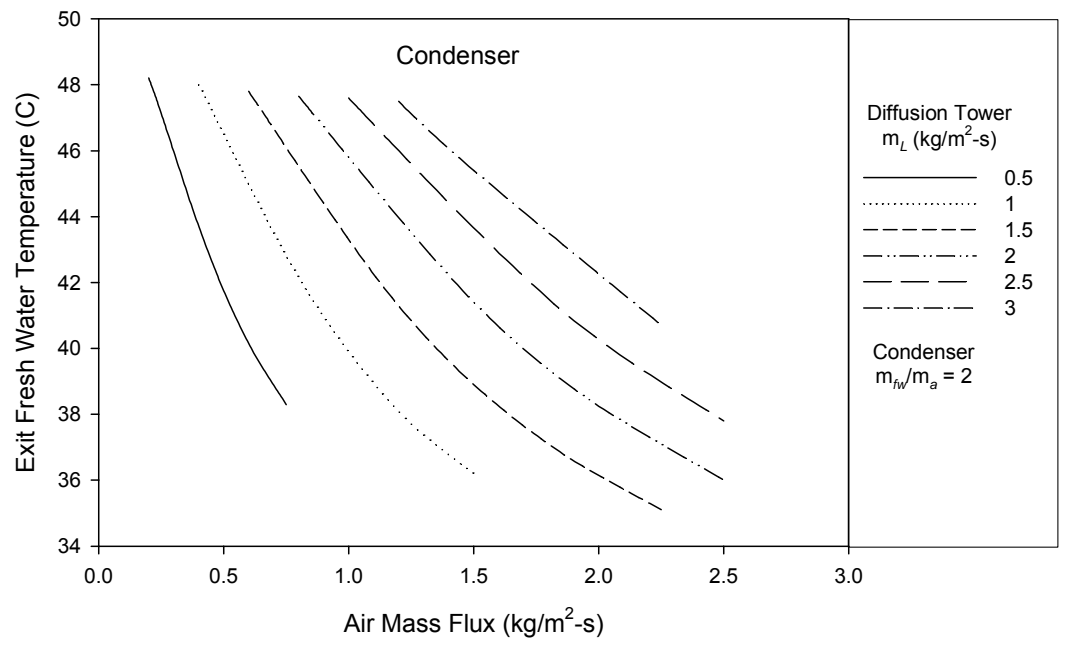

Figure 35 Condenser fresh water exit temperature variation with air mass flux 


\section{Fresh Water Production Efficiency}

Figure 36 shows the fresh water production efficiency of the system with varying air mass flux. It is clear that there exists a maximum fresh water production efficiency, and that maximum occurs with an air to feed water mass flow ratio close to unity. It is also interesting to note that the maximum fresh water production efficiency tends to approach a value of 0.032 for all operating conditions considered. The maximum production efficiency is largely controlled by the ratio of the diffusion tower inlet water temperature to the sink temperature. In this case, it is 1.12 .

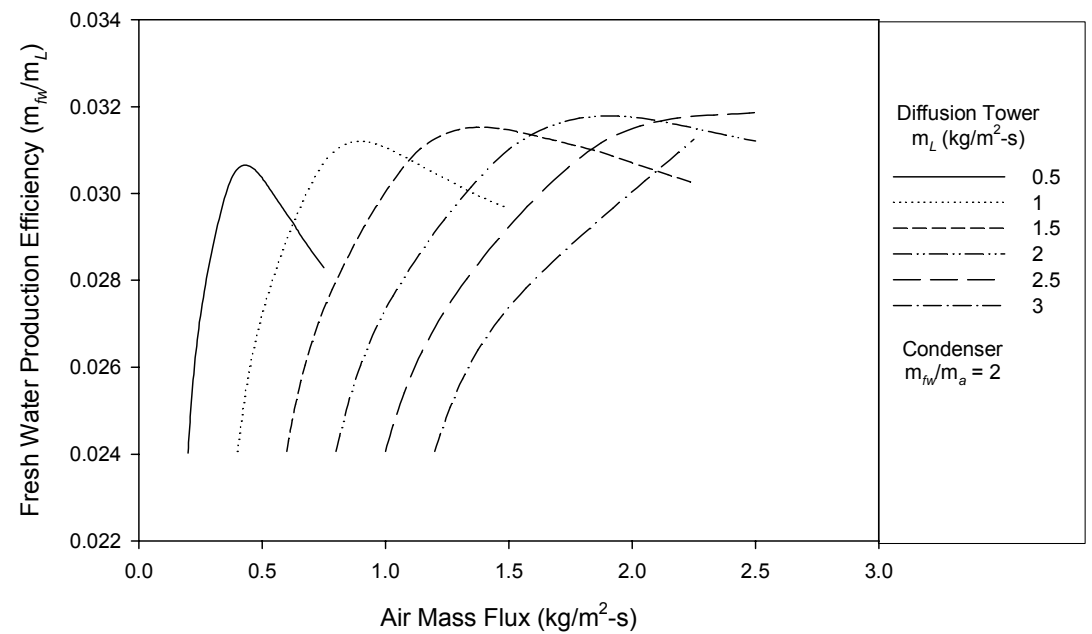

Figure 36 Variation of the fresh water production efficiency with air mass flux

\section{Energy Consumption}

Perhaps the most important consideration in this analysis is the rate of energy consumption due to pumping because the operating cost of the DDD process is largely dependent on the cost of electricity to drive the pumps and blowers. Figure 37 shows the energy consumption rate for the diffusion tower for different inlet feed water mass flux and varying air to feed water mass flow ratios. The energy consumption increases with increasing inlet water mass flux for a fixed air to feed water mass flow ratio. It is particularly interesting that a minimum energy consumption occurs when the air to feed water mass flow ratio is approximately 0.5 . As the inlet water mass flux decreases, the energy consumption becomes relatively insensitive to variations in the air to feed water mass flow ratio. 


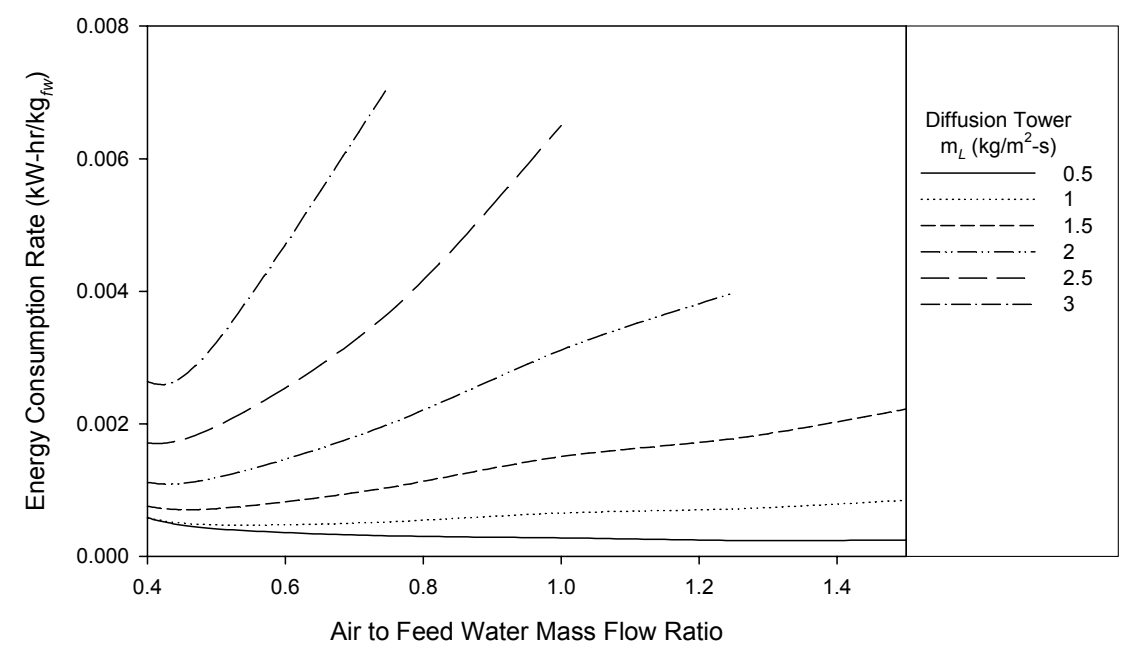

Figure 37 Variation of the energy consumption with air to feed water mass flow ratio in diffusion tower

Figure 38 shows the energy consumption rate for the direct contact condenser with fixed fresh water to air mass flow ratio of 2 . It shows clearly that there exists a critical point for every feed water mass flux. When the air mass flux is higher than the critical condition, the energy consumption rate in the condenser will increase very rapidly with increasing air mass flux. An interesting result is that the energy consumption rate in the condenser will remain low for all feed water inlet mass flux considered provided the air mass flux remains below $1.5 \mathrm{~kg} / \mathrm{m}^{2}-\mathrm{s}$.

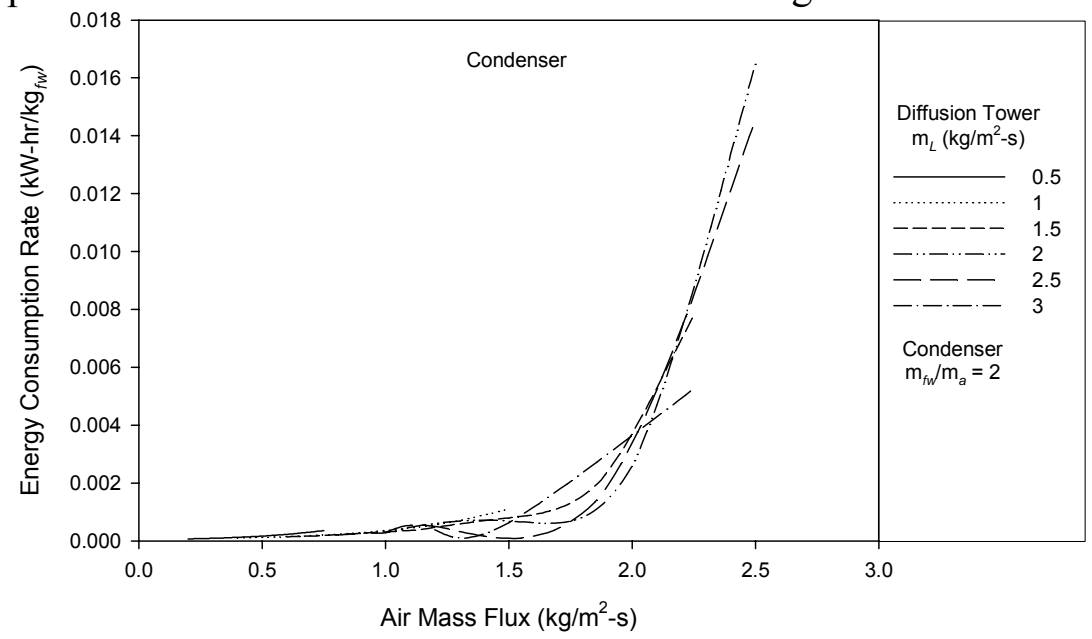

Figure 38 Variation of the energy consumption with air mass flux in condenser

Figure 39 shows the variation of the total energy consumption rate for the system with air mass flux. There exists a minimum energy consumption rate for every feed water mass flux, and it increases with increasing feed water inlet mass flux. However, when the air mass flux is less than $1.5 \mathrm{~kg} / \mathrm{m}^{2}-\mathrm{s}$ the total energy consumption rate for the system is below $0.0039 \mathrm{~kW}-\mathrm{hr} / \mathrm{kg}_{f w}$ for all feed water inlet mass flux. The minimum shown in this figure, $0.00043 \mathrm{~kW}-\mathrm{hr} / \mathrm{kg}_{f w}$, occurs when the air mass flux is $0.375 \mathrm{~kg} / \mathrm{m}^{2}-\mathrm{s}$, air to feed water mass flow ratio is 0.75 , and fresh water to air mass flow ratio is 2 . At these conditions a fresh water production rate of $0.015 \mathrm{~kg} / \mathrm{m}^{2}-\mathrm{s}$ is 
realized. This minimum is about an order of magnitude less energy consumption than reverse osmosis. However, operating at these low mass fluxes requires a sizable land footprint, and is not likely to be practical for a large production rate facility.

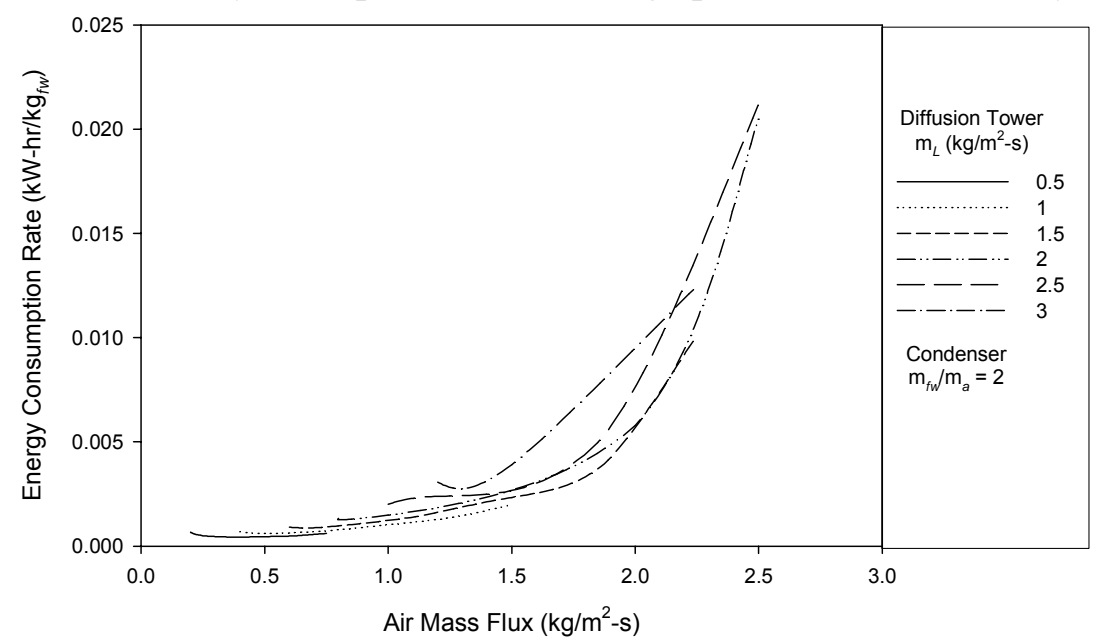

Figure 39 Variation of the total energy consumption rate with air mass flux

Finally, the optimum operating conditions of the system should satisfy competing requirements: high fresh water production efficiency and low energy consumption rate. Based on data presented in Fig. 36 and Fig. 39, a reasonable optimum operating condition has an air mass flux of $1.5 \mathrm{~kg} / \mathrm{m}^{2}$-s, air to feed water mass flow ratio of 1 , and fresh water to air mass flow ratio of 2 . These conditions can yield a fresh water production efficiency of 0.0314 and energy consumption rate of 0.0023 $\mathrm{kW}-\mathrm{hr} / \mathrm{kg}_{\text {fw }}$.

\section{Economic Analysis}

As an example, consider a $100 \mathrm{MW}$ power plant where the thermal efficiency is $40 \%$. The total input energy is then $250 \mathrm{MW}$ and the waste heat is $150 \mathrm{MW}$. If the power plant operates with $9.7 \mathrm{cmHg}$ pressure in the main condenser, there would be approximately $150 \mathrm{MW}$ of energy at $50^{\circ} \mathrm{C}$ available from low pressure condensing steam. If retrofitted with a diffusion driven desalination (DDD) plant, there is a potential to produce as much as 1.03 million gallons/day of fresh water assuming the feed water temperature enters the diffusion tower at $50^{\circ} \mathrm{C}$. The energy consumption from the feed water, air, and cold fresh water pumps in the DDD process is about $0.0023 \mathrm{~kW}$-hr per kilogram of fresh water. This requires a land footprint of approximately 0.47 acres. The total electrical power requirement is $380 \mathrm{~kW}$ in total. The thermal energy consumed in the DDD process is waste heat, and is not of concern for the economic analysis.

The fresh water production cost strongly depends on the process capacity, site characteristics and design features. The system capacity defines the required sizes for various process equipment, pumping units, and required heat exchanger surface area. Site characteristics have a strong influence on the type of pretreatment and posttreatment equipment, and consumption rate of chemicals. Process design features affect consumption of electric power and chemicals (Wangnick et al [9] and Hisham et al 
[10]). Production cost is divided into direct and indirect capital costs and annual operating costs. Direct capital costs include the purchase cost of major equipment, auxiliary equipment, land and construction. Indirect capital costs include labor, maintenance, and amortization. They are usually expressed as percentages of the total direct capital cost.

Land - The cost of land may vary considerably, from zero to a sum that depends on site characteristics. Government-owned plants normally have zero charges. Plants constructed under build-own-operate-transfer (BOOT) contracts with governments or municipalities can have near zero or greatly reduced charges. The price of the land near the coast of Florida varies significantly from $1 \mathrm{k}-1,000 \mathrm{k} \$$ /acre.

Building construction - Construction costs vary from $\$ 100-1,000 / \mathrm{m}^{2}$. This cost is sitespecific and depends on the building type. Buildings could include a control room, laboratory, offices and workshops.

Process equipment - This category includes processing equipment, as well as instrumentation and controls, pipes and valves, electric wiring, pumps, process cleaning systems, and pre- and post-treatment equipment. These are some of the most expensive items, and their cost depends on the type of process and capacity. Equipment costs may be less than $\$ 1,000$ (e.g., a laboratory-scale RO unit used to treat lowsalinity water). On the other hand, the equipment cost for a $100,000 \mathrm{~m}^{3} /$ day RO system could approach $\$ 50$ million. MSF and MEE equipment are generally more expensive than that of RO systems - current estimates for a plant capacity of $27,000 \mathrm{~m}^{3} /$ day are $\$ 40$ million. Because the increase in salinity concentration of the DDD discharge water is small, there is no need for post-treatment. Also the feed water flow is supplied by the main pumps used in the power plant's cooling system. So the capital cost of the pretreatment, post-treatment and main feed water pumps will not be included in this analysis. The other process equipment costs among different manufacturers range from \$200k-\$1,700k.

Auxiliary equipment - The following are considered auxiliary equipment: open intakes or wells, transmission piping, storage tanks, generators and transformers, pumps, pipes and valves. The current analysis will not include these items.

As an example, consider the DDD system coupled with a 100 MW power plant. The capital cost calculations are based on the following assumptions:

1) interest rate $i=5 \%$

2) plant life $n=30 \mathrm{yr}$

3) amortization factor $a i=\frac{i(1+i)^{n}}{(1+i)^{n}-1}=0.0651 / \mathrm{yr}$

4) plant availability $f=0.9$

5) chemical costs are not considered

6) electricity is considered as operating cost 
7) the specific cost of operating labor is typically $\$ 0.1 / \mathrm{m}^{3}$ for the thermal processes and $\$ 0.05 / \mathrm{m}^{3}$ for RO. Because the DDD is a low temperature and pressure process, the labor cost is assumed lower which typically ranges from $\gamma=0.025-0.05 \$ / \mathrm{m}^{3}$.

Table 1 Summary of direct costs

\begin{tabular}{|l|c|c|c|}
\hline \multicolumn{1}{|c|}{ Name } & Land & Building construction & Major equipment \\
\hline Cost (\$) & $470-470,000$ & $190,202-1,902,023$ & $200,000-1,700,000$ \\
\hline Total Direct Cost DC (\$) & $390,672-4,072,023$ & \\
\hline
\end{tabular}

Table 2 Details of cost calculations

\begin{tabular}{|l|l|c|}
\hline \multicolumn{1}{|c|}{ Name } & \multicolumn{1}{|c|}{ Formula } & Result \\
\hline $\begin{array}{l}\text { Annual fixed charges Afixed } \\
(\$)\end{array}$ & $A C_{\text {fixed }}=a i \cdot D C$ & $25,433-265,089$ \\
\hline Annual labor cost Alabor $(\$)$ & $A C_{\text {labor }}=\gamma \cdot f \cdot m_{f w} \cdot 365$ & $31,975-63,959$ \\
\hline Total annual cost Atotal $(\$)$ & $A C_{\text {total }}=A C_{\text {fixed }}+A C_{\text {labor }}$ & $57,408-329,048$ \\
\hline $\begin{array}{l}\text { Unit product cost in terms of } \\
\text { production Aunit, } \mathrm{p}(\$ / \mathrm{m} 3)\end{array}$ & $A C_{\text {unit }, p}=A C_{\text {total }} \cdot\left(f \cdot m_{f w} \cdot 365\right)^{-1}$ & $0.045-0.257$ \\
\hline
\end{tabular}

The computation reveals that the production cost, not including electricity costs, ranges from $0.17-0.97 \$ / 10^{3}$ gal. For illustrative purposes, we take the production cost to be $0.6 \$ 110^{3}$ gal. Here two cases are considered:

First, the DDD utility is economically independent from the power plant, which means although the DDD process the waste heat from the power plant, it needs to pay the electricity cost in additional to basic production cost. So the fresh water profit in this situation can be calculated as,

$$
\Pi_{f w}=Q_{f w}-A C_{u n i t, p}-E_{f w} Q_{\text {elec }},
$$

where $\Pi_{\mathrm{fw}}\left(\$ / 10^{3}\right.$ gal) is the net fresh water profit, $\mathrm{Q}_{\mathrm{fw}}\left(\$ / 10^{3}\right.$ gal) is the retail price of fresh water, and $\mathrm{Q}_{\text {elec }}(\$ / \mathrm{kW}-\mathrm{hr})$ is the retail price of electricity. Here $\mathrm{AC}_{\mathrm{unit}, \mathrm{p}}$ is $0.6 \$ / 10^{3}$ gal. Figure 40 shows the net fresh water profit variation with the electricity retail price for different fresh water retail price. The fresh water profit decreases with increasing electricity cost, and increases with increasing the fresh water price. As seen in Fig. 40 , profit is only realized when the fresh water retail price is greater than $1 \$ / 10^{3}$ gal. 


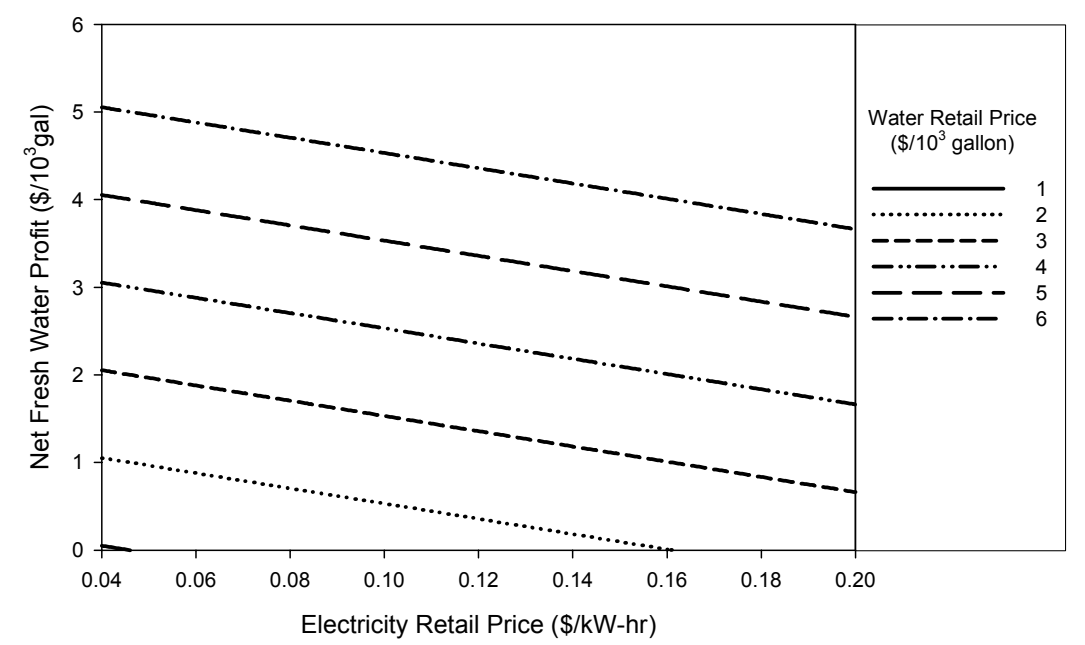

Figure 40 Net fresh water profit with electricity retail price for different fresh water retail price.

Second, the DDD utility is combined with a power plant, which means this combined system has a fresh water production capacity of 1.03 million gallons/day besides the electricity production. But the total electrical power requirement of the DDD process will be subtracted from the total electricity production of the power plant as the operating cost. The daily profit of the combined system is calculated from,

$$
\Pi_{\text {total }}=m_{f w} \Pi_{f w}+\left(E_{\text {elec }}-E_{f w}\right) \Pi_{\text {elec }},
$$

where $\Pi_{\text {total }}\left(\$ /\right.$ day) is the daily profit of the combined system, $E_{\text {elec }}(\mathrm{MW})$ is the electricity production capacity of the power plant before combining with the DDD system, and $\Pi_{\text {elec }}(\$ / \mathrm{kWhr})$ is the electricity profit. The percent increase in profit of the combined power plant is calculated as,

$$
\beta=\frac{\Pi_{\text {total }}-E_{\text {elec }} \Pi_{\text {elec }}}{E_{\text {elec }} \Pi_{\text {elec }}} .
$$

The percent increase in profit for the power plant combined with the DDD process for different fresh water profits is shown in Fig. 41. This figure shows that the profit increase decreases with increasing electricity profit. It is also important to note that the profit increase of the combined power and DDD plant tends to be zero when the electricity profit is higher than $\$ 0.2 / \mathrm{kW}-\mathrm{hr}$, which is not likely in the near future. The profit increase grows almost proportionally with the fresh water price that can be commanded on the open market. It clearly shows that the combined power and DDD plants yield a profit increase when the fresh water is sold at a rate higher than $1 \$ / 10^{3}$ gal. This is strongly competitive in most regions of the world. 


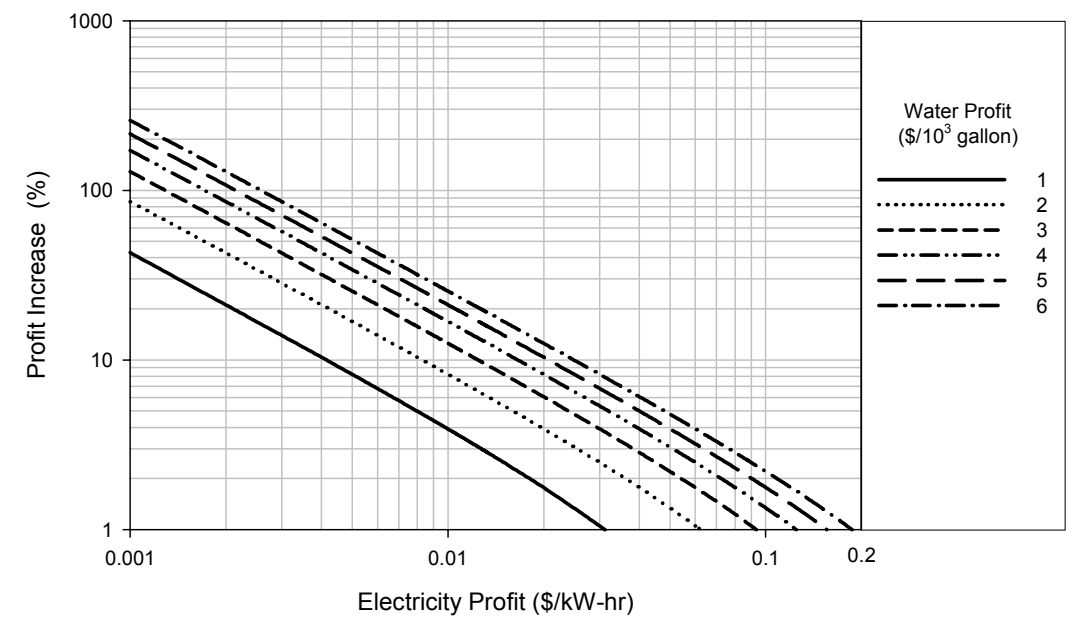

Figure 41 Percent increase in profit with electricity profit for different fresh water profit

A recent survey [11] by the NUS Consulting Group studying water rates across the world found that rates increased from 2001 to 2002 in 12 of 14 countries surveyed. The result is shown in Figure 42. The survey was based on prices as of July 1, 2002 for an organization with an annual usage of 10,000 cubic meters. Where there was more than a single supplier, an unweighted average of available prices was used. The percentage change for each country was calculated using the local currency in order to eliminate currency exchange distortion. Water rates in the United States were among the lowest in the countries surveyed and were one half to one third the rates charged in most European countries. And it is also important to recognize that most countries investigated show a positive increase in water price, which reflects the increased demand for fresh water.

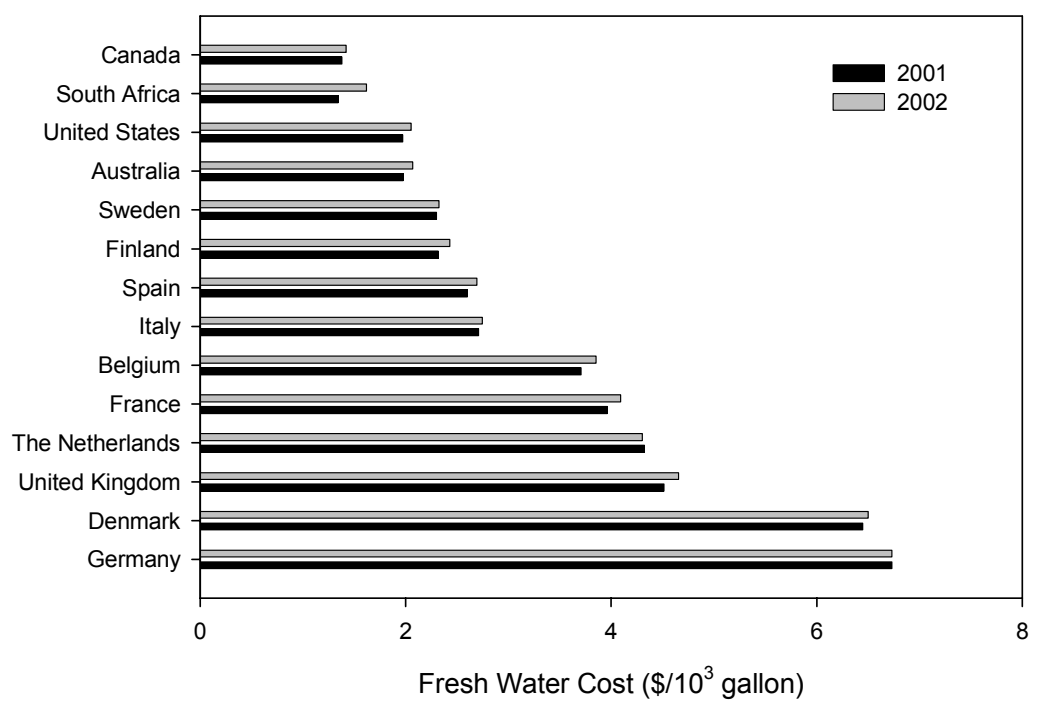

Figure 42 Water price in different countries for year $2001 \& 2002$

Finally, an investigation of the electricity market in the United States is conclueded to explore the economic advantage of the DDD process within different geographical markets. The average revenue in the United States for electricity generation [12] is $\$ 0.0693 / \mathrm{kW}-\mathrm{hr}$. The average cost to produce electricity in 2001 [13] is 
$\$ 0.06 / \mathrm{kWhr}$ for gas and oil and $\$ 0.02 / \mathrm{kW}-\mathrm{hr}$ for coal. Since electricity profits are low, the DDD process provides an opportunity for electric utilities to realize additional revenues through fresh water production.

The above considerations suggest that there exists economic benefit for the DDD process to electric utilities. It is anticipated that this benefit will grow as the world fresh water supply continues to diminish.

\section{Numerical Modeling of Falling Droplet Direct Contact Condenser}

In addition to the packed bed direct contact condenser, a falling droplet direct contact condenser was also fabricated and tested. This section describes a mathematical model that has been developed to predict the thermal performance of the falling droplet counter-current flow direct contact condenser. A one-dimensional, quasi-steady mathematical model for a falling droplet in the direct contact condenser is developed. This model is treated as a boundary value problem with a system of ODEs to track down the dynamic changes of the falling droplets and the rate of water vapor and energy transfer due to condensation of the air-vapor mixture.

In this counter-current flow falling droplet type condenser, the cooling water at a low temperature $T_{d}$, enters at the top of the condenser and the hot air/vapor mixture corresponding to a temperature $T_{a}$ enters at the bottom of the condenser. A simple flow diagram is shown below in Fig. 43.

\section{Cold Water spray, $\mathbf{T}_{\mathrm{d} 0}$}

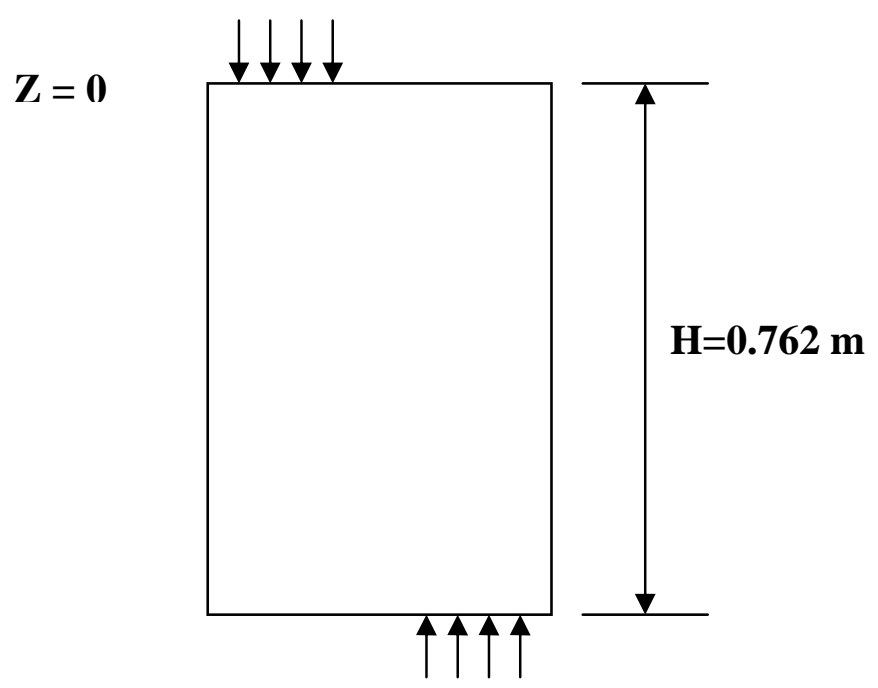

Hot Air-vapor mixture, $\mathbf{T}_{\mathbf{a} 0}$

Figure 43 Simple Flow Diagram For Falling Droplet Direct Contact Condenser.

The following physical assumptions are made for the model development:

a. Droplets are of spherical shape and a uniform droplet distribution is assumed.

b. No droplet interactions with one another in the axial or transverse direction are considered, i.e., no droplet agglomeration or break up is accounted for. 
c. An average droplet temperature is considered for the quasi-steady state calculations on the droplet side, but later modified to include the non-uniform temperature within the droplet.

d. Empirical correlations are used for the heat and mass transfer coefficient calculations and depend on the droplet Reynolds number.

The vertical downward z-direction is taken as the positive direction with the origin at the initial droplet location at the top of the condenser.

Conservation equations for mass, momentum, and energy of a moving droplet are summarized. Considering a single droplet in the control volume, the rate of change of droplet radius, $\mathrm{R}_{\mathrm{d}}$ is:

$$
\frac{d R_{d}}{d z}=\frac{\gamma_{d}\left(\rho_{v}\left(T_{a}\right)-\rho_{s a t}\left(T_{d}\right)\right)}{\rho_{w} v_{d}}
$$

where $\gamma_{d}$ is the mass transfer coefficient $(\mathrm{m} / \mathrm{s}), \rho_{w}$ is the water droplet density $\left(\mathrm{kg} / \mathrm{m}^{3}\right)$, $\rho_{v}$ is the vapor density at temperature $T_{a}$ and $\rho_{\text {sat }}$ is the vapor density corresponding to temperature $T_{\text {sat }}$, and $R_{d}$ and $v_{d}$ are the radius and velocity of the droplet. The rate of change of momentum of the continuously accelerating droplet considers the aerodynamic drag force and the gravitational force, and is given by

$$
\frac{d v_{d}}{d z}=\frac{g}{v_{d}}-C_{d r a g} \frac{\rho_{a}\left(v_{d}-u_{a i r}\right)^{2}}{2 m_{d} v_{d}} \pi R_{d}^{2}-\frac{3}{R_{d}} v_{d} \frac{d R_{d}}{d z} .
$$

Here, $C_{d r a g}$ is the aerodynamic drag coefficient, $u_{a i r}$ is the velocity of air/vapor mixture, and $m_{d}$ is the droplet mass. The rate of change of droplet volume-average (bulk) temperature due to condensation of water vapor on the droplet surface is given as:

$$
\frac{d T_{d}}{d z}=\frac{3\left\{U\left(T_{a}-T_{d}\right)+\gamma_{d}\left(\rho_{v}\left(T_{a}\right)-\rho_{s a t}\left(T_{d}\right)\right)\left(h_{f \mathrm{~g}}-C_{p w} T_{d}\right)\right\}}{\rho_{w} C_{p w} v_{d} R_{d}} .
$$

where, $T_{d}$ and $T_{a}$ are the temperatures of droplet and air/vapor mixture respectively, $U$ is the heat transfer coefficient, $h_{f g}$ is the latent heat of vaporization at $T_{a}$, and $C_{p w}$ is the specific heat of the water droplet. Similarly, conservation of energy and mass on the airvapor mixture yields expressions for the change in the air temperature and vapor density, respectively,

$$
\frac{d T_{a}}{d z}=-\frac{4 \pi R_{d}^{2} N_{d}\left\{U\left(T_{a}-T_{d}\right)-h_{l} \gamma_{d}\left(\rho_{v}\left(T_{a}\right)-\rho_{s a t}\left(T_{d}\right)\right)\right\}}{\rho_{\text {mix }} C_{p m i x} u_{a}} .
$$

and

$$
\frac{d \rho_{v}}{d z}=\frac{4 \pi R_{d}^{2} N_{d} \gamma_{d}\left(\rho_{v}\left(T_{a}\right)-\rho_{s u}\left(T_{d}\right)\right) .}{u_{a}} .
$$

Here, the saturated vapor density and relative humidity are related as: $\rho_{s a t}\left(T_{a}\right) \Phi=\rho_{s a t}\left(T_{d}\right)$. In the equations (25-26), $h_{l}$ is the specific liquid enthalpy at $T_{a}, N_{d}$ is the specific droplet number (Number of droplets per unit volume) at any axial location. $N_{d}$ is related to the mass flux of water, $L$, droplet radius, $R_{d}(z)$, and droplet velocity as:

$$
N_{d}=\frac{L}{(4 / 3) \pi R_{d}^{3} \rho_{w} v_{d}} .
$$

The density and specific heat of the air/vapor mixture are computed as $\rho_{\text {mix }}=\rho_{a}+\rho_{v}$ and ${ }_{C p_{\text {mix }}}=\frac{\rho_{a}}{\rho_{a}+\rho_{v}} C p_{a}+\frac{\rho_{v}}{\rho_{a}+\rho_{v}} C p_{v}$. In this analysis, $N_{d}^{*} v_{d}$, is the number flux of 
droplets through the cross section, and is constant. The heat transfer coefficient, $U$ is estimated from $N u=2 R_{d} U / k_{a}$. The empirical relation for Nusselt number is given as

$$
N u=2+0.5 \mathrm{Re}^{0.5}
$$

and, the droplet Reynolds number $R e$ is calculated as,

$$
\operatorname{Re}=\frac{2 \rho_{a} R_{d}\left|v_{d}-u_{a}\right|}{\mu_{a}},
$$

where, $\mu_{a}$ is the dynamic viscosity of air. For the range of Reynolds number and Schmidt numbers, the mass transfer coefficient for the droplet $\gamma_{d}$ is estimated from the correlation,

$$
\gamma_{d}=\frac{D}{2 R_{d}}\left\{1+\left(1+\frac{1}{\operatorname{Re} S c}\right)^{1 / 3} \operatorname{Re}^{0.41} S c^{1 / 3}\right\},
$$

where $S c=\frac{v}{D}$ is the Schmidt number and $D$ is the diffusion coefficient of water vapor. The drag coefficient $C_{d r a g}$, is estimated using the empirical relation,

$$
C_{\text {drag }}=\frac{24}{\operatorname{Re}}\left(1+\frac{1}{6} \operatorname{Re}^{2 / 3}\right) \text {. }
$$

Note that the properties $D, \mu_{a}$, and $k_{a}$ are temperature dependent, which is accounted for in the computations.

\section{Boundary conditions}

At $\mathrm{z}=0$, the initial droplet size, velocity, and temperature are specified as $R_{d 0}, v_{d 0}$, and $T_{d 0}$ and at $\mathrm{z}=\mathrm{H}$. The initial air-vapor mixture temperature $T_{a 0}$, and water vapor density $\rho_{v}$ are known.

$$
\left.R_{d}\right|_{z=0}=R_{d 0} ;\left.v_{d}\right|_{z=0}=v_{d 0} ;\left.T_{d}\right|_{z=0}=T_{d 0} ;\left.\& T_{a}\right|_{z=H}=T_{a 0} ;\left.\rho_{v}\right|_{z=H}=\rho_{v 0} ;
$$

Note:- Initial and boundary values considered in this sample calculation(exp \# 18) are: $G=0.04 \mathrm{~kg} / \mathrm{m}^{2} \mathrm{sec} ; L=0.066 \mathrm{~kg} / \mathrm{m}^{2} \mathrm{sec} ; A=0.056934 \mathrm{~m}^{2} ; R_{d 0}=500 \mu \mathrm{m} ; v_{d 0}=0.65 \mathrm{~m} / \mathrm{s} ; T_{d 0}=26.1^{\circ} \mathrm{C} ;$ and $T_{a 0}=34.2^{0} \mathrm{C}$.

\section{Solution methodology}

The above set of nonlinear, coupled first order ODEs (22-26) is solved using a finitedifference shooting method. A forward difference scheme is used for equations (22-24) and a backward difference scheme is used for equations (25) \& (26), with a reasonable initial guesses for the unknowns. For example equation (22) in finite difference form is written as

$$
R_{d}(i+1)=R_{d}(i+1 / 2)+\left.\frac{d R_{d}}{d z}\right|_{i+1 / 2}\left(\frac{\Delta z}{2}\right)
$$

where,

$$
R_{d}(i+1 / 2)=0.5 *\left(R_{d}(i+1)+R_{d}(i)\right)
$$

and

$$
\left.\frac{d R_{d}}{d z}\right|_{i+1 / 2}=0.5 *\left(\left.\frac{d R_{d}}{d z}\right|_{i+1}+\left.\frac{d R_{d}}{d z}\right|_{i}\right)
$$

Similarly, equation (25) is written as

$$
T_{a}(i-1)=T_{a}(i-1 / 2)-\left.\frac{d T_{a}}{d z}\right|_{i-1 / 2}\left(\frac{\Delta z}{2}\right)
$$


with

$$
T_{a}(i-1 / 2)=0.5^{*}\left(T_{a}(i-1)+T_{a}(i)\right)
$$

and

$$
\left.\frac{d T_{a}}{d z}\right|_{i-1 / 2}=0.5 *\left(\left.\frac{d T_{a}}{d z}\right|_{i-1}+\left.\frac{d T_{a}}{d z}\right|_{i}\right)
$$

First, Eqs.(22-24) are evaluated from $z=0$ to $z=H$. Then, Eqs.(25-26) are swept backwards from $\mathrm{z}=\mathrm{H}$ to $\mathrm{z}=0$ using the updated values of the droplet variables. This completes one sweep on both the droplet and air/vapor side. Values of each of these variables at the current iteration are compared to their corresponding previous iteration values, and the total error is checked for a tolerance of $1.0 \mathrm{e}-12$.

The mass flow rate of air is constant with the density of air, $\rho_{a}$ taken as a constant at $1.16 \mathrm{~kg} / \mathrm{m}^{3}$ based on an average temperature of $(40+25) / 2=32.5^{\circ} \mathrm{C}$. Hence, the air/vapor velocity, $u_{a}$ is calculated as $u_{a}=\frac{G}{\rho_{a}+\rho_{v 0}}$, and is maintained constant.

Mass of condensed vapor

The rate of condensed liquid into the water droplets is given as

$$
\dot{m}_{\text {cond.vap }}=\frac{4}{3} \pi\left(R_{d f}^{3}-R_{d 0}^{3}\right) \rho_{w} N_{d 0} v_{d 0} .
$$

To verify the mass balance, the rate of vapor condensed out of the air/vapor mixture,

$$
\dot{m}_{\text {cond.vap }}=\left(\rho_{v 0}-\rho_{v f}\right) u_{a} \text {. }
$$

where, $R_{d f}$ and $\rho_{v f}$ are the final droplet radius and water vapor density of air/vapor mixture, respectively, leaving the condenser. Also, the rate of condensed vapor out of air/vapor mixture calculated from the absolute specific humidity, $\omega$, as

$$
\dot{m}_{\text {cond.vap }}=\left(\omega_{0}-\omega_{f}\right) G /\left(1+\omega_{0}\right)
$$

where $\omega=\frac{0.622 \phi P_{s a t}\left(T_{a}\right)}{P-\phi P_{s a t}\left(T_{a}\right)}$ for an air/vapor mixture, $P_{s a t}\left(T_{a}\right)$ is the saturation pressure at $T_{a}$ and $\phi$ is the relative humidity.

\section{Non-uniform Temperature Analysis of the droplet}

The computations revealed that the difference between the volume-averaged temperature $T_{d}$ taken for the entire droplet may not accurately represent the thermodynamic potential ( $\Delta T=T_{a}-T_{d}$ ) driving the heat and mass transfer during the condensation process. The actual driving potential is the difference between the droplet surface and the surrounding air temperature. The droplet surface temperature is greater than the volume-averaged droplet temperature because the droplet is not getting sufficient time to achieve a uniform temperature. Thus the transient temperature profile of the droplet at each time should be considered for a more accurate prediction. As such the dynamic equations for the droplet and conservation equations for the air/vapor mixture utilize the surface temperature of the droplet as the interface temperature as opposed to the volume-averaged droplet temperature. All the surface heat and mass transfer properties are evaluated at the new surface temperature at each z-location in the condenser. The analysis used to evaluate the 
droplet surface temperature at each time step is described below. In this analysis, the droplet is considered to be axisymmetric in the $\theta$ and $\phi$ directions and hence only the radial distribution is considered. The change in droplet size due to condensation is negligible and hence the droplet size is fixed at its initial value $R_{d 0}$. The $1-\mathrm{D}$ transient heat diffusion equation within the droplet is given as:

$$
\frac{\partial^{2} T}{\partial r^{2}}+\frac{2}{r} \frac{\partial T}{\partial r}=\frac{1}{\alpha_{d}} \frac{\partial T}{\partial t}
$$

Initial \& Boundary conditions;

$$
\left.\begin{array}{l}
T(r, 0)=f(r) \\
T(0, t) \text { is finite } \\
k_{d} \frac{\partial T}{\partial r}+U\left(T_{a}-T\right)+\left.\gamma_{d} h_{f g}\left(\rho_{v}-\rho_{\text {sat }}\left(T_{d}\right)\right)\right|_{r=r_{0}}=0
\end{array}\right\} .
$$

Here, $k_{d}$ is droplet thermal conductivity, $\alpha_{d}$ is the droplet thermal diffusivity. By doing the transformation $\theta(r, t)=T_{a}-T(r, t)$ and $V(r, t)=r \theta(r, t)$, the spherical coordinates are transformed into Cartesian ones and the final equation we solve for is,

$$
\frac{\partial^{2} V}{\partial r^{2}}=\frac{1}{\alpha_{d}} \frac{\partial V}{\partial t}
$$

with initial and boundary conditions

$$
\left.\begin{array}{l}
V(r, 0)=r\left[T_{a}-f(r)\right] \\
V(0, t)=0 \\
k_{d}\left[\frac{\partial V}{\partial r}-\theta\right]+U V\left(r_{0}, t\right)+\left.\gamma_{d} h_{f g}\left(\rho_{v}-\rho_{s a t}\left(T_{d}\right)\right) r\right|_{r=r_{0}}=0
\end{array}\right\} .
$$

Solution of coupled ODE's, Eqs. (22-26), give the droplet radius, velocity, bulk temperature, air temperature, and vapor density. With the solution of the droplet temperature field from Eq.(42), Eq.(24) is no longer required. At each elevation (i.e., at each z-location) the residence time of the droplet is calculated and the temperature field within the droplet is estimated for this residence time. The temperature field at the previous step is used as the initial condition for next z-location. Equation (44) is solved with a simple central difference scheme with 50 points $(m=50)$ in the radial direction for the droplet. The finite difference equation for the interior points $(\mathrm{i}=1$ to $\mathrm{m}-1)$ is given as:

$$
\begin{aligned}
& \frac{V_{i}^{n+1}-V_{i}^{n}}{\Delta t}=\alpha_{d}\left[\frac{V_{i+1}^{n}-2 V_{i}^{n}+V_{i-1}^{n}}{(\Delta r)^{2}}\right] \\
& \Rightarrow V_{i}^{n+1}=\left[\alpha_{d} \frac{\Delta t}{(\Delta r)^{2}}\right]\left\{V_{i+1}^{n}+V_{i-1}^{n}\right\}+\left\{1-2 \alpha_{d} \frac{\Delta t}{(\Delta r)^{2}}\right\} V_{i}^{n} .
\end{aligned}
$$

For the boundary point at the interface, the finite-difference equation is,

$$
V_{m}^{n+1}\left[\frac{(m-1) k_{d}}{m \Delta r}+U\right]-\frac{k_{d} V_{m-1}^{n+1}}{\Delta r}+C^{n+1} m \Delta r=0
$$

where $C^{n+1}=\gamma_{d} h_{f g}\left(\rho_{v}-\rho_{s a t}\left(T_{d}\right)\right)$ which is constant at a specific z-location. Using Eq.(47), Eq.(48) becomes,

$$
\begin{aligned}
& V_{m}^{n+1}\left[\frac{(m-1) k_{d}}{m \Delta r}+U\right]=k_{d} \alpha_{d} \frac{\Delta t}{(\Delta r)^{3}}\left[V_{m}^{n}+V_{m-2}^{n}\right]+ \\
& \frac{k_{d}}{\Delta r}\left(1-2 \alpha_{d} \frac{\Delta t}{(\Delta r)^{2}}\right) V_{m-1}^{n}-C^{n+1} m \Delta r .
\end{aligned}
$$

The time step $\Delta t$ is chosen carefully to satisfy the stability criterion, 


$$
\frac{k_{d} \alpha_{d} \Delta t}{(\Delta r)^{3}\left[\frac{m-1}{m} \frac{k_{d}}{\Delta r}+U\right]} \leq \frac{1}{2} .
$$

From the order of magnitude of each term in Eq.(50), $\Delta t \leq 5 \times 10^{-4} \mathrm{sec}$ is appropriate. Hence, a value of $\Delta t=1 \times 10^{-5} \mathrm{sec}$ is taken as the time step.

\section{Bulk Temperature calculation}

The volume-averaged bulk temperature of the droplet is calculated as

$$
T_{\text {Bulk }}=\frac{\int_{0}^{r_{0}} T(r) 4 \pi r^{2} d r}{\frac{4}{3} \pi R_{d}^{3}}
$$

Simpson's rule is used for the numerical integration.

\section{Results and Discussion}

Figs. 44(a-c) show the computed variation of the droplet radius, velocity, and temperature along the condenser. Figs. 44(d-f) show the variation of air/vapor mixture temperature, vapor density, and humidity along the condenser. Computations for both the uniform and non-uniform temperature analyses for the droplets are shown for comparison.

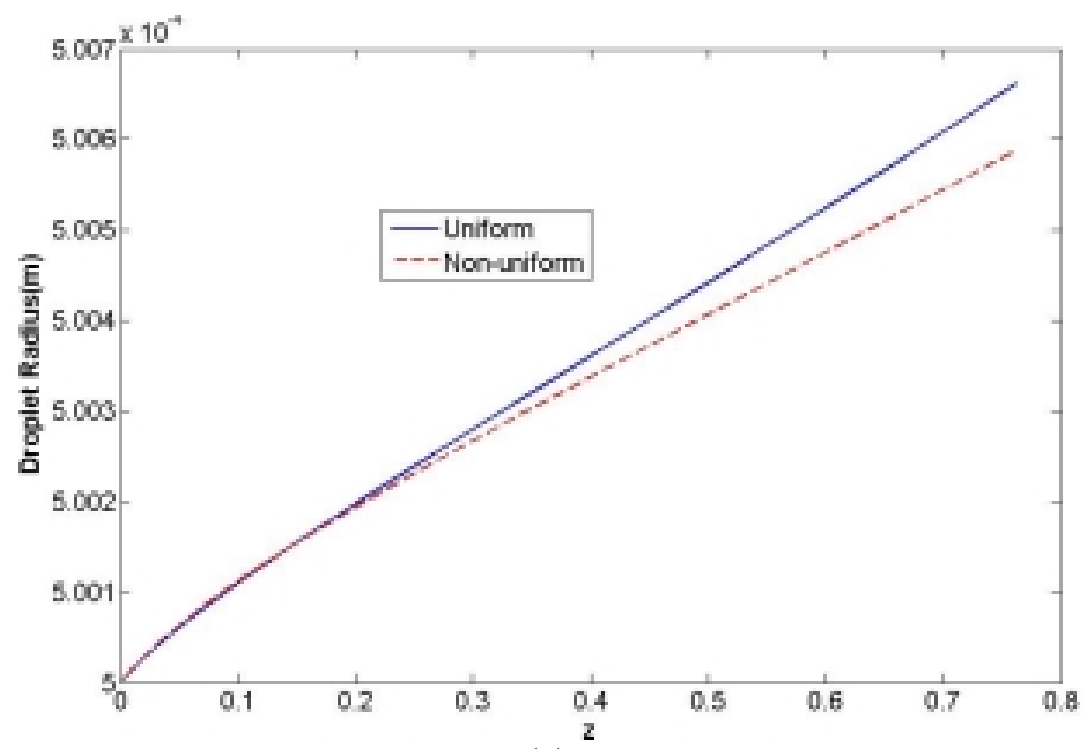

(a) 


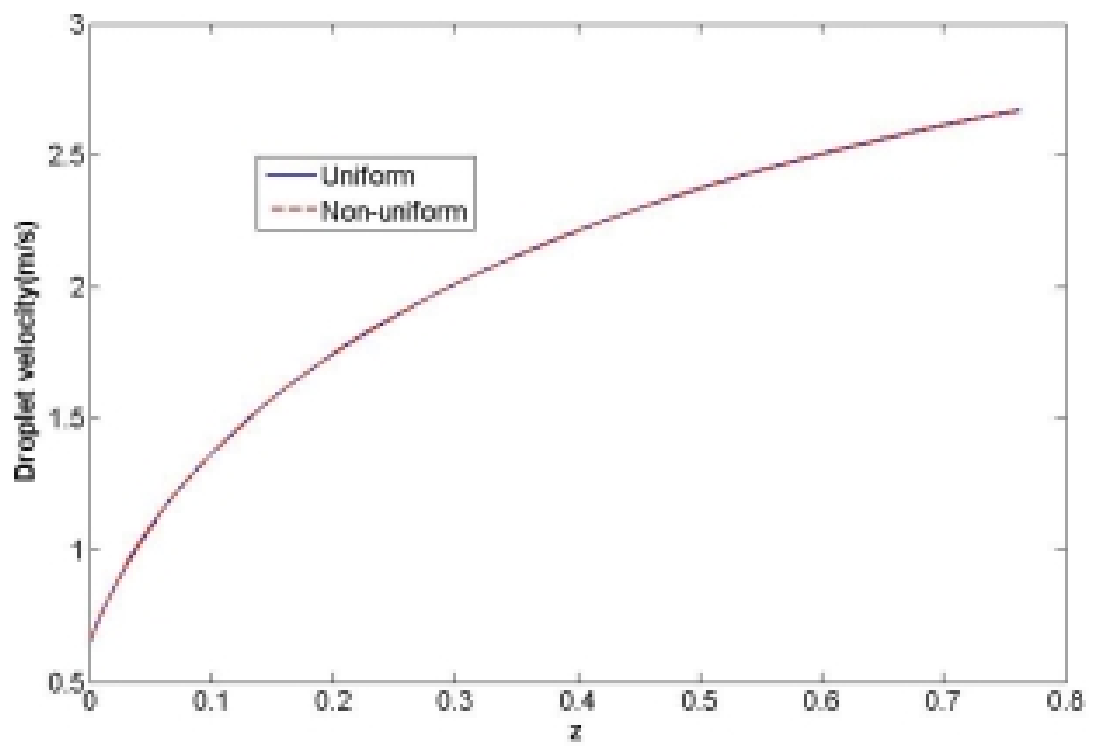

(b)

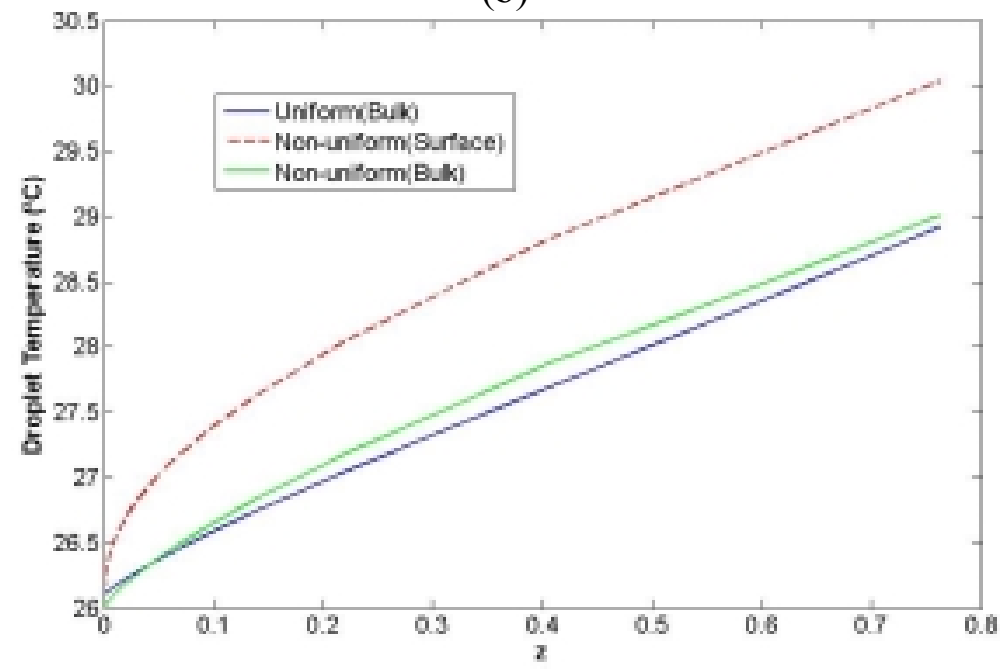

(c)

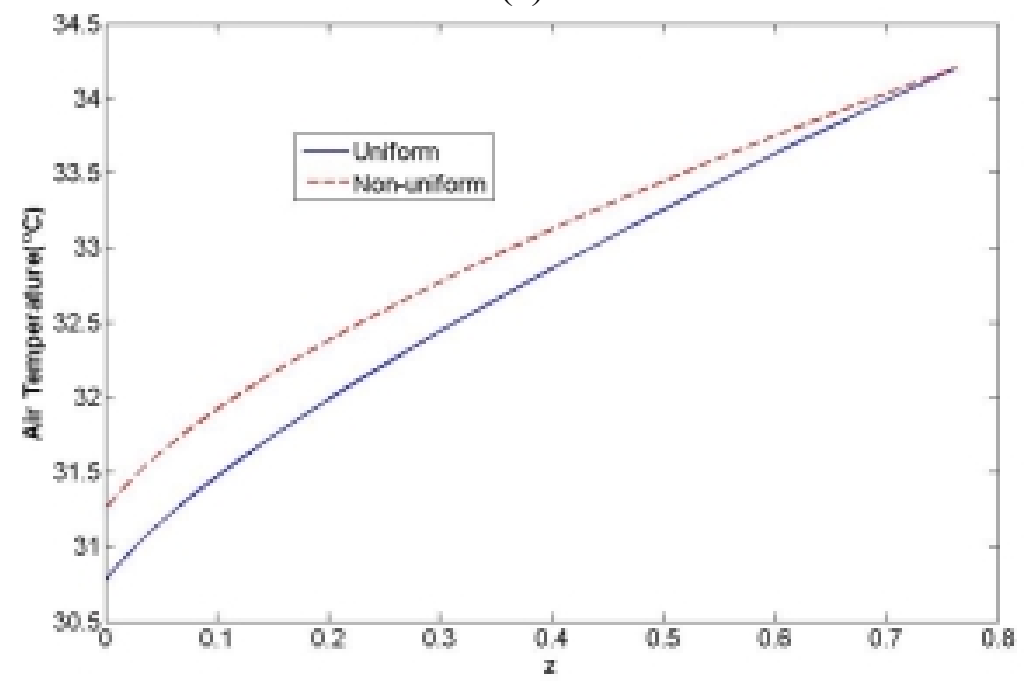

(d) 


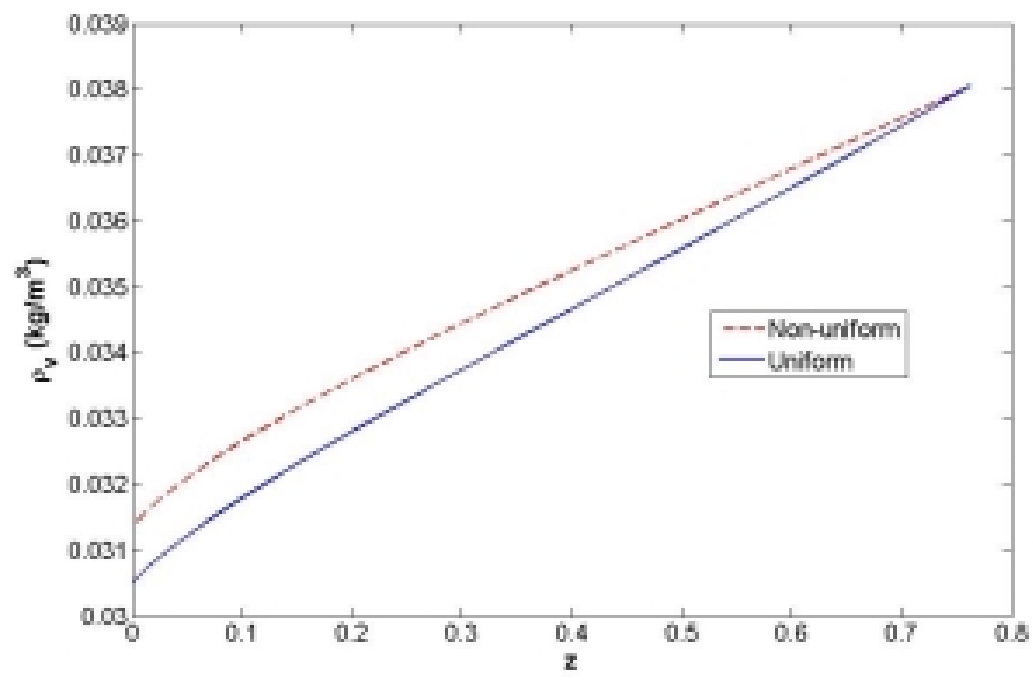

(e)

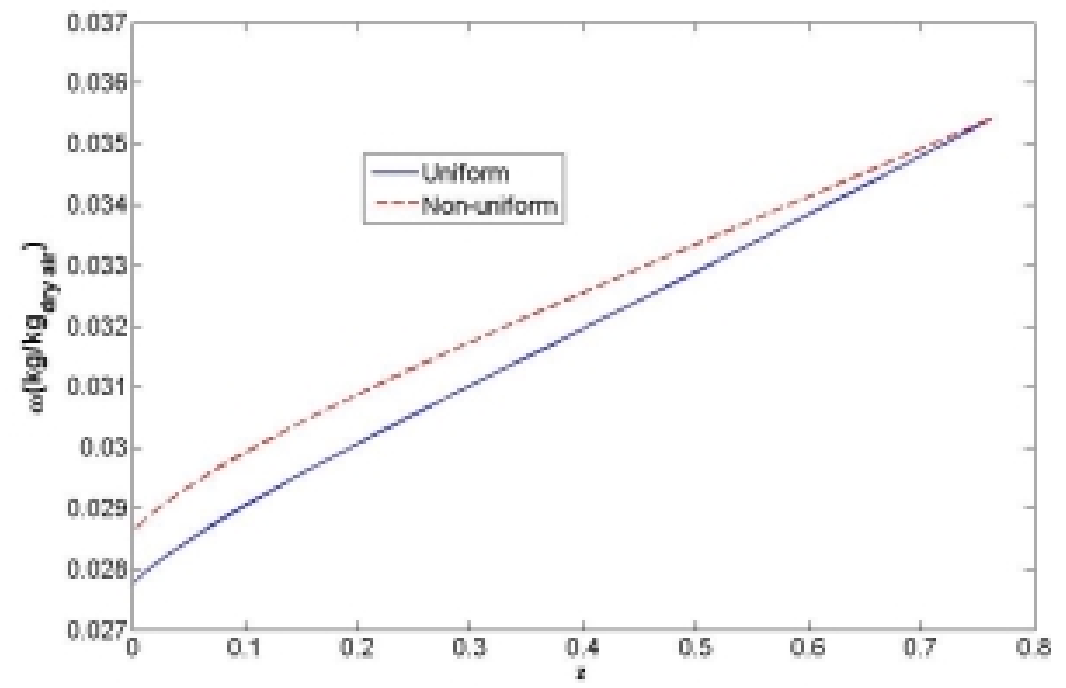

(f)

Figure 44 Variation of (a) droplet radius, (b) droplet velocity, (c) droplet temperature, (d) Air-vapor mixture temperature, (e) Vapor density, and (f) Specific humidity with axial position for the uniform and non-uniform droplet analysis.

Figure 44(c) shows the droplet surface temperature along with the bulk temperature and air temperature. The temperature difference between the air and the droplet gives us the available thermodynamic potential for heat and mass transfer. When accounting for non-uniform temperature distribution this reduced potential results in a reduced rate of condensed vapor.

With the uniform bulk temperature assumption for the droplet, for an air/vapor mixture flow rate of $0.04 \mathrm{~kg} / \mathrm{sec}$ for the given cross section area entering at $34.2^{\circ} \mathrm{C}$, the exit air temperature is predicted as $30.73^{\circ} \mathrm{C}$. The water droplet temperature increased from $26.1^{\circ} \mathrm{C}$ to $28.84^{0} \mathrm{C}$ and the mass of water vapor condensed is predicted to be 1.066 $\mathrm{kg} / \mathrm{hr}$ for the given condenser cross section area. Now, with the non-uniform temperature field considered within the droplet, the air exit temperature slightly rises to $31.22^{\circ} \mathrm{C}$, and the droplet surface temperature rises to $30.02^{\circ} \mathrm{C}$. The volume-averaged bulk temperature 
still is predicted to be $29.01^{\circ} \mathrm{C}$. The mass of vapor condensed in this case is $0.947 \mathrm{~kg} / \mathrm{hr}$ for the given cross-sectional area of condenser. This elucidates the importance of including the non-uniform droplet temperature in the analysis.

Table3. Experimental measurements and numerical predictions.

\begin{tabular}{|c|c|c|c|c|c|c|c|c|c|c|c|c|}
\hline \multirow[t]{3}{*}{$\begin{array}{l}\text { Exp } \\
\text { eri } \\
\text { me } \\
\text { nt \# }\end{array}$} & \multirow{3}{*}{$\begin{array}{c}\begin{array}{c}\text { Air } \\
\text { inlet } \\
\text { temp }\end{array} \\
\left({ }^{\circ} \mathrm{C}\right)\end{array}$} & \multirow{3}{*}{$\begin{array}{c}\begin{array}{l}\text { Water } \\
\text { inlet } \\
\text { temp }\end{array} \\
\left({ }^{\circ} \mathrm{C}\right)\end{array}$} & \multicolumn{2}{|c|}{$\begin{array}{l}\text { Air outlet } \\
\text { temp }\left({ }^{0} \mathrm{C}\right)\end{array}$} & \multicolumn{4}{|c|}{ Water outlet temp $\left({ }^{0} \mathbf{C}\right)$} & \multicolumn{2}{|c|}{$\begin{array}{l}\text { Exit Specific } \\
\text { Humidity }\end{array}$} & \multicolumn{2}{|c|}{$\begin{array}{l}\text { Fresh water } \\
\text { production } \\
(\mathrm{kg} / \mathrm{hr})\end{array}$} \\
\hline & & & $\begin{array}{l}\text { Experim } \\
\text { ent }\end{array}$ & Model & \multicolumn{2}{|c|}{ Experiment } & \multicolumn{2}{|c|}{ Model } & $\begin{array}{l}\text { Experim } \\
\text { ent }\end{array}$ & Model & $\begin{array}{l}\text { Experim } \\
\text { ent }\end{array}$ & Model \\
\hline & & & & & $\begin{array}{l}\text { Meas } \\
\text { ured }\end{array}$ & $\begin{array}{l}\text { Calcul } \\
\text { ated }\end{array}$ & $\begin{array}{c}\text { Surfac } \\
\text { e }\end{array}$ & Bulk & & & & \\
\hline 11 & 34.5 & 26 & 32.8 & 31.4 & 28 & 27.97 & 30.15 & 29.1 & 0.032 & 0.029 & 0.6943 & 1.0013 \\
\hline 12 & 33.8 & 26.2 & 31.8 & 30.55 & 28 & 27.88 & 29.77 & 28.8 & 0.030 & 0.028 & 0.6957 & 0.9927 \\
\hline 13 & 33.2 & 26.3 & 30.9 & 29.83 & 28.3 & 27.77 & 29.41 & 28.6 & 0.029 & 0.026 & 0.6963 & 0.9757 \\
\hline 14 & 32.7 & 26.2 & 30.2 & 29.04 & 28 & 27.66 & 28.99 & 28.2 & 0.028 & 0.025 & 0.8356 & 1.0020 \\
\hline 15 & 32.5 & 26.2 & 30 & 28.88 & 28 & 27.62 & 28.88 & 28.1 & 0.028 & 0.025 & 0.8356 & 0.9796 \\
\hline 16 & 32.9 & 26 & 30.5 & 29.37 & 28 & 27.41 & 29.06 & 28.2 & 0.029 & 0.026 & 0.6963 & 0.9932 \\
\hline 17 & 33.4 & 26 & 31.4 & 30.17 & 28.1 & 27.38 & 29.43 & 28.5 & 0.031 & 0.027 & 0.5565 & 0.9598 \\
\hline 18 & 34.2 & 26.1 & 32.6 & 31.24 & 28 & 27.71 & 30.04 & 29 & 0.034 & 0.029 & 0.5549 & 0.9467 \\
\hline
\end{tabular}

Table 3 above summarizes the experimental measurements and model predictions for various thermal and flow conditions.

Figure 45 shows the (a) exit air temperature, and (b) water droplet exit temperature from experimental measurements and model predictions. As we can see from the curves, there is a reasonable agreement between experimental measurements and numerical model predictions.

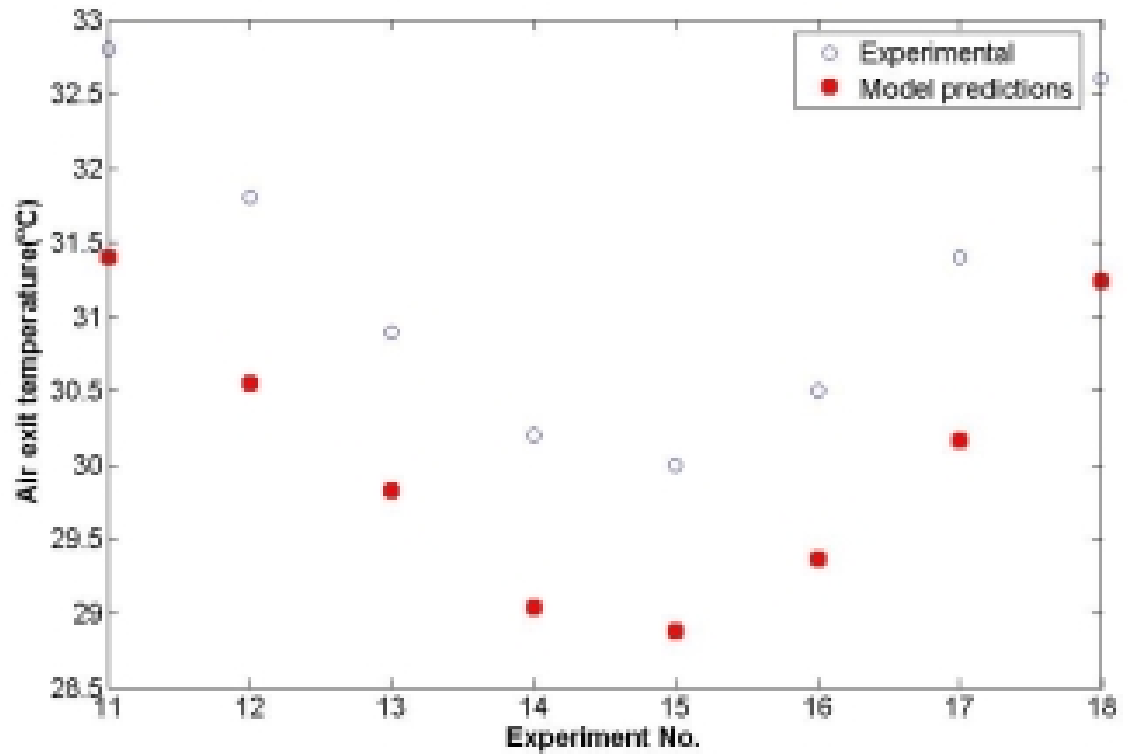

(a) 


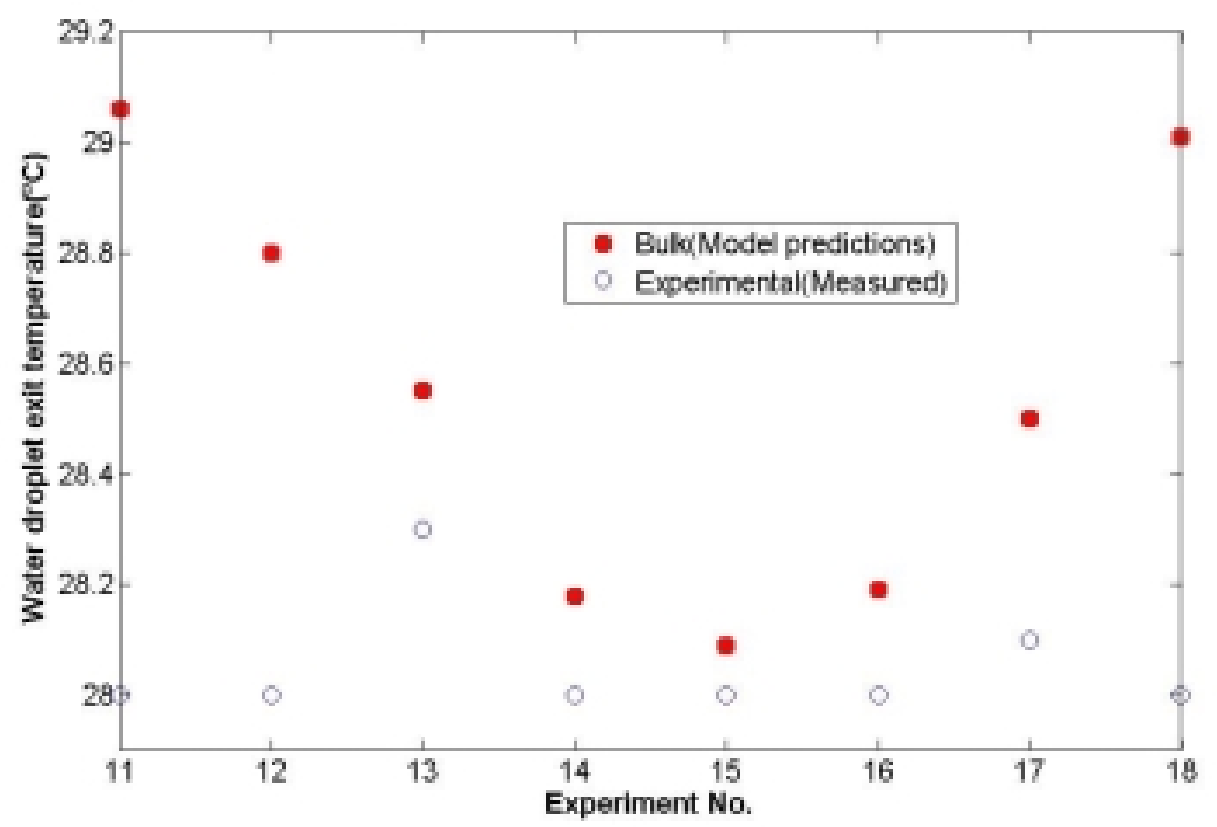

(b)

Figure 45 Plot of (a) exit air temperature and (b) exit water droplet temperatures from experimental measurements and model predictions.

The exit specific humidity of the air-vapor mixture is predicted from the model are compared with those measured experimentally in Fig. 46.

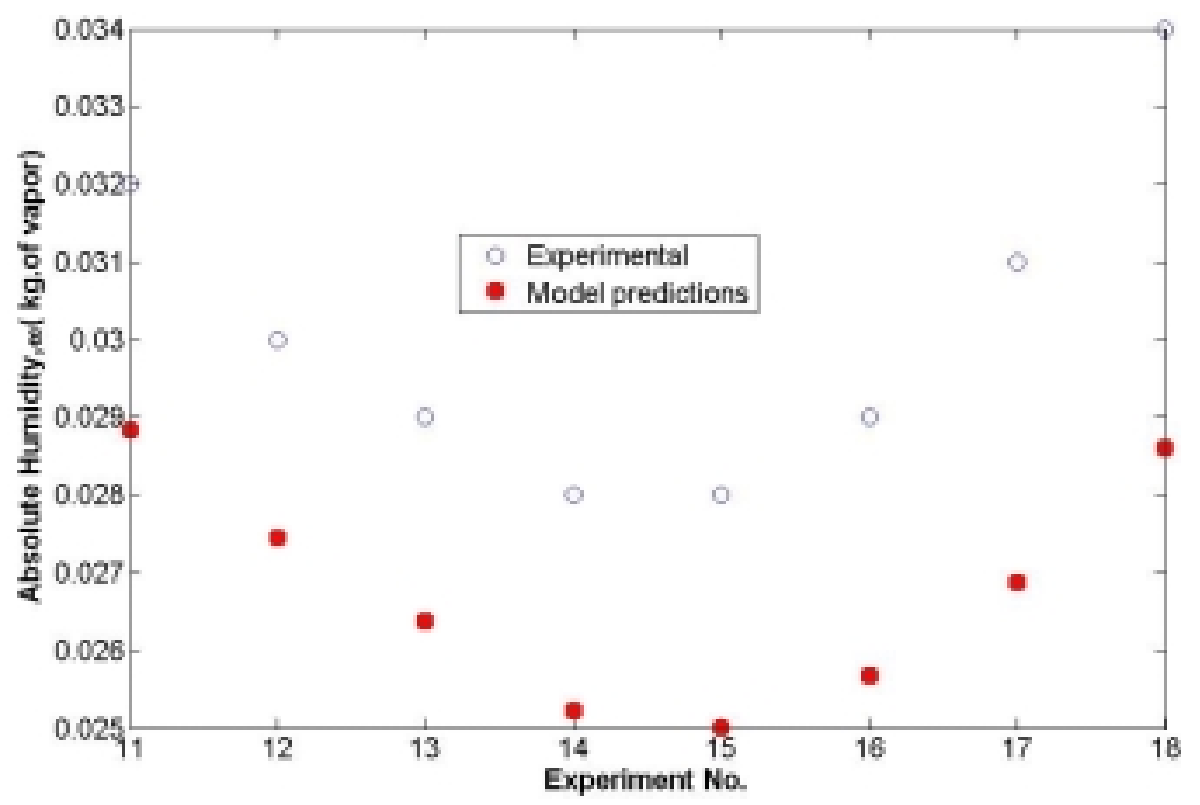

Figure 46 Exit Specific Humidity from experiments and model predictions.

Finally, the rate of fresh water production $(\mathrm{kg} / \mathrm{hr})$ for a given cross sectional area is compared with experimental measurements and model predictions as shown in Fig. 47. 


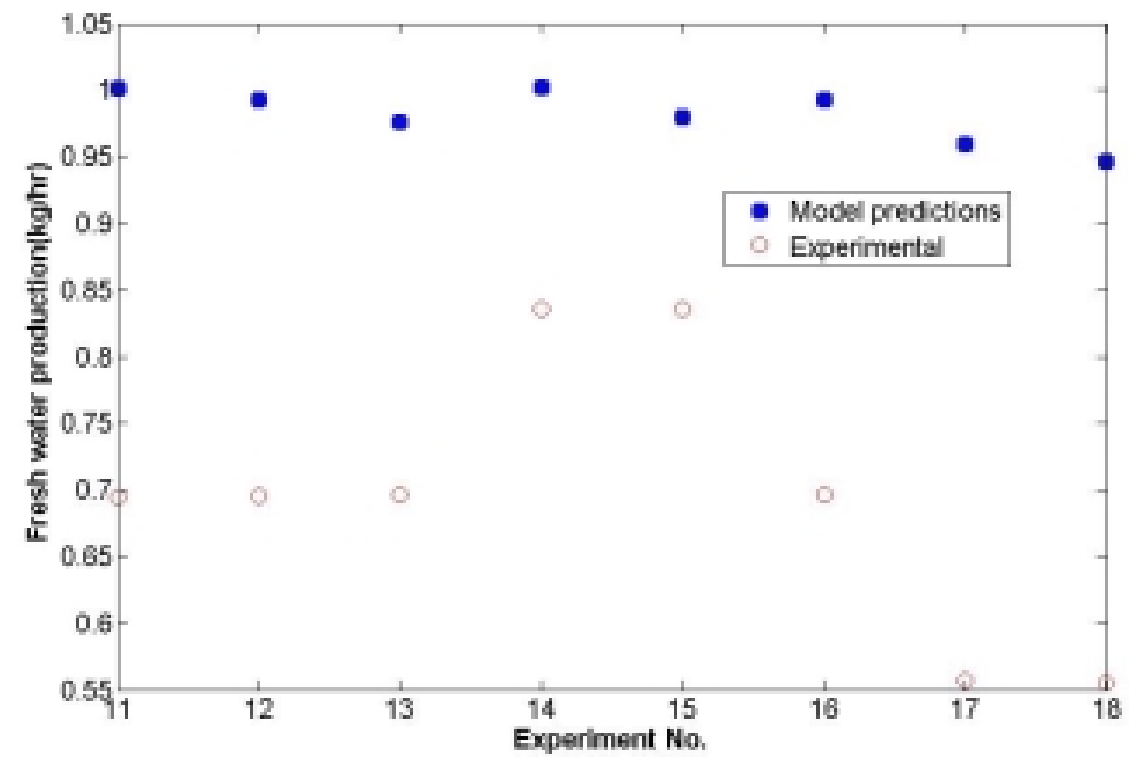

Figure 47 Fresh water production $(\mathrm{kg} / \mathrm{hr})$ from experiments and model predictions.

The comparison between the model prediction and the experiments demonstrate a need to refine the model. Further multi-dimensional analysis of droplet dynamics would possibly result in a better estimation of direct contact condensation and may improve the model.

\section{Experiment Exploration of the DDD Process with Air Heating}

Several experiments using the heated air input in the diffusion tower have been conducted over a varying range of parameters. For the experiments both the air inlet and the inlet feed water to the diffusion tower were fixed at $60^{\circ} \mathrm{C}$. The air mass flux ranged from 0.9 to $1.80 \mathrm{~kg} / \mathrm{m}^{2}$-s. For a fixed air inlet temperature and mass flux, a full range of inlet feed water mass fluxes varying from 0.45 to $1.50 \mathrm{~kg} / \mathrm{m}^{2}-\mathrm{s}$ was explored. For each flow rate steady state conditions were achieved. Therefore several distinct steady state experiments were run for each flow rate. The data collected are summarized in the proceeding figures.

Fig. 48 shows the temperature drop of the water as it passes through the diffusion tower. For both air flux cases it is apparent that the temperature drop increases with increasing air to water mass flow ratios. 


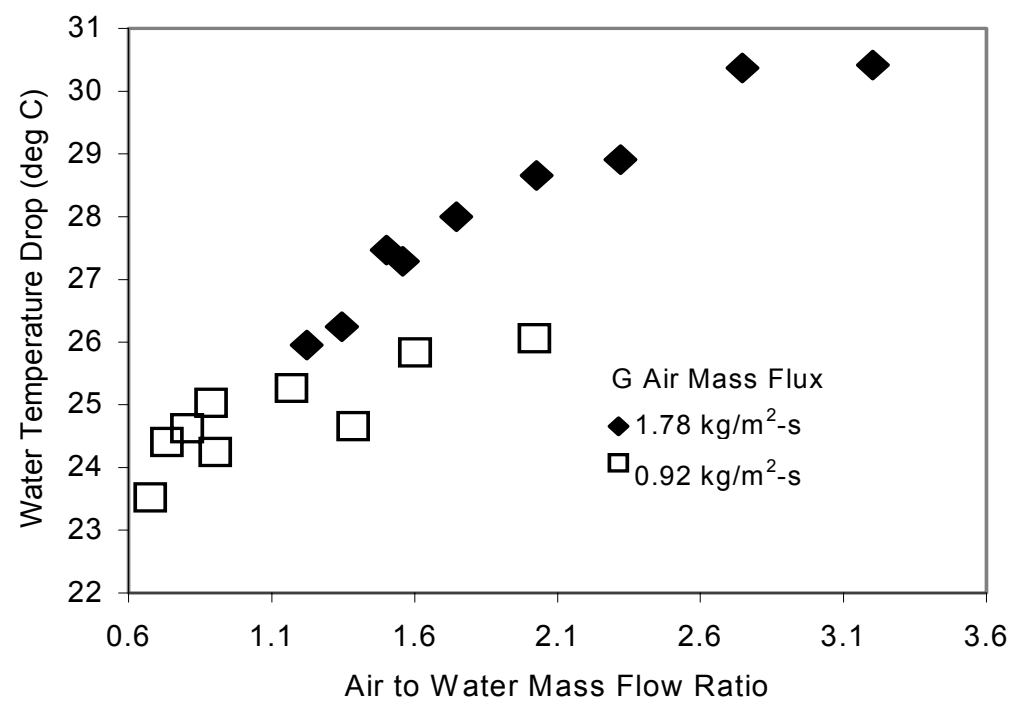

Figure 48 Temperature drop of water with varying air to water mass flow ratios

Fig. 49 shows the air temperature drop through the diffusion tower. As with the water temperature drop, the air temperature drop also increases with increasing air to water mass flow ratio. It should be noted that the water temperature drop and air temperature drop are not equal for the corresponding air mass flux and air to water mass flow ratio. It is also worthy to note that since the temperature drops of air and water increase with increasing air to water mass flow ratio, less input feed water is required. This will have an impact on the fresh water conversion efficiency of the process.

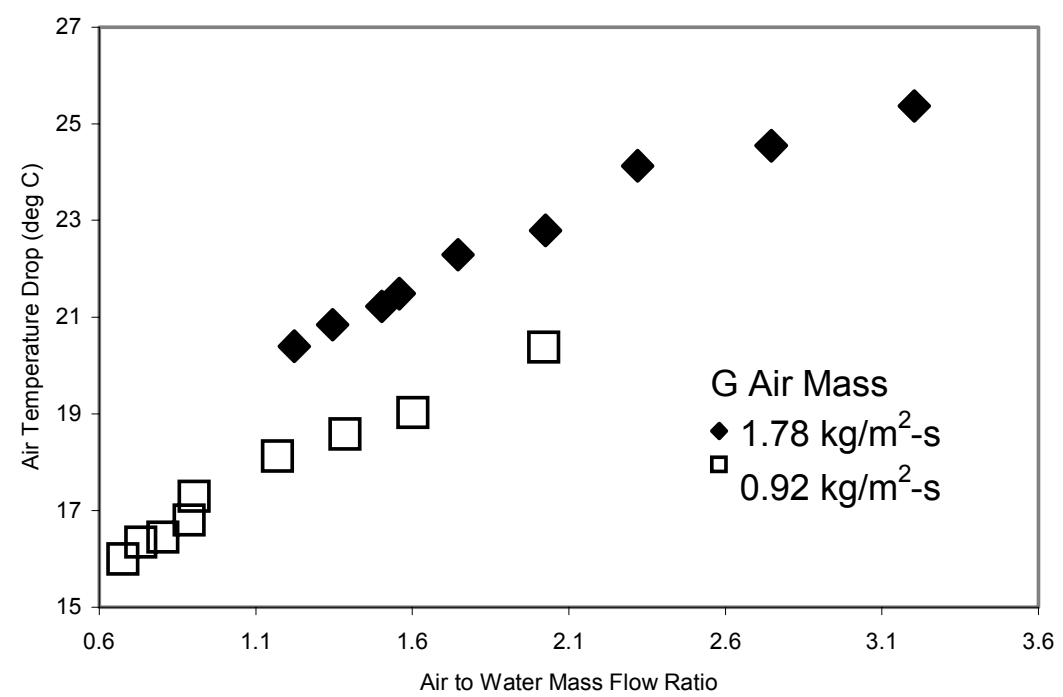

Figure 49 Temperature drop of the air with varying air to water mass flow ratios

Fig. 50 shows the variation of humidity change with varying air to water mass flow ratios. The change in humidity decrease with increasing air to water mass flow ratios. 


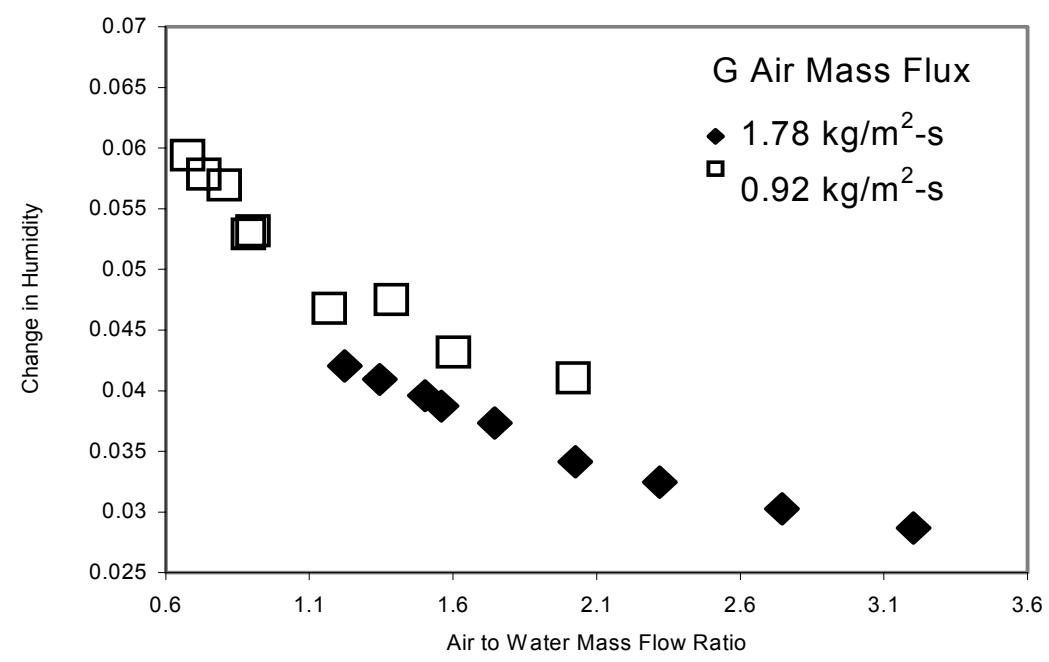

Fig 50 Change in humidity for varying air to water mass flow ratios

An important consideration for the experiments is the fresh water production efficiency, the fraction of feed water evaporated in the diffusion tower. Fig. 51 shows the fresh water production efficiency with varying air to water mass flow ratio. As expected, as the air to water mass flow ratio increases, the fresh water production efficiency also increases. This is an important result because it shows that when the input air is heated, less inlet water flow rate is required to achieve a specified fresh water production rate since the fresh water conversion efficiency increases. The data suggest that there could be considerable heat loss, which leads to lower efficiency than expected. Experiments will be run again with guard heaters to prevent heat loss. Despite the heat loss, however, the experiments with the heated air successfully demonstrate that the fresh water production efficiency increases with air heating. It should be noted that the maximum efficiency obtained without heating the air was only $2 \%$. In these preliminary experiments the maximum efficiency is close to $9.5 \%$. It is expected that a higher efficiency can be achieved when the heat loss to the environment is diminished.

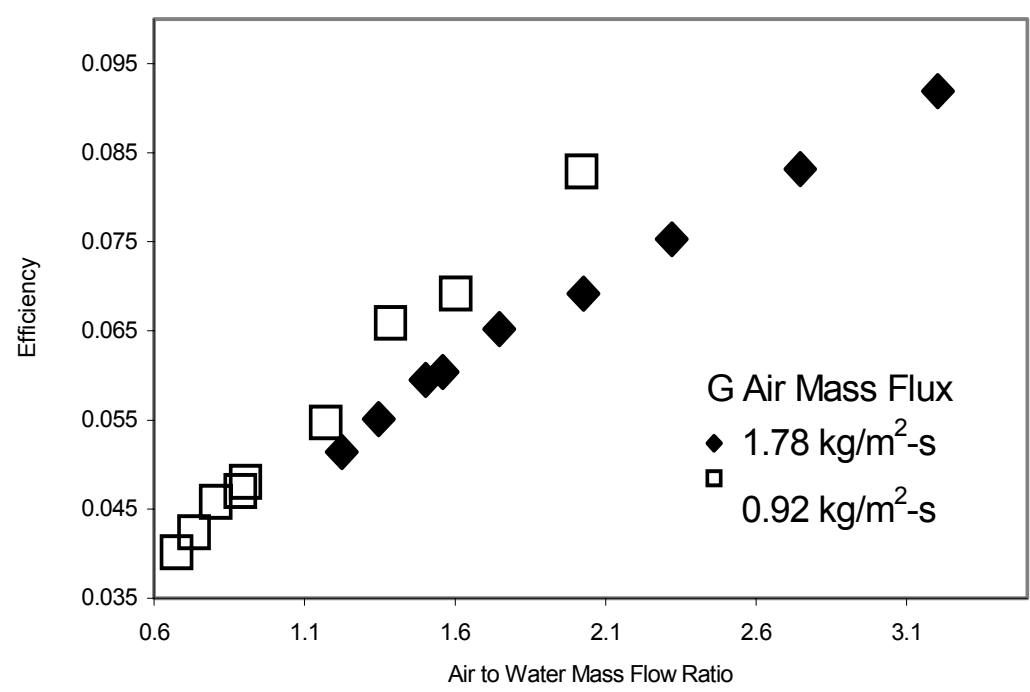

Figure 51 Efficiency of the process with varying air to water mass flow ratio 
From the data presented it is obvious that heating the input air could be a sufficient means of increasing the fresh water production efficiency of the DDD process. More experiments need to be conducted to fully understand the benefits of the heated air input. In addition, a cost analysis should be performed to analyze the additional costs of the heated air.

\section{Summary of Completed Tasks}

The following project tasks have been completed:

1) Develop a numerical simulation tool for predicting heat, mass, and momentum transfer in the direct contact condenser

2) Conduct experiments on the co-current flow condenser to validate or calibrate computational model

3) Conduct experiments on the counter-current flow condenser to calibrate the computational model

4) Use dynamic simulation of the heat and mass transfer process to predict the overall system performance

5) Use numerical tools to investigate optimum design criteria and operating conditions for the DDD process

6) Improve the previously reported economic analysis based on a complete system simulation

7) Modify the DDD process by adding the air heating section and conduct experiments to observe the improvement of the fresh water production efficiency

\section{Summary}

The third year of work on the development of a Diffusion Driven Desalination facility has been completed, and the results are promising. A detailed analysis shows that the waste heat from a $100 \mathrm{MW}$ power plant can be used to produce 1.03 million gallons of fresh water per day using the DDD process. The energy used to drive the process is low thermodynamic availability waste heat, and the only energy cost is that used to power the pumps and fans. An economic simulation of the DDD system shows that the production costs of the DDD combined power plant is very competitive compared with the costs required for reverse osmosis or flash evaporation technologies. A laboratory scale DDD facility, which includes the diffusion tower, direct contact condenser and air heating section has been fabricated. The whole system has been fully instrumented for detailed heat and mass transfer measurements. Extensive measurements of the diffusion tower and direct contact condenser were made during this year to validate their simulated performance. The analytical model of the direct contact condensers proves to be quite satisfactory in predicting the thermal performance of co-current and counter-current flow packed beds. Further work is required to analyze the evaporation in the diffusion tower when the air is preheated.

Current analysis shows that the Diffusion Driven Desalination process appears to be an economically attractive distillation process. The precise values presented in the report need to be viewed with caution since losses other than pressure losses have not been considered, and the assumed feed water temperature into the diffusion tower may be 
optimistic. Nevertheless, the trends presented demonstrate the potential that can be gained from the DDD process, and it provides useful and practical guidance for choosing the operating conditions to achieve near optimum performance.

Although the Diffusion Driven Desalination facility is a promising technology for fresh water production using waste heat from electric power plants, current industry practice will limit its implementation until the value of fresh water sharply increases. The current practice of electric power plants is to pump a very large rate of cooling water through the main condenser so that the temperature rise of the water across the condenser is only about $6^{\circ} \mathrm{C}$. The DDD requires the discharge water from the condenser to be approximately $40^{\circ} \mathrm{C}$. This could be accomplished by lowering the flow rate through the condenser and providing more heat transfer surface area to compensate for the reduced heat transfer rate. This would require a power plant installing a DDD facility to also replace or modify the main condenser. This is not a likely scenario. The best prospect for incorporating the DDD facility into an electric power plant for fresh water production is with the fabrication of new plants where the main condenser could be sized appropriately for the specified flow conditions. Another promising option is to incorporate DDD into power plants installing air-cooled condensers. The heated air discharging the condenser could be directly ducted to the diffusion tower. This type of configuration requires further scrutiny. 


\section{References}

[1] World Resources Institute, United Nations Development Programme, the United Nations Environment Programme, and the World Bank, "World Resources 2000 2001 People and Ecosystems", 2 104-105 (Sep 2000).

[2] Muller-Holst, H., Engelhardt, M., Scholkopf, W., Jul 1999, Small-scale thermal seawater desalination simulation and optimization of system design, Desalination 122-3, 255-262.

[3] Al-Hallaj, S., Selman, J.R., 2002, A comprehensive study of solar desalination with a humidification - dehumidification cycle, a report by the Middle East Desalination Research Center, Muscat, Sultanate of Oman.

[4] Klausner, J.F., Li,Y., Mei, R., 2004, Innovative diffusion driven desalination process, Journal of Energy Resources Technology.

[5] Bharathan, D., Parsons, B.K., and Althof, J.A., 1988, Direct-Contact Condensers for Open-Cycle OTEC Applications, National Renewable Energy Laboratory Report SERI/TP-252-3108 for DOE Contract No. DE-AC02-83CH10093.

[6] Klausner, J.F., Mei, R., and Li,Y. et al., 2004, Innovative Fresh Water Production Process for Fossil Fuel Plants, U.S. DOE - Energy Information Administration annual report.

[7] Kays, W.M. and Crawford, M.E, "Convective Heat and Mass Transfer", $2^{\text {nd }}$ Edition, McGraw-Hill Higher Education, 243 (1980).

[8] Klausner J.F., Li Y. and Mei R., "Evaporative Heat and Mass Transfer for the Diffusion Driven Desalination Process", in press J. Heat \& Mass Transfer, Springer Verlag, New York (2005).

[9] Wangnick, K. (2002), 2002 IDA Worldwide Desalting Plants Inventory Report No. 17, produced by Wangnick Consulting for IDA, Gnarrenburg, Germany.

[10] Hisham M. Ettouney and Hisham T. El-Dessouky, Kuwait Univ., Ron S. Faibish and Peter J. Gowin, IAEA, Evaluating the Economics of Desalination, Chemical Engineering Progress, Dec. 2002, pp 32-39.

[11] Survey by the NUS Consulting Group, based on the municipal water price as of July 1,2002 in U.S.

[12] U.S. DOE - Energy Information Administration, Electric Power Monthly Annual, August, 2001, U.S.

[13] Nuclear Energy Institute, "The Economic Benefits Of Oyster Creek Generating Station", Prepared for AmerGen Energy Co. LLC, Ocean County, New Jersey (March 2004).

[14] K. Onda, H. Takechi, and Y. Okumoto, Mass transfer coefficients between gas and liquid phases in packed columns, Journal of Chemical Engineering of Japan, 1, (1968) 56-62. 


\section{Appendix A}

Onda's correlation

$$
\begin{aligned}
& k_{L}=0.0051 \operatorname{Re}_{L w}{ }^{2 / 3} S c_{L}{ }^{-0.5}\left(a d_{p}\right)^{0.4}\left[\frac{\mu_{L} g}{\rho_{L}}\right]^{1 / 3} \\
& k_{G}=5.23 \operatorname{Re}_{G A}{ }^{0.7} S c_{G}{ }^{1 / 3}\left(a d_{p}\right)^{-2} a D_{G} \\
& a_{w}=a\left\{1-\exp \left[-2.2\left(\frac{\sigma_{c}}{\sigma_{L}}\right)^{\frac{3}{4}} \operatorname{Re}_{L A}{ }^{1 / 2} F_{L}{ }^{-0.05} W e_{L}{ }^{1 / 5}\right]\right\}
\end{aligned}
$$

$\operatorname{Re}_{L W}=\frac{L}{a_{w} \mu_{L}}, \operatorname{Re}_{G A}=\frac{G}{a \mu_{G}}, \operatorname{Re}_{L A}=\frac{L}{a \mu_{L}}$,

$S c_{L}=\frac{\mu_{L}}{\rho_{L} D_{L}}, S c_{G}=\frac{\mu_{G}}{\rho_{G} D_{G}}, F r_{L}=\frac{L^{2} a}{\rho_{L} g}, W e_{L}=\frac{L^{2}}{\rho_{L} \sigma_{L} a}$

The equation of $\mathrm{a}_{w}$ has been modified from the Onda's original correlation [14].

Heat transfer coefficient on the liquid side

$$
U_{L}=k_{L}\left(\rho_{L} C_{P L} \frac{K_{L}}{D_{L}}\right)^{1 / 2}
$$

Heat transfer coefficient on the gas side

$$
U_{G}=k_{G}\left(\rho_{G} C_{P G}\right)^{1 / 3}\left(\frac{K_{G}}{D_{G}}\right)^{2 / 3}
$$

where $\mathrm{K}$ denotes thermal conductivity and $\mathrm{D}$ denotes the molecular diffusion coefficient. 


\section{Appendix B Co-current Flow Condenser Experimental Data with Packing}

\begin{tabular}{|cccccccc|}
\hline $\begin{array}{c}\text { Water } \\
\text { flow rate } \\
(\mathrm{kg} / \mathrm{s})\end{array}$ & $\begin{array}{c}\text { Air flow } \\
\text { rate }(\mathrm{kg} / \mathrm{s})\end{array}$ & $\begin{array}{c}\text { Water inlet } \\
\text { temperature } \\
(\mathrm{C})\end{array}$ & $\begin{array}{c}\text { Water exit } \\
\text { temperature } \\
(\mathrm{C})\end{array}$ & $\begin{array}{c}\text { Air inlet } \\
\text { temperature } \\
(\mathrm{C})\end{array}$ & $\begin{array}{c}\text { Air exit } \\
\text { temperature } \\
(\mathrm{C})\end{array}$ & $\begin{array}{c}\text { Air inlet } \\
\text { humidity }\end{array}$ & $\begin{array}{c}\text { Air exit } \\
\text { humidity }\end{array}$ \\
0.068 & 0.031 & 28.3 & 29.9 & 32.8 & 29.6 & 0.035 & 0.027 \\
0.059 & 0.031 & 28.3 & 30.0 & 32.7 & 29.7 & 0.035 & 0.027 \\
0.051 & 0.031 & 28.5 & 30.2 & 32.8 & 29.9 & 0.035 & 0.027 \\
0.041 & 0.031 & 28.4 & 30.3 & 32.6 & 30.0 & 0.034 & 0.027 \\
0.032 & 0.031 & 28.1 & 30.3 & 32.6 & 30.3 & 0.034 & 0.028 \\
0.022 & 0.031 & 27.9 & 31.1 & 32.8 & 30.7 & 0.034 & 0.028 \\
& & & & & & & \\
0.017 & 0.031 & 28.1 & 31.1 & 32.7 & 31.0 & 0.034 & 0.029 \\
0.024 & 0.031 & 28.0 & 31.3 & 32.7 & 30.7 & 0.034 & 0.028 \\
0.033 & 0.031 & 28.3 & 30.4 & 32.7 & 30.4 & 0.034 & 0.028 \\
0.046 & 0.031 & 28.2 & 30.2 & 32.7 & 30.0 & 0.034 & 0.027 \\
0.056 & 0.031 & 28.2 & 30.1 & 33.0 & 29.9 & 0.034 & 0.027 \\
0.064 & 0.032 & 28.3 & 29.8 & 32.7 & 29.9 & 0.033 & 0.027 \\
\hline & & & & & & & \\
\hline Water & Air flow & Water inlet & Water exit & Air inlet & Air exit & \multirow{2}{*}{ Air inlet } & Air exit \\
flow rate & rate (kg/s) & temperature & temperature & temperature & temperature & humidity & humidity \\
$(\mathrm{kg} / \mathrm{s})$ & & $(\mathrm{C})$ & $(\mathrm{C})$ & $(\mathrm{C})$ & & \\
0.062 & 0.030 & 28.0 & 33.7 & 40.3 & 32.9 & 0.050 & 0.032 \\
0.055 & 0.031 & 28.2 & 34.2 & 40.1 & 33.4 & 0.049 & 0.033 \\
0.034 & 0.030 & 28.0 & 35.3 & 40.2 & 34.3 & 0.049 & 0.035 \\
0.027 & 0.030 & 27.8 & 36.0 & 40.2 & 35.1 & 0.049 & 0.037 \\
0.018 & 0.030 & 27.8 & 36.2 & 40.3 & 36.6 & 0.049 & 0.040 \\
& & & & & & & \\
0.020 & 0.030 & 27.8 & 36.2 & 40.3 & 36.2 & 0.049 & 0.039 \\
0.036 & 0.031 & 27.9 & 35.6 & 40.3 & 35.0 & 0.049 & 0.037 \\
0.041 & 0.031 & 28.0 & 35.3 & 40.4 & 34.4 & 0.049 & 0.036 \\
0.052 & 0.031 & 28.0 & 34.5 & 40.3 & 33.9 & 0.049 & 0.034 \\
0.060 & 0.031 & 28.1 & 34.1 & 40.4 & 33.5 & 0.049 & 0.034 \\
\hline
\end{tabular}

\begin{tabular}{|cccccccc|}
\hline $\begin{array}{c}\text { Water } \\
\text { flow rate } \\
(\mathrm{kg} / \mathrm{s})\end{array}$ & $\begin{array}{c}\text { Air flow } \\
\text { rate }(\mathrm{kg} / \mathrm{s})\end{array}$ & $\begin{array}{c}\text { Water inlet } \\
\text { temperature } \\
(\mathrm{C})\end{array}$ & $\begin{array}{c}\text { Water exit } \\
\text { temperature } \\
(\mathrm{C})\end{array}$ & $\begin{array}{c}\text { Air inlet } \\
\text { temperature } \\
(\mathrm{C})\end{array}$ & $\begin{array}{c}\text { Air exit } \\
\text { temperature } \\
(\mathrm{C})\end{array}$ & $\begin{array}{c}\text { Air inlet } \\
\text { humidity }\end{array}$ & $\begin{array}{c}\text { Air exit } \\
\text { humidity }\end{array}$ \\
0.069 & 0.030 & 28.6 & 35.8 & 44.5 & 35.0 & 0.061 & 0.037 \\
0.055 & 0.030 & 28.0 & 36.7 & 44.9 & 35.7 & 0.062 & 0.038 \\
0.047 & 0.030 & 28.0 & 37.5 & 44.8 & 36.1 & 0.062 & 0.039 \\
0.034 & 0.030 & 28.4 & 38.3 & 44.1 & 37.1 & 0.060 & 0.041 \\
0.025 & 0.030 & 28.0 & 39.3 & 43.9 & 38.1 & 0.059 & 0.044 \\
0.016 & 0.030 & 28.0 & 39.1 & 44.1 & 39.4 & 0.060 & 0.047 \\
& & & & & & & \\
0.023 & 0.031 & 27.9 & 39.3 & 43.8 & 38.5 & 0.059 & 0.045 \\
0.032 & 0.031 & 28.0 & 38.5 & 43.6 & 37.4 & 0.058 & 0.042 \\
0.043 & 0.030 & 28.1 & 37.7 & 44.4 & 36.5 & 0.061 & 0.040 \\
0.051 & 0.031 & 28.2 & 36.9 & 44.2 & 35.9 & 0.060 & 0.039 \\
0.061 & 0.030 & 28.3 & 36.0 & 44.1 & 35.3 & 0.060 & 0.037 \\
\hline
\end{tabular}




\section{Appendix C Counter-current Flow Condenser Experimental Data with Packing}

\begin{tabular}{|cccccccc|}
\hline $\begin{array}{c}\text { Water } \\
\text { flow rate } \\
(\mathrm{kg} / \mathrm{s})\end{array}$ & $\begin{array}{c}\text { Air flow } \\
\text { rate }(\mathrm{kg} / \mathrm{s})\end{array}$ & $\begin{array}{c}\text { Water inlet } \\
\text { temperature } \\
(\mathrm{C})\end{array}$ & $\begin{array}{c}\text { Water exit } \\
\text { temperature } \\
(\mathrm{C})\end{array}$ & $\begin{array}{c}\text { Air inlet } \\
\text { temperature } \\
(\mathrm{C})\end{array}$ & $\begin{array}{c}\text { Air exit } \\
\text { temperature } \\
(\mathrm{C})\end{array}$ & $\begin{array}{c}\text { Air inlet } \\
\text { humidity }\end{array}$ & $\begin{array}{c}\text { Air exit } \\
\text { humidity }\end{array}$ \\
0.024 & 0.029 & 20.4 & 40.3 & 42.7 & 34.8 & 0.057 & 0.036 \\
0.033 & 0.030 & 20.5 & 38.5 & 42.7 & 31.9 & 0.057 & 0.031 \\
0.041 & 0.031 & 20.4 & 37.2 & 42.7 & 30.1 & 0.057 & 0.027 \\
0.051 & 0.031 & 19.7 & 34.8 & 42.8 & 28.4 & 0.058 & 0.025 \\
& & & & & & & \\
0.061 & 0.030 & 19.5 & 33.3 & 42.8 & 27.1 & 0.058 & 0.023 \\
0.054 & 0.030 & 19.7 & 34.0 & 42.9 & 28.0 & 0.058 & 0.024 \\
0.045 & 0.030 & 19.8 & 34.8 & 42.9 & 29.1 & 0.058 & 0.026 \\
0.034 & 0.030 & 20.3 & 37.0 & 42.9 & 31.7 & 0.058 & 0.030 \\
0.030 & 0.030 & 20.5 & 37.8 & 42.9 & 33.1 & 0.058 & 0.033 \\
\hline
\end{tabular}

\begin{tabular}{|cccccccc|}
\hline $\begin{array}{c}\text { Water } \\
\text { flow rate } \\
(\mathrm{kg} / \mathrm{s})\end{array}$ & $\begin{array}{c}\text { Air flow } \\
\text { rate }(\mathrm{kg} / \mathrm{s})\end{array}$ & $\begin{array}{c}\text { Water inlet } \\
\text { temperature } \\
(\mathrm{C})\end{array}$ & $\begin{array}{c}\text { Water exit } \\
\text { temperature } \\
(\mathrm{C})\end{array}$ & $\begin{array}{c}\text { Air inlet } \\
\text { temperature } \\
(\mathrm{C})\end{array}$ & $\begin{array}{c}\text { Air exit } \\
\text { temperature } \\
(\mathrm{C})\end{array}$ & $\begin{array}{c}\text { Air inlet } \\
\text { humidity }\end{array}$ & $\begin{array}{c}\text { Air exit } \\
\text { humidity }\end{array}$ \\
0.024 & 0.029 & 19.5 & 37.5 & 40.8 & 31.6 & 0.051 & 0.030 \\
0.035 & 0.031 & 19.3 & 34.6 & 40.6 & 29.4 & 0.051 & 0.026 \\
0.048 & 0.030 & 19.4 & 32.9 & 40.9 & 27.4 & 0.052 & 0.023 \\
0.058 & 0.031 & 19.0 & 31.3 & 40.7 & 26.2 & 0.051 & 0.022 \\
& & & & & & & \\
0.053 & 0.031 & 18.9 & 31.9 & 40.7 & 26.5 & 0.051 & 0.022 \\
0.044 & 0.030 & 19.1 & 32.7 & 40.7 & 27.5 & 0.051 & 0.023 \\
0.038 & 0.031 & 19.3 & 33.1 & 40.7 & 28.3 & 0.051 & 0.025 \\
0.031 & 0.030 & 19.3 & 35.5 & 40.8 & 29.6 & 0.051 & 0.027 \\
0.023 & 0.030 & 19.4 & 36.6 & 40.8 & 31.4 & 0.051 & 0.030 \\
\hline
\end{tabular}

\begin{tabular}{|cccccccc|}
\hline $\begin{array}{c}\text { Water } \\
\text { flow rate } \\
(\mathrm{kg} / \mathrm{s})\end{array}$ & $\begin{array}{c}\text { Air flow } \\
\text { rate }(\mathrm{kg} / \mathrm{s})\end{array}$ & $\begin{array}{c}\text { Water inlet } \\
\text { temperature } \\
(\mathrm{C})\end{array}$ & $\begin{array}{c}\text { Water exit } \\
\text { temperature } \\
(\mathrm{C})\end{array}$ & $\begin{array}{c}\text { Air inlet } \\
\text { temperature } \\
(\mathrm{C})\end{array}$ & $\begin{array}{c}\text { Air exit } \\
\text { temperature } \\
(\mathrm{C})\end{array}$ & $\begin{array}{c}\text { Air inlet } \\
\text { humidity }\end{array}$ & $\begin{array}{c}\text { Air exit } \\
\text { humidity }\end{array}$ \\
0.024 & 0.031 & 19.9 & 33.2 & 36.5 & 29.7 & 0.041 & 0.027 \\
0.033 & 0.030 & 20.1 & 32.2 & 36.8 & 27.7 & 0.041 & 0.024 \\
0.048 & 0.030 & 19.4 & 30.4 & 36.8 & 25.8 & 0.041 & 0.021 \\
0.062 & 0.030 & 19.5 & 28.6 & 37.0 & 24.4 & 0.041 & 0.019 \\
& & & & & & & \\
0.054 & 0.030 & 19.4 & 29.5 & 37.0 & 24.7 & 0.041 & 0.020 \\
0.044 & 0.030 & 19.3 & 30.2 & 37.0 & 26.2 & 0.041 & 0.022 \\
0.038 & 0.031 & 20.3 & 31.4 & 37.1 & 27.0 & 0.041 & 0.023 \\
0.031 & 0.031 & 20.5 & 32.0 & 37.1 & 28.5 & 0.042 & 0.025 \\
\hline
\end{tabular}




\section{Appendix D Diffusion Tower Experimental Data with Air Heating}

\begin{tabular}{|cccccccc|}
\hline $\begin{array}{c}\text { Water } \\
\text { flow rate } \\
(\mathrm{kg} / \mathrm{s})\end{array}$ & $\begin{array}{c}\text { Air flow } \\
\text { rate }(\mathrm{kg} / \mathrm{s})\end{array}$ & $\begin{array}{c}\text { Water inlet } \\
\text { temperature } \\
(\mathrm{C})\end{array}$ & $\begin{array}{c}\text { Water exit } \\
\text { temperature } \\
(\mathrm{C})\end{array}$ & $\begin{array}{c}\text { Air inlet } \\
\text { temperature } \\
(\mathrm{C})\end{array}$ & $\begin{array}{c}\text { Air exit } \\
\text { temperature } \\
(\mathrm{C})\end{array}$ & $\begin{array}{c}\text { Air inlet } \\
\text { humidity }\end{array}$ & $\begin{array}{c}\text { Air exit } \\
\text { humidity }\end{array}$ \\
0.020 & 0.080 & 60.25 & 29.0 & 61.19 & 34.1 & 0.009 & 0.034 \\
0.025 & 0.080 & 60.25 & 29.5 & 61.19 & 35.6 & 0.009 & 0.037 \\
0.029 & 0.080 & 60.25 & 30.2 & 61.19 & 36.4 & 0.009 & 0.039 \\
0.035 & 0.080 & 60.25 & 31.0 & 61.19 & 37.3 & 0.009 & 0.041 \\
0.040 & 0.080 & 60.25 & 31.7 & 61.19 & 38.1 & 0.009 & 0.043 \\
0.046 & 0.080 & 60.25 & 32.6 & 61.19 & 39.3 & 0.009 & 0.046 \\
0.052 & 0.080 & 60.25 & 33.3 & 61.19 & 39.8 & 0.009 & 0.047 \\
0.054 & 0.080 & 60.25 & 33.46 & 61.19 & 40.2 & 0.009 & 0.048 \\
\hline & & & & & & & \\
\hline Water & Air flow & Water inlet & Water exit & Air inlet & Air exit & Air inlet & Air exit \\
flow rate & rate $(\mathrm{kg} / \mathrm{s})$ & temperature & temperature & temperature & temperature & humidity & humidity \\
$(\mathrm{kg} / \mathrm{s})$ & 0.04 & 60.3 & $(\mathrm{C})$ & $(\mathrm{C})$ & $(\mathrm{C})$ & & \\
0.021 & 0.04 & 34.5 & 61.5 & 40.6 & 0.009 & 0.049 \\
0.027 & 0.04 & 60.3 & 34.2 & 61.5 & 41.6 & 0.009 & 0.052 \\
0.031 & 0.04 & 60.3 & 35.9 & 61.5 & 43.0 & 0.009 & 0.056 \\
0.036 & 0.04 & 60.3 & 34.6 & 61.5 & 42.8 & 0.009 & 0.055 \\
0.046 & 0.04 & 60.3 & 35.8 & 61.5 & 44.6 & 0.009 & 0.062 \\
0.048 & 0.04 & 60.3 & 35.2 & 61.5 & 44.7 & 0.009 & 0.062 \\
0.052 & 0.04 & 60.3 & 36.1 & 61.5 & 45.6 & 0.009 & 0.066 \\
0.057 & 0.04 & 60.3 & 36.2 & 61.5 & 45.8 & 0.009 & 0.067 \\
0.062 & 0.04 & 60.3 & 36.8 & 61.5 & 46.2 & 0.009 & 0.068 \\
\hline
\end{tabular}




\section{Nomenclature}

\begin{tabular}{|c|c|}
\hline A & control surface area $\left(\mathrm{m}^{2}\right)$ \\
\hline $\mathrm{a}$ & specific area of packing material $\left(\mathrm{m}^{2} / \mathrm{m}^{3}\right)$ \\
\hline ai & amortization factor $\left(\mathrm{yr}^{-1}\right)$ \\
\hline $\mathrm{C}_{\text {drag }}$ & aerodynamic drag on droplet \\
\hline $\mathrm{C}_{\mathrm{p}}$ & specific heat of air $(\mathrm{kJ} / \mathrm{kg})$ \\
\hline c & electric cost, $\left(\$ / \mathrm{m}^{3}\right)$ \\
\hline $\mathrm{D}$ & molecular diffusion coefficient $\left(\mathrm{m}^{2} / \mathrm{s}\right)$ \\
\hline $\mathrm{DC}$ & direct capital cost $(\$)$ \\
\hline $\mathrm{dp}$ & diameter of the packing material $(\mathrm{m})$ \\
\hline $\mathrm{E}$ & Power from a power plant (MW) \\
\hline $\mathrm{f}$ & plant availability \\
\hline G & air mass flux $\left(\mathrm{kg} / \mathrm{m}^{2}-\mathrm{s}\right)$ \\
\hline g & gravitational acceleration $\left(\mathrm{m} / \mathrm{s}^{2}\right)$ \\
\hline $\mathrm{H}$ & diffusion tower height $(\mathrm{m})$ \\
\hline $\mathrm{h}$ & enthalpy $(\mathrm{kJ} / \mathrm{kg})$ \\
\hline$h_{f g}$ & latent heat of vaporization $(\mathrm{kJ} / \mathrm{kg})$ \\
\hline $\mathrm{i}$ & interest rate \\
\hline $\mathrm{k}$ & specific chemicals cost $\left(\$ / \mathrm{m}^{3}\right)$ \\
\hline $\mathrm{k}_{\mathrm{G}}$ & mass transfer coefficient $(\mathrm{m} / \mathrm{s})$ \\
\hline $\mathrm{L}$ & water mass flux $\left(\mathrm{kg} / \mathrm{m}^{2}-\mathrm{s}\right)$ \\
\hline $\mathrm{M}_{\mathrm{V}}$ & vapor molecular weight $(\mathrm{kg} / \mathrm{kmol})$ \\
\hline $\mathrm{m}$ & mass flow rate $(\mathrm{kg} / \mathrm{s})$ \\
\hline$m_{\text {drop }}$ & mass of an individual droplet $(\mathrm{kg})$ \\
\hline $\mathrm{m}_{\mathrm{p}}$ & plant capacity $\left(\mathrm{m}^{3} /\right.$ day $)$ \\
\hline $\mathrm{n}$ & plant life $(y r)$ \\
\hline $\mathrm{P}_{\mathrm{a}}$ & partial pressure of air $(\mathrm{Pa}$ or $\mathrm{kPa})$ \\
\hline $\mathrm{P}_{\text {sat }}$ & partial pressure of vapor $(\mathrm{Pa}$ or $\mathrm{kPa})$ \\
\hline $\mathrm{P}$ & electrical power consumption for pumps (W, $\mathrm{kW}$ or $\mathrm{MW})$ \\
\hline PR & performance ratio (kg product $/ \mathrm{kg}$ steam) \\
\hline q & heat exchanged in condenser $(\mathrm{W})$ \\
\hline $\mathrm{R}$ & universal gas constant $(\mathrm{kJ} / \mathrm{kmol}-\mathrm{K})$ \\
\hline $\mathrm{R}_{\mathrm{a}}$ & engineering gas constant for air $(\mathrm{kJ} / \mathrm{kg}-\mathrm{K})$ \\
\hline $\mathrm{r}$ & energy convert efficiency \\
\hline $\mathrm{S}$ & heating steam cost $(\$ / \mathrm{MkJ})$ \\
\hline $\mathrm{T}$ & temperature $\left({ }^{\circ} \mathrm{C}\right.$ or $\left.{ }^{\circ} \mathrm{K}\right)$ \\
\hline $\mathrm{U}$ & heat transfer coefficient $\left(\mathrm{W} / \mathrm{m}^{2}-\mathrm{K}\right)$ \\
\hline $\mathrm{u}$ & air/vapor velocity $(\mathrm{m} / \mathrm{s})$ \\
\hline V & control volume $\left(\mathrm{m}^{3}\right)$ \\
\hline $\mathrm{V}_{\mathrm{G}}$ & air/vapor volume flow rate $\left(\mathrm{m}^{3} / \mathrm{s}\right)$ \\
\hline $\mathrm{v}_{\mathrm{d}}$ & droplet velocity $(\mathrm{m} / \mathrm{s})$ \\
\hline $\mathrm{W}$ & specific consumption of electric power $\left(\mathrm{kWh} / \mathrm{m}^{3}\right)$ \\
\hline$\Phi$ & relative humidity \\
\hline$\omega$ & humidity ratio \\
\hline
\end{tabular}




$\begin{array}{ll}\mu & \text { dynamic viscosity }(\mathrm{kg} / \mathrm{m}-\mathrm{s}) \\ \rho & \text { density }\left(\mathrm{kg} / \mathrm{m}^{3}\right) \\ \sigma_{\mathrm{L}} & \text { surface tension of liquid }(\mathrm{N} / \mathrm{m}) \\ \sigma_{\mathrm{C}} & \text { critical surface tension of the packing material }(\mathrm{N} / \mathrm{m}) \\ \gamma & \text { specific cost of operating labor }\left(\$ / \mathrm{m}^{3}\right) \\ \gamma_{\mathrm{d}} & \text { mass transfer coefficient for droplet condensation }(\mathrm{m} / \mathrm{s}) \\ \lambda & \text { average latent heat of steam }(\mathrm{kJ} / \mathrm{kg})\end{array}$

$\begin{array}{ll}\text { Subscripts } & \\ \mathrm{a} & \text { air } \\ \mathrm{b} & \text { seawater } \\ \mathrm{c} & \text { cold fresh water } \\ \text { DC } & \text { direct contact condenser } \\ \text { Dif } & \text { diffusion tower } \\ \text { DDD } & \text { DDD system } \\ \text { d } & \text { droplet } \\ \text { elec } & \text { electricity } \\ \text { evap } & \text { the portion of liquid evaporated } \\ \text { fw } & \text { fresh water } \\ \text { H } & \text { high } \\ i & \text { interface } \\ \text { L } & \text { low } \\ l & \text { water in liquid phase } \\ \text { mix } & \text { air/vapor mixture } \\ \text { nopack } & \text { without packing } \\ \text { v } & \text { water in vapor phase } \\ \text { in } & \text { inlet parameter } \\ \text { out } & \text { exit parameter } \\ \text { pack } & \text { with packing } \\ \text { s } & \text { steam } \\ \text { sat } & \text { saturate state } \\ \text { Total } & \text { total input } \\ \text { waste } & \text { waste } \\ & \end{array}$


